\title{
Spanish Edition: Chasing the Phantom Ship: Revisiting Interpretations of the Boca Chica No. 2 Shipwreck on the Texas Coast
}

Amy A. Borgens

Texas Historical Commission

Steven D. Hoyt

Texas Historical Commission

Follow this and additional works at: https://scholarworks.sfasu.edu/ita

Part of the American Material Culture Commons, Archaeological Anthropology Commons, Environmental Studies Commons, Other American Studies Commons, Other Arts and Humanities Commons, Other History of Art, Architecture, and Archaeology Commons, and the United States History Commons

Tell us how this article helped you.

This Article is brought to you for free and open access by the Center for Regional Heritage Research at SFA ScholarWorks. It has been accepted for inclusion in Index of Texas Archaeology: Open Access Gray Literature from the Lone Star State by an authorized editor of SFA ScholarWorks. For more information, please contact cdsscholarworks@sfasu.edu. 


\section{Spanish Edition: Chasing the Phantom Ship: Revisiting Interpretations of the Boca Chica No. 2 Shipwreck on the Texas Coast}

\section{Licensing Statement}

Reproduction, posting, transmission, or other distribution or use of the Journal volume, individual article or any portion of the material therein, in any medium, is permitted strictly for personal, non-commercial purposes via a personal-use exemption under a Creative Commons license granted by JTAH.org, Inc. This license exemption requires, as a condition of its granted permission, proper credit be attributed to JTAH.org as copyright holder (e.g., Journal of Texas Archeology and History.org @ 2019). No part of this publication may be reproduced, posted, transmitted, or otherwise utilized or distributed in any form by any means or method for commercial purposes without the express written consent of the Publisher. Inquiries should be addressed to JTAH Publisher, Suite 307, Box 361, 5114 Balcones Woods Drive, Austin, Texas, 78759.

The Journal of Texas Archeology and History.org is an organization dedicated to furthering research, education and public outreach in the fields of archeology and history concerning Texas and its bordering states of Louisiana, Arkansas, Oklahoma, New Mexico and Northern Mexico; a region we call the "Texas Borderlands." The J.T.A.H. is collaborating with the Index of Texas Archaeology and S.F.A.S.U. to distribute their publication library to the general public via free and open-access channels. Visit www.JTAH.org to submit an article. 


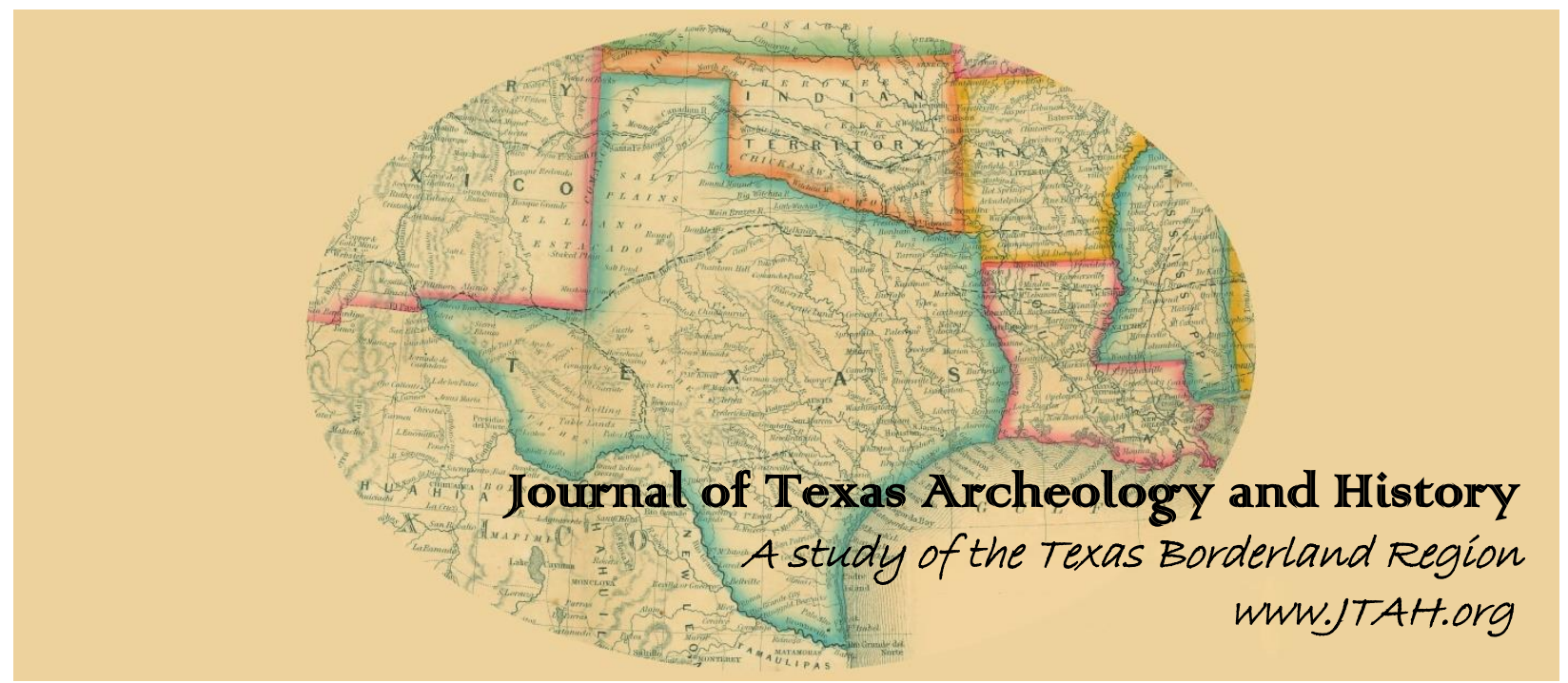

\section{Article Title: (Spanish Edition) PERSIGUIENDO AL BARCO FANTASMA: RECONSIDERANDO LAS INTERPRETACIONES DEL PECIO BOCA CHICA NO. 2 EN LA COSTA DE TEXAS}
Author(s): $\quad$ Amy A. Borgens, Texas Historical Commission con contribuciones de Steven D. Hoyt. Traducción de José Luis Casabán, Ph.D., Institute of Nautical Archaeology, Texas A\&M University

Original Source: J.T.A.H. Volume 5 (2018/2019), Article 3, pp. 89 - 139; online 27 December 2019

Recommended Citation: Borgens, Amy A., and Steven D. Hoyt; a reprint of "Chasing the Phantom Ship: Revisiting Interpretations of the Boca Chica No. 2 Shipwreck on the Texas Coast", (2019), Journal of Texas Archeology and History Volume 5 (2018/2019), pp. 89 - 139.

Copyright $(2019$ by Journal of Texas Archeology and History.org, Inc. All rights reserved. Online/Digital publication: ISSN 2334-1874 The online, digital, and print versions of the publication "Journal of Texas Archeology and History" are published by Journal of Texas Archeology and History.org, Inc., a Texas nonprofit IRC Section 501(c)(3) corporation.

Reproduction, posting, transmission, or other distribution or use of the Journal volume, individual article or any portion of the material therein, in any medium, is permitted strictly for personal, non-commercial purposes via a personal-use exemption under a Creative Commons license granted by JTAH.org, Inc. This license exemption requires, as a condition of its granted permission, proper credit be attributed to JTAH.org as copyright holder (e.g., Journal of Texas Archeology and History.org (C) 2019). No part of this publication may be reproduced, posted, transmitted, or otherwise utilized or distributed in any form by any means or method for commercial purposes without the express written consent of the Publisher. Inquiries should be addressed to JTAH Publisher, Suite 307, Box 361, 5114 Balcones Woods Drive, Austin, Texas, 78759.

The Journal of Texas Archeology and History.org is an organization dedicated to furthering research, education and public outreach in the fields of archeology and history concerning Texas and its bordering states of Louisiana, Arkansas, Oklahoma, New Mexico and Northern Mexico; a region we call the "Texas Borderlands." The J.T.A.H. is collaborating with the Index of Texas Archaeology and S.F.A.S.U. to distribute their publication library to the general public via free and open-access channels. Visit www.JTAH.org to submit an article. 

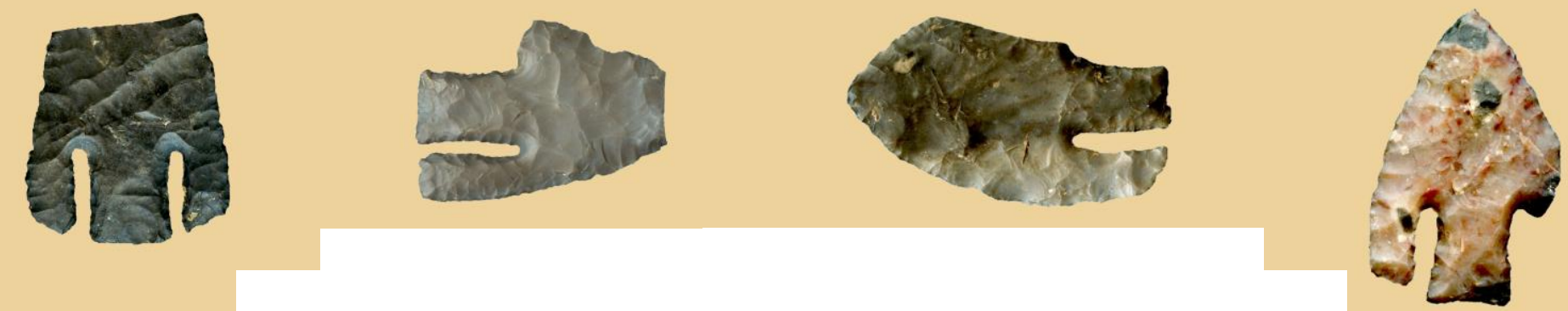

\section{Revista de Arqueología e Historia de Texas (JTAH)}
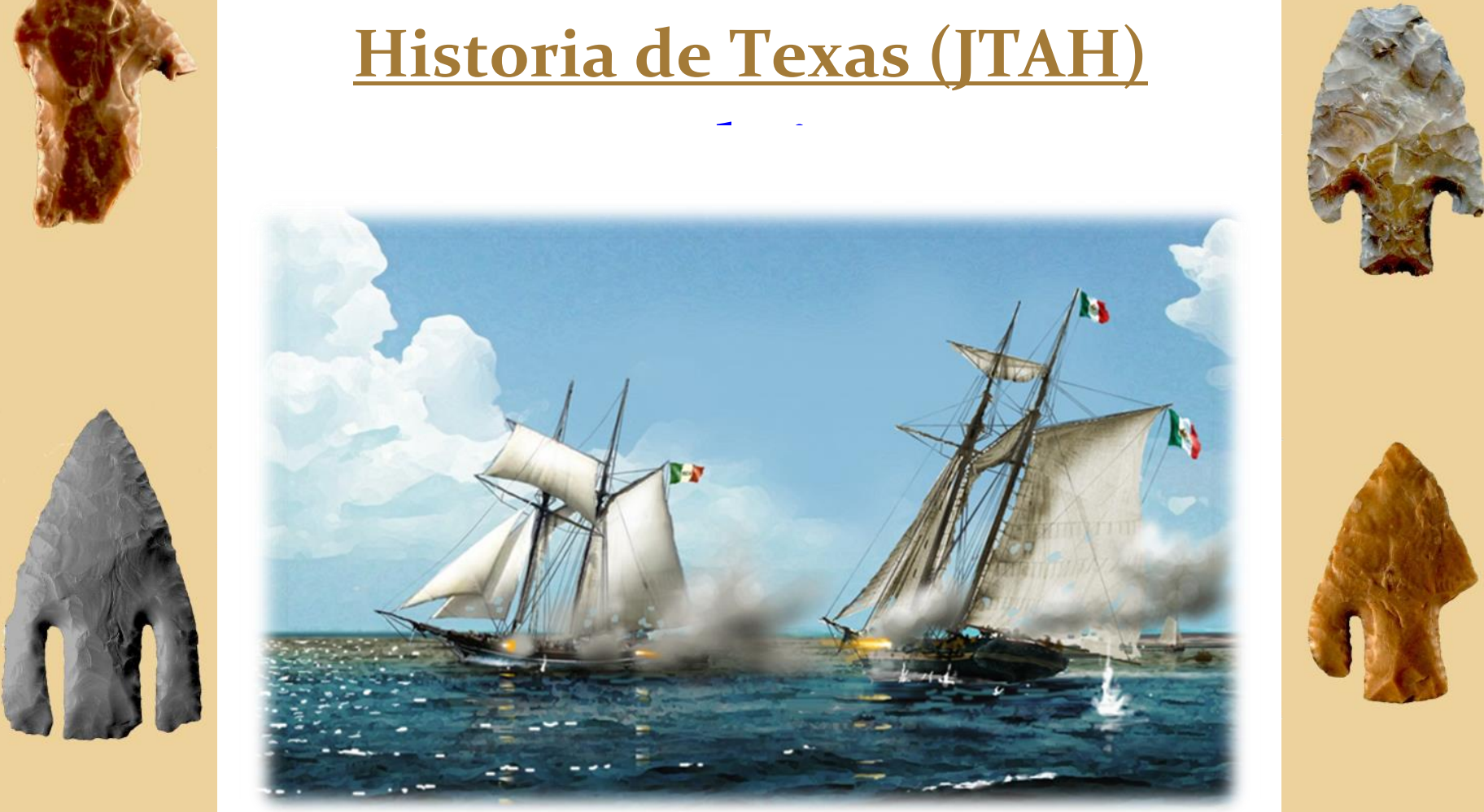

Dr. Todd M. Ahlman, coeditor jefe

Dra., Mary Jo Galindo, coeditora jefa Steve Davis, Editor

Volumen $5(2018 / 2019)$

Diciembre 2019
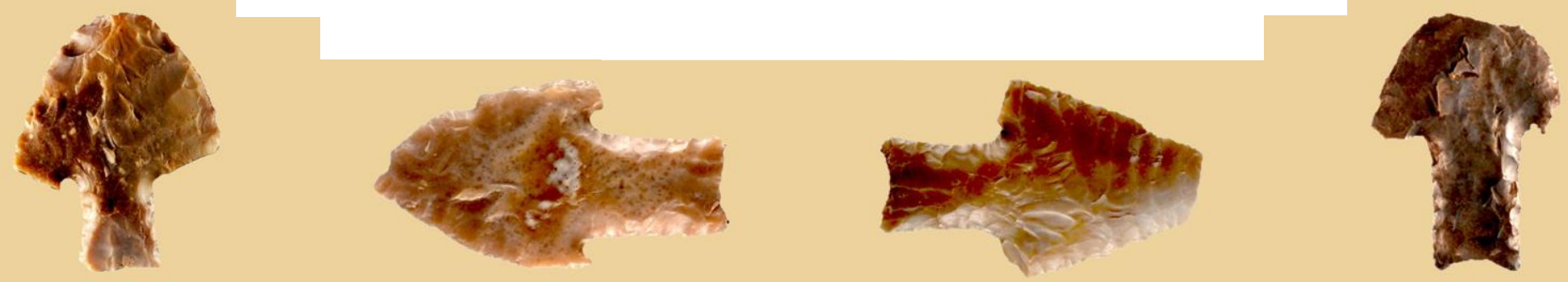


\title{
LA REVISTA DE ARQUEOlogía E Historia DE TEXAS
}

\author{
Volumen $5(2018 / 2019)$
}

\author{
Dr. Todd M. Ahlman, Editor Emeritus y Tutor \\ Dra. Mary Jo Galindo, Coeditora jefa \\ Dr. J. Kevin Hanselka, Coeditora jefe \\ Steve Davis, Editor
}

\author{
Publicada \\ por la
}

Journal of Texas Archeology and History.org, Inc.

Austin, Texas 
Copyright (C 2019 Journal of Texas Archeology and History.org, Inc.

Todos los derechos reservados.

Publicación en línea/digital: ISSN 2334-1874

Publicación impresa doméstica y Kindle: ISBN 978-170945194

Publicación impresa internacional: ISBN 978-170945194

Las versiones impresas y en línea de la publicación "Revista de Arqueología e Historia a de Texas" son publicadas por

Journal of Texas Archeology and History.org, Inc., una organización de Texas sin ánimo de lucro IRC Sección 501 (c) (3).

El diseño de la frontera de la cubierta y el eslogan "Un estudio de la región fronteriza de Texas" son las marcas comerciales de Journal of Texas Archeology y History.org, Inc.

La reproducción, muestra, transmisión, distribución o uso del volumen de la Revista, de un artículo individual o de cualquier porción del material en cualquier medio, está únicamente permitida para uso personal y con fines no comerciales a través de una cláusula de exención para uso personal bajo una licencia de Creative Commons concedida por la JTAH.org, Inc. La concesión de dicha exención requiere como condición que se reconozca adecuadamente a la JTAH.org como titular de los derechos de autor (por ejemplo, Journal of Texas Archeology and History.org (C) 2019).

No está permitida la reproducción parcial, muestra, transmisión, o cualquier utilización o distribución de esta publicación en cualquier formato o medio con fines comerciales sin el consentimiento expreso por escrito del editor. Las consultas deben dirigirse a JTAH Publisher, Suite 307, Box 361, 5114 Balcones Woods Drive, Austin, Texas, 78759.

El diseño de la portada del borde gracing Volumen 5 presenta una muestra representativa de los puntos de dardos de Andice y Bell del sitio Gault (41BL323) fechados en entre 6.000 y 5.750 cal BP. Incluidas en el arte fronterizo son catorce imágenes representativas en $2 \mathrm{D}$ de estos puntos de dardo de la era de Calf Creek por Antonio Arcudi y el autor. Para obtener una descripción de la tecnología lítica de Calf Creek encontrada en Gault, consulte el artículo titulado "Calf Creek Horizon Evidence At The Gault Site (41BL323)" de Sergio J. Ayala en la página xi. Además, el lector puede hacer clic en cualquier imagen en el arte del borde de la portada o en el artículo para que aparecen una imagen de pantalla completa y alta resolución de ese artefacto. Este es el segundo de una serie de diseños de portadas especiales para el JTAH por el talentoso equipo de la Escuela Gault de Investigación Arqueológica de la Universidad de Texas. Las portadas futuras pueden destacar temas como la colección de puntos Folsom y el kit de herramientas "más antiguo que Clovis".

La "Flip-Cover"/Back Cover es una cubierta especial diseñada para honrar nuestra primera publicación en dos idiomas. Voltee el libro para revelar una portada en español, asunto sorverto y versión traducida del artículo de Amy A. Borgens "Chasing the Phantom Ship: Revisiting Interpretations of the Boca Chica No. 2 Shipwreck on the Texas Coast" publicado originalmente en J.T.A.H. Volumen 4 (2017/2018). En el panel central de la doble cubierta especial: la pintura que se muestra en la cubierta es la Figura 9, página 62 y 112, del Artículo 1, la escena representa el combate naval ocurrido frente a Brazos Santiago el 3 de abril de 1836 y se titula "Invencible contra Bravo". Esta obra artística fue creada especialmente por Peter Rindlisbacher (2017). 
INTRODUCCION: La Revista de Arqueología e Historia de Texas y History.org es una organización dedicada a promover la investigación, educación y la divulgación de la arqueología y la historia de Texas y sus estados limítrofes incluyendo Luisiana, Arkansas, Oklahoma, Nuevo México y el norte de México; una región que llamamos "las tierras fronterizas de Texas". Este volumen está compuesto por artículos de investigación originales revisados por pares. En este volumen, nos sentimos honrados de poder ofrecer nuestra primera publicación bilingüe en español. Nos sentimos orgullosos de presentar nuestra distintiva marca de trabajo editorial para el año 2018/2019: "La Revista de Arqueología e Historia de Texas, Volumen 5".

El Comité editorial de la Revista de Arqueología e Historia de Texas está compuesto por los siguientes voluntarios que brindan generosamente su tiempo y experiencia con el fin de proporcionar un acceso libre y gratuito a los trabajos de investigación:

\section{Comité editorial de Arqueología}

Dr. Stephen L. Black

Gustavo Ramirez Castilla, M.A.

Jeffrey S. Girard, M.A.

Dra. Ashley K. Lemke

Dr. Chris Lintz

Dr. Emiliano Gallaga Murrieta

Dra. Karen Steelman

Dra. Mary Beth Trubitt

Dr. Bradley J. Vierra

\section{Comité editorial de Historia}

sblack@txstate.edu

gustavoramirezc@gmail.com

girard@nsula.edu

ashley.lemke@uta.edu

chris.lintz@tpwd.gov

gallagam@gmail.com

ksteelman@shumla.org

trubitm@hsu.edu

bvierra@sricrm.com
Dr. Neil Foley

Kay Hindes

Dr. F. Todd Smith

Dr. Omar Valerio-Jimenez

\section{Editores}

Dr. Todd M. Ahlman

Editor emeritus/consejero

Dra. Mary Jo Galindo

Coeditora jefa

Dr. J. Kevin Hanselka

Coeditora jefa

Steve Davis

Editor foleyn@mail.smu.edu

kaythindes@yahoo.com

ftsmith@unt.edu

omar-valerio@uiowa.edu

toddahlman@txstate.edu

GalindoENV@gmail.com

khanselk@yahoo.com

Steve.Davis@JTAH.org 


\section{Notas del editor sobre la publicación del Volumen 5}

Primero, acepte nuestras disculpas por la demora en la entrega de este volumen que originalmente se programó para su publicación a principios de agosto. Experimentamos más dificultades para finalizar las traducciones de la versión en español que se encuentran en este volumen de lo previsto. Sin embargo, nos pareció sumamente importante lograr nuestro objetivo de proporcionar artículos en español que alcanzar una fecha de publicación arbitraria. Confiamos en que usted, el lector, aceptará esta decisión y disfrutará del producto final. Además, fue una experiencia de aprendizaje valiosa que nos ha preparado mucho mejor para futuras publicaciones en dos idiomas.

Es importante para nosotros expresar nuestro agradecimiento especial al Dr. José Luis Casabán por su valiosa ayuda en la elaboración de la versión en español del artículo sobre el naufragio de Borgens Boca Chica en el Volumen 5. Además de proporcionar la traducción al español del artículo sobre el naufragio de Borgens, proporcionó la traducción del especial español "flip-cover" y gran parte de la "cuestión principal" relacionada. La Dra. Mary Jo Galindo proporcionó la traducción de Publishers Forward. Sin embargo, en la producción final y el ensamblaje de este volumen, "Google Translate" o "Microsoft Translate" han traducido al español varias secciones incidentales, como esta página de "Notas del editor". Esperemos que estas herramientas de traducción sean lo suficientemente precisas para transmitir el mensaje deseado.

En el Volumen 5, reimprimimos una versión editada del artículo original en inglés escrito por Amy Borgens sobre el naufragio No. 2 de Boca Chica. Durante el proceso de traducción y edición del artículo para este volumen, el autor descubrió varios listados en la Tabla 1 y faltaban algunas citas de la publicación original que se encuentra en el Volumen 4. de JTAH. Para corregir esta situación, proporcionamos el artículo corregido aquí para uso futuro. y referencia de investigadores marítimos serios.

\section{Editor}




\section{TABLA de CONTENIDOS}

Prologo al Volumen 5 (2018/2019)

Steve Davis

Lista de Autores

Acerca de la cubierta delantera y trasera:

"CALF CREEK HORIZON EVIDENCE

$\mathrm{xi}$

AT THE GAULT SITE (41BL323)

Sergio J. Ayala, Gault School of Archaeological Research

Convocatoria para Autores - JTAH Volumen 6 (2020)

xix

HISTORY OF ARCHEOLOGICAL INVESTIGATIONS AT

1 PALO DURO CANYON STATE PARK

Veronica M. Arias, West Texas A\&M University Anthony S. Lyle, Texas Parks and Wildlife Department Rolla H. Shaller, Panhandle-Plains Historical Museum

Reimpresión del idioma inglés:

PERSIGUIENDO AL BARCO FANTASMA: RECONSIDERANDO LAS INTERPRETACIONES DEL PECIO BOCA CHICA NO. 2 EN LA COSTA DE TEXAS.

Amy A. Borgens, Texas Historical Commission Contributions by Steven D. Hoyt

Versión en español:

PERSIGUIENDO AL BARCO FANTASMA: RECONSIDERANDO LAS

INTERPRETACIONES DEL PECIO BOCA CHICA NO. 2 EN LA COSTA DE TEXAS.

Amy A. Borgens, Texas Historical Commission con contribuciones de Steven D. Hoyt y traducido al español por Jose Luis Casabán 


\section{PROLOGO AL VOLUMEN 5 (2018/2019): REFLEXIONES DEL EDITOR}

Por cuarta vez, al mirar al año pasado me sorprendo del gran trabajo que nuestro talentoso y dedicado grupo de voluntarios y autores ha producido. Mientras esperamos al quinto aniversario de J.T.A.H. en noviembre y nuestras iniciativas planeadas para el próximo año, le debo un agradecimiento desde el corazón a los individuos que generosamente han contribuido con su tiempo y esfuerzo en esta publicación y al gobierno corporativo de la organización sin fines de lucro. Los aproximadamente quince profesionales que constituyen nuestro Consejo Editorial y los cinco que constituyen nuestro consejo corporativo de directores han hecho posible que J.T.A.H. crezca y ofrezca nuevos productos, publicaciones y servicios para la comunidad arqueológica e histórica.

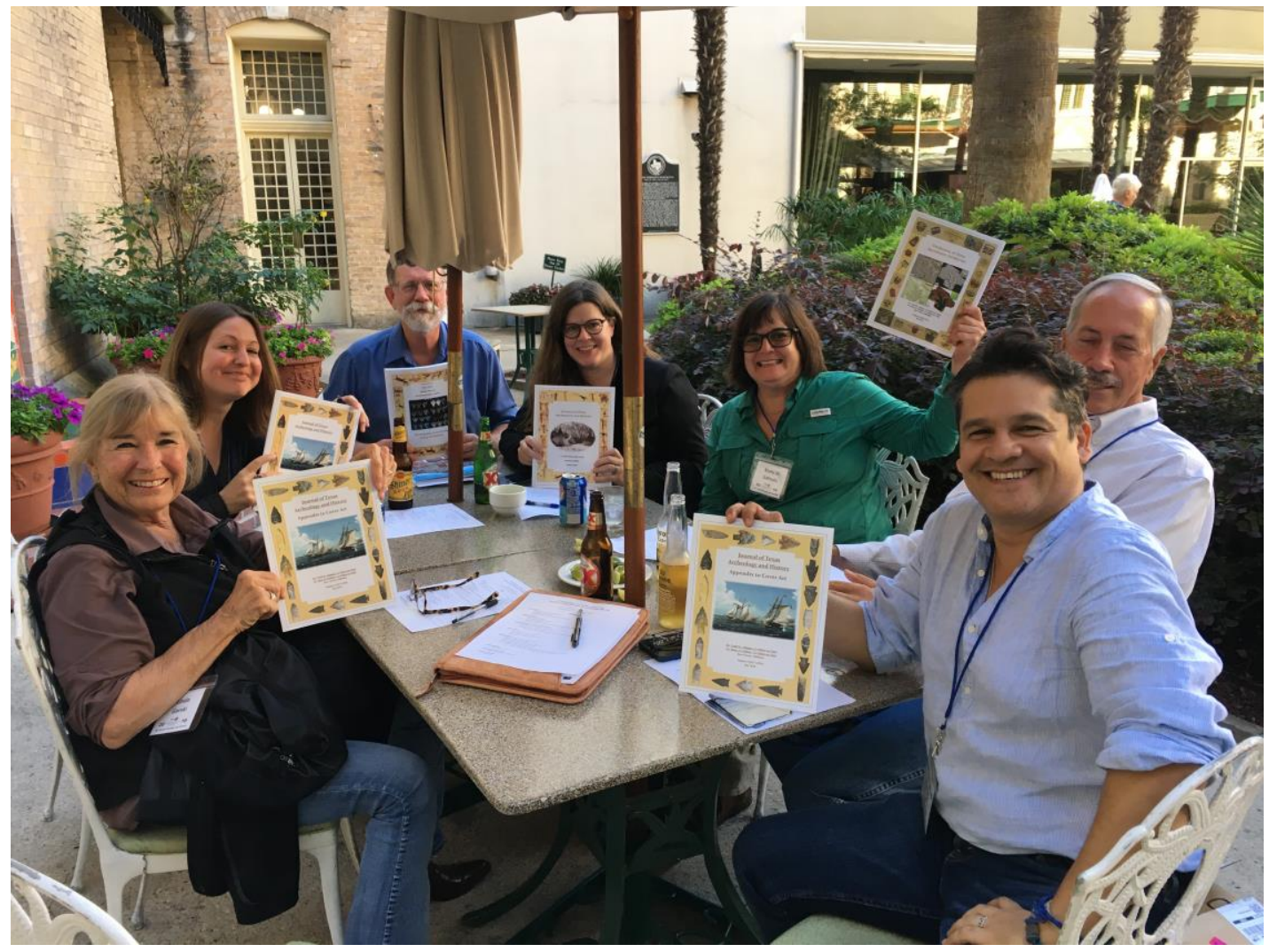

Figura 1 - Varios miembros de J.T.A.H. Juntas corporativas y editoriales mostrando copias de nuestro

"Diario" en San Antonio. De izquierda a derecha se muestran: Linda Gorski, Ashley Lemke, Steve

Black, Amy Borgens, Mary Jo Galindo, Chris Meis, Emiliano Gallaga Murrieta.

En el Volumen 5, presentamos tres artículos destacados que cubren una amplia variedad de temas que el lector disfrutará y del cual podrá obtener un vasto conocimiento y entendimiento del asunto. Uno de estos es un fascinante y detallado estudio un naufragio disputado por tanto tiempo en la era de la Revolución de Texas, escrito por la arqueóloga marina de Texas, Amy Borgens. Planeamos que este artículo sea nuestra primera publicación en dos idiomas debido al interés en 
común con nuestro vecino al sur, México. En el futuro, planeamos ofrecer artículos y publicaciones adicionales en publicados en ambos inglés y español.

La primavera pasada, el Consejo de Directores y Editores de J.T.A.H. aprobó un plan para producir publicaciones especiales compuestas de estudios a nivel postgrado de universidades en la región fronteriza: Luisiana, Arkansas, Oklahoma, Nuevo México, Texas y el norte de México. Esto incluirá una serie de publicaciones de estilo diario con título: "Ensayos Postgrado de la Región Fronteriza”. Nuestra invitación para participar en esta serie especial será enviada en septiembre buscando entregas de estudiantes de postgrado de sus tesis o disertaciones para revisión y consideración. Proyectamos que la primera de esta serie especial estará disponible en el otoño de 2019.

Este año le dimos la bienvenida a tres nuevos miembros a nuestro Consejo Editorial: la Dra. Ashley Lemke de la Universidad de Texas en Arlington; la Dra. Karen Steelman, Directora de Investigación en SHUMLA; y Kay Hindes, Maestría en Artes, Arqueóloga de la ciudad de San Antonio. Estas mujeres son cada una, líder en su campo y aportan una vasta experiencia para mejorar el balance de género en nuestro Consejo Editorial. Estamos orgullosos del grupo de expertos que constituyen nuestro consejo y les agradecemos por donar su tiempo y experiencia en la búsqueda de publicaciones gratuitas y de libre acceso de investigaciones nuevas e importantes.

J.T.A.H. patrocinará y organizará nuevamente un simposio internacional para la Reunión Anual de T.A.S. en San Antonio en octubre de 2018. Este año el tema se enfoca en el 300 aniversario de la ciudad de San Antonio. Varios simposios están siendo organizados para profundizarnos en la influencia de la España colonial en el desarrollo del Estado de Texas. Nuestro simposio contará con tres académicos invitados de México que están investigando la influencia de la era de España colonial en la "región fronteriza". Estamos especialmente agradecidos con la Fundación Gilmore y los Amigos de la Comisión Histórica de Texas por su apoyo financiero, el cual será usado para costear los gastos de viaje de nuestros invitados especiales de México.

Ya hemos empezado la planeación del Festival del Libro J.T.A.H. 2019 para la próxima Reunión Anual T.A.S. Dos autores con nuevos libros ya han recibido la invitación para participar. Ha sido un gran año. Deseamos que otro gran año sirviendo la comunidad arqueológica e histórica de la región fronteriza de Texas.

\section{Steve Davis, editor}

la Navidad 2019 


\section{LISTA DE AUTORES}

Veronica M. Arias, Ph.D., Curator of Anthropology and Natural History, Panhandle-Plains Historical Museum, West Texas A\&M University, Canyon, Texas.

Sergio J. Ayala, Experimental Archaeologist \& Technical Illustrator at the Gault School of Archaeological Research, Prehistory Research Project, and the Texas Archaeological Research Laboratory at the University of Texas, Austin, Texas, Sergio.Ayala@austin.utexas.edu

Amy A. Borgens, State Marine Archeologist, Texas Historical Commission, Austin, Texas (amy.borgens@thc.texas.gov).

Jose Luis Casabán, Postdoctoral Research Associate, Institute of Nautical Archaeology, Department of Anthropology, Texas A \& M University, jlcasaban@gmail.com .

Steven D. Hoyt, Former State Marine Archeologist, Texas Historical Commission, Austin, Texas.

Anthony S. Lyle, Cultural Resources Coordinator, Cultural Resources Program, Texas Parks and Wildlife Department, Waco, Texas.

Rolla H. Shaller, Adjunct Curator of Archeology, Panhandle-Plains Historical Museum, West Texas A\&M University, Canyon, Texas. 


\title{
PERSIGUIENDO AL BARCO FANTASMA: RECONSIDERANDO LAS INTERPRETACIONES DEL PECIO BOCA CHICA NO. 2 EN LA COSTA DE TEXAS
}

\author{
Amy A. Borgens, Texas Historical Commission \\ con contribuciones de Steven D. Hoyt
}

Traducción de José Luis Casabán, Ph.D., Institute of Nautical Archaeology, Texas A\&M University

\section{RESUMEN}

La playa de Boca Chica se extiende aproximadamente 12 kilómetros a lo largo la costa sur de Texas, en el condado de Cameron, entre el paso de Brazos Santiago y la desembocadura del río Bravo (río Grande) en la frontera entre Texas y México. Se tienen noticias del naufragio de más de 165 barcos históricos a lo largo de la costa sur de Texas, de los cuales, al menos cuatro o parte de ellos, han sido descubiertos hasta el momento. El más conocido de estos naufragios es el pecio 41CF184, apodado Boca Chica No. 2, que ha adquirido un estatus casi mitológico en la región, ya que durante mucho tiempo se le ha vinculado de forma circunstancial al buque de guerra mexicano Moctezuma, el cual, no por casualidad, resulta ser uno de los naufragios más famosos de la región. ¿Es Boca Chica No. 2, el famoso buque de guerra que, en alguna ocasión, se consideró un "buque fantasma" debido a la frecuencia con la que eludía a las patrullas texanas? La evidencia sugiere lo contrario, pero la importancia, tanto de la nave histórica como del yacimiento arqueológico, invita a reexaminar este misterio no resuelto.

\section{INTRODUCCIÓN}

Al igual que otros naufragios costeros descubiertos en la playa, el pecio 41CF184, conocido como Boca Chica No. 2, ha intrigado durante años tanto a arqueólogos como al público en general. La Texas Historical Commission (THC) conoce la existencia de este naufragio desde hace casi dos décadas, durante la cuales, su exposición periódica en la playa cerca de la desembocadura del río Bravo (río Grande) (Figura 1), ha permitido su monitorización y documentación de forma semirregular. No se han observado artefactos y es muy probable que el barco fuera objeto de un intenso salvamento en el momento de su hundimiento, incluyendo tal vez partes del mismo. El folclore local lleva mucho tiempo sugiriendo que podría tratarse del buque de la Marina mexicana Moctezuma (también llamado a menudo Montezuma, Bravo, y General Bravo), supuestamente

\footnotetext{
JOURNAL OF TEXAS ARCHEOLOGY AND HISTORY

VOLUME 5:89-139

THE ONLINE PUBLICATION JOURNAL OF TEXAS ARCHEOLOGY AND HISTORY (ISSN 2334-1874)

IS PUBLISHED BY JOURNAL OF TEXAS ARCHEOLOGY AND HISTORY.ORG.

COPYRIGHT (C) 2019 JOURNAL OF TEXAS ARCHEOLOGY AND HISTORY.ORG. ALL RIGHTS RESERVED.
} 
hundido por la goleta de la Marina de Texas Invincible en abril de 1836. Esto se considera un importante hito en la historia de Texas, ya que México había utilizado este buque con éxito tanto para impedir que los texanos recibieran suministros para la revolución, como para ayudar en los preparativos del avance militar mexicano. La hipótesis local de que los restos del pecio Boca Chica No. 2 corresponden a Moctezuma no se apoya en ninguna evidencia arqueológica o histórica.

Al igual que otros naufragios costeros descubiertos en la playa, el pecio 41CF184, conocido como Boca Chica No. 2, ha intrigado durante años tanto a arqueólogos como al público en general. La Texas Historical Commission (THC) conoce la existencia de este naufragio desde hace casi dos décadas, durante la cuales, su exposición periódica en la playa cerca de la desembocadura del río Bravo (río Grande) (Figura 1), ha permitido su monitorización y documentación de forma semirregular. No se han observado artefactos y es muy probable que el barco fuera objeto de un intenso salvamento en el momento de su hundimiento, incluyendo tal vez partes del mismo. El folclore local lleva mucho tiempo sugiriendo que podría tratarse del buque de la Marina mexicana Moctezuma (también llamado a menudo Montezuma, Bravo, y General Bravo), supuestamente hundido por la goleta de la Marina de Texas Invincible en abril de 1836. Esto se considera un

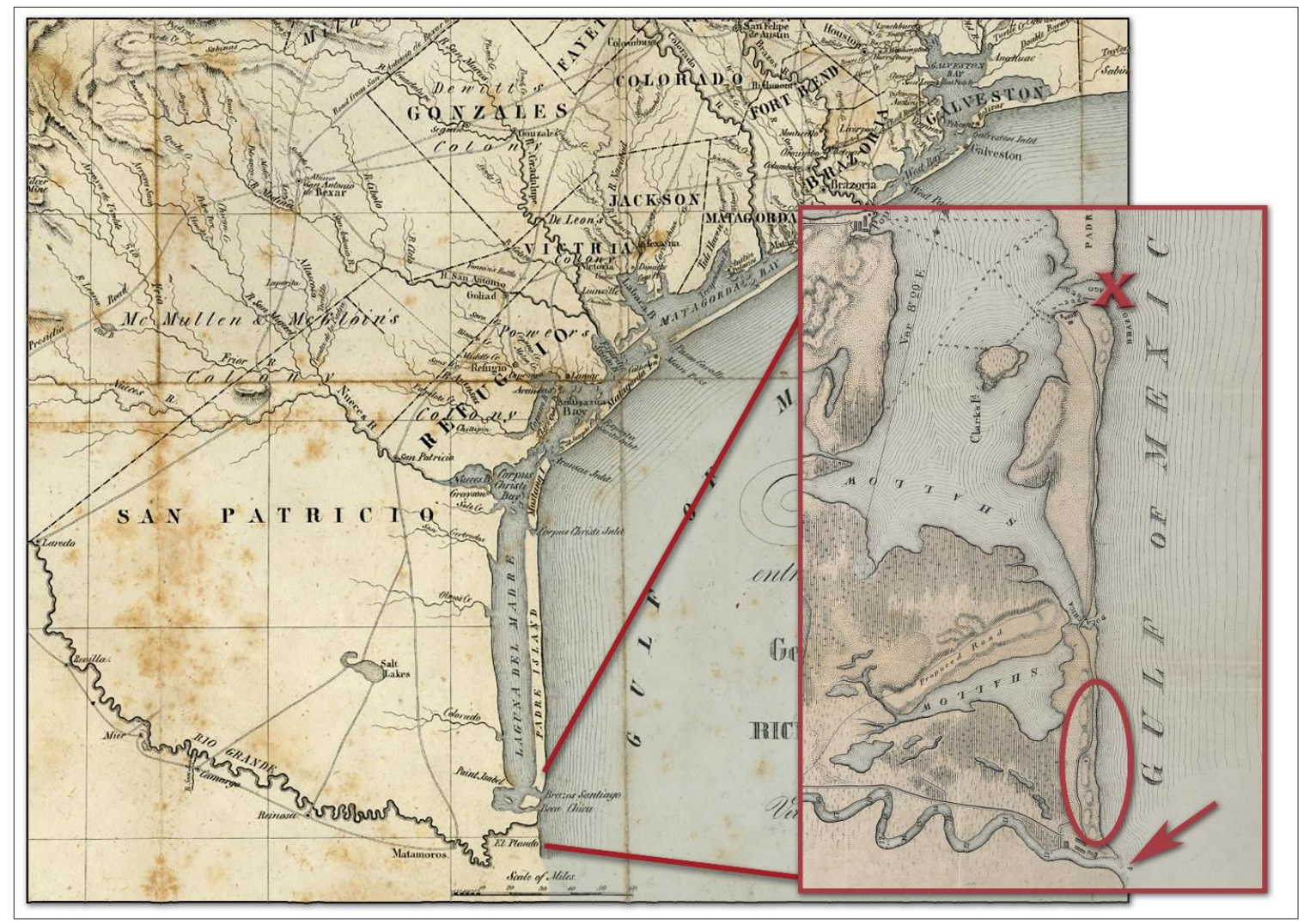

Figura 1. Mapas en color modificados de 1839 (Hunt y Randel 1841) con detalles añadidos de 1847 (Webster et al. 1847) que muestran el paso de Brazos Santiago (X), la desembocadura del río Bravo (río Grande) (flecha) y la ubicación aproximada del pecio 41CF184 (círculo) (Imagen de la autora, 2017). 
importante hito en la historia de Texas, ya que México había utilizado este buque con éxito tanto para impedir que los texanos recibieran suministros para la revolución, como para ayudar en los preparativos del avance militar mexicano. La hipótesis local de que los restos del pecio Boca Chica No. 2 corresponden a Moctezuma no se apoya en ninguna evidencia arqueológica o histórica.

\section{EL DESCUBRIMIENTO}

Randy Blankenship del Texas Parks and Wildlife Department (TPWD) informó acerca de este yacimiento arqueológico al anterior arqueólogo marino estatal de la THC Steve Hoyt en 1999. El yacimiento había quedado al descubierto después de una tormenta y dañado por un equipo de limpieza de playas del Condado de Cameron (Hoyt 1999a: 1). Hoyt se puso en contacto con la Oficina de Ingenieros del Condado, solicitando que se detuvieran los trabajos y visitó el yacimiento en mayo de 1999 (Figura 2). Porciones de la proa y popa estaban expuestas y Hoyt observó 29 cuadernas en la banda de babor, algunas de ellas dobles. Las cuadernas observadas no estaban espaciadas de forma uniforme, con huecos de hasta 3.3 metros (10 5/6 pies), ya que muchas de ellas habían desparecido. Hoyt sugirió que los espacios entre las cuadernas podían deberse a la erosión natural de la costa arenosa, pero supuso que los daños fueron causados probablemente por maquinaria pesada (Hoyt 1999a: 3). Una curva de peralto suelta y una tabla del forro interior habían sido recuperadas anteriormente por el TPWD y examinadas por Hoyt. Se documentó que la curva de peralto tenía una altura vertical truncada e incompleta de $33 \mathrm{~cm}$ (13 pulgadas) y una

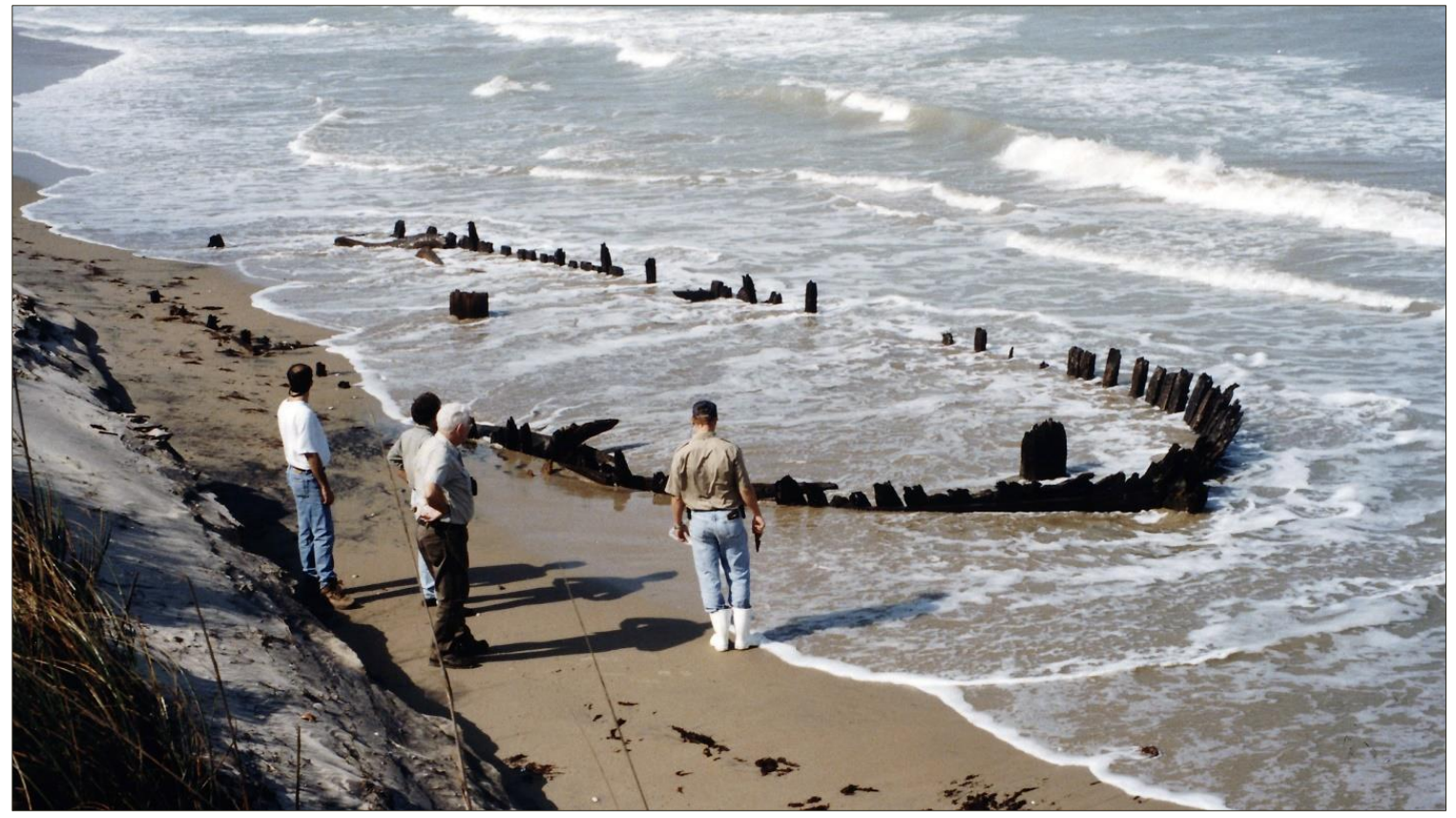

Figura 2. Pecio 41CF184 en 1999 (foto de Steve Hoyt, 1999). 
longitud horizontal de $68.6 \mathrm{~cm}$ (27 pulgadas). La tabla del forro interior tenía una longitud incompleta de $2.9 \mathrm{~m}$ (9.5 pies) con un grosor de $3.8 \mathrm{~cm}$ (1.5 pulgadas) (Hoyt 1999a: 4; Hoyt 1999b: $6)$.

Randy Blankenship del Texas Parks and Wildlife Department (TPWD) informó acerca de este yacimiento arqueológico al anterior arqueólogo marino estatal de la THC Steve Hoyt en 1999. E1 yacimiento había quedado al descubierto después de una tormenta y dañado por un equipo de limpieza de playas del Condado de Cameron (Hoyt 1999a: 1). Hoyt se puso en contacto con la Oficina de Ingenieros del Condado, solicitando que se detuvieran los trabajos y visitó el yacimiento en mayo de 1999 (Figura 2). Porciones de la proa y popa estaban expuestas y Hoyt observó 29 cuadernas en la banda de babor, algunas de ellas dobles. Las cuadernas observadas no estaban espaciadas de forma uniforme, con huecos de hasta 3.3 metros (10 5/6 pies), ya que muchas de ellas habían desparecido. Hoyt sugirió que los espacios entre las cuadernas podían deberse a la erosión natural de la costa arenosa, pero supuso que los daños fueron causados probablemente por maquinaria pesada (Hoyt 1999a: 3). Una curva de peralto suelta y una tabla del forro interior habían sido recuperadas anteriormente por el TPWD y examinadas por Hoyt. Se documentó que la curva de peralto tenía una altura vertical truncada e incompleta de $33 \mathrm{~cm}$ (13 pulgadas) y una longitud horizontal de $68.6 \mathrm{~cm}$ (27 pulgadas). La tabla del forro interior tenía una longitud incompleta de $2.9 \mathrm{~m}$ (9.5 pies) con un grosor de $3.8 \mathrm{~cm}$ (1.5 pulgadas) (Hoyt 1999a: 4; Hoyt 1999b: $6)$.

La THC, con la ayuda de su grupo de voluntarios (los marine stewards) y los ciudadanos locales, han monitorizado el pecio desde 1999 y documentado su migración desde las dunas hasta interior del área intermareal. Esto ha acelerado enormemente la degradación de las maderas del casco. La acción combinada de la fuerza destructiva del oleaje, el consumo de madera por parte del "gusano marino" Teredo navalis, los daños causados al pecio por las actividades de limpieza de la playa, el vandalismo y el saqueo han contribuido al rápido deterioro de este importante yacimiento.

Las observaciones de campo y el examen adicional de la fotografía de 1999 muestran que cuando el pecio 41CF184 fue descubierto por primera vez, aún conservaba las tablas del forro exterior e interior del casco, dos de sus curvas de peralto (las que sostienen los baos de la cubierta; Figura 3), el codaste y los barraganetes de la regala que se proyectan por encima de la terminación natural de las cuadernas - todo lo cual indica que la estructura del casco se llegó a conservar alguna vez al nivel de la cubierta o por encima de ella. La mayoría de las curvas de peralto habían desaparecido, además de todos los baos y tablazón de la cubierta, y todas las superestructuras y 
atributos típicos situados por encima de la cubierta. La ausencia de estas maderas podría deberse a procesos ambientales, pero a menudo los pecios varados en playas podían ser rescatados no solo por su carga sino también por sus robustas maderas, especialmente en áreas escasamente pobladas o carentes de abundantes recursos madereros locales. Incluso a pesar de su estado incompleto, en el momento de su descubrimiento, el pecio 41CF184 constituye uno de los pecios más completos y mejor conservados que se han descubierto hasta el momento en Texas.

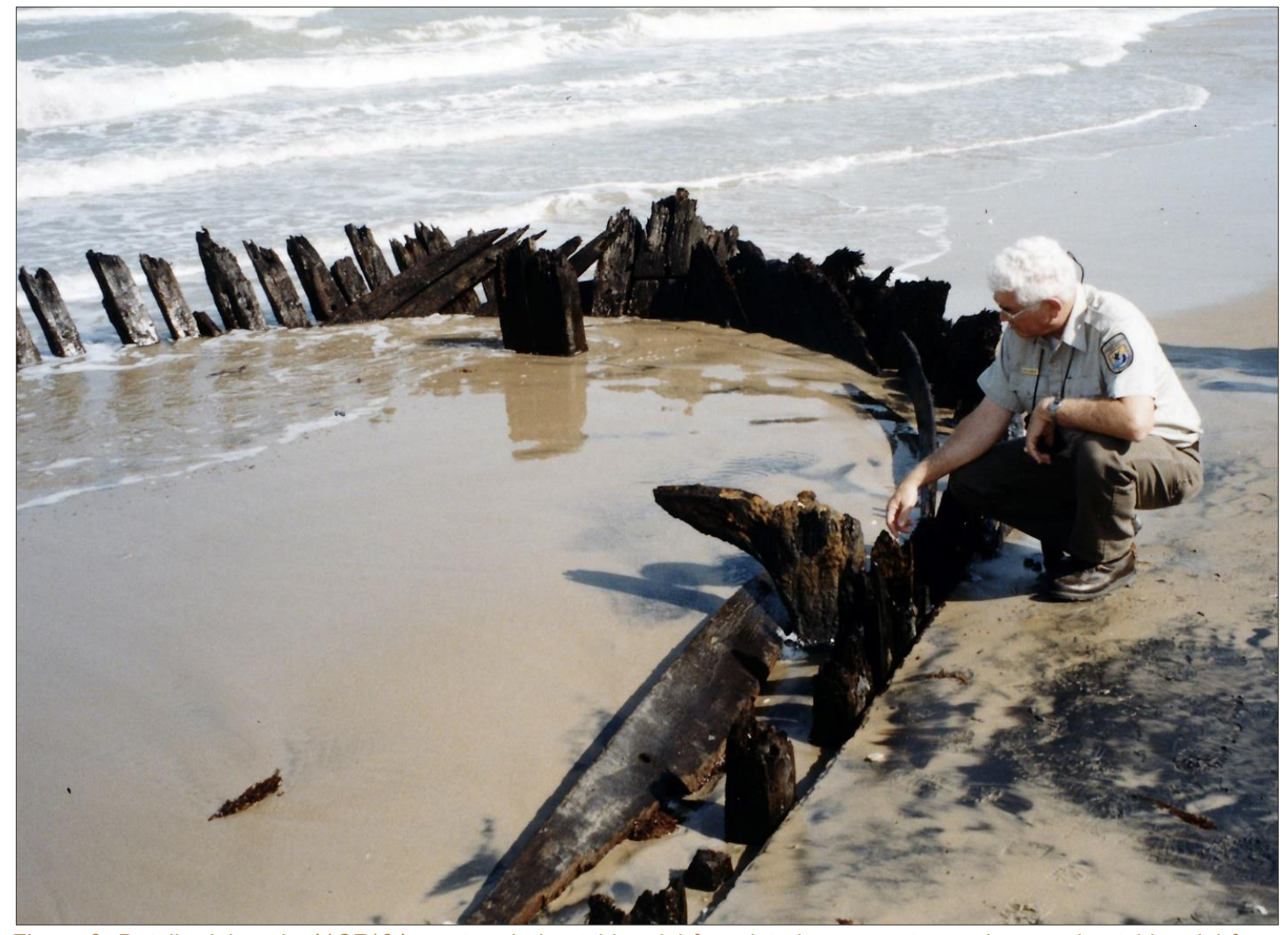

Figura 3. Detalle del pecio 41CF184 mostrando las tablas del forro interior expuestas en la proa, las tablas del forro exterior del casco de la banda de estribor, una curva de peralto, y la carlinga del bauprés (Foto de Steve Hoyt, 1999).

\section{EL BARCO}

En 2002 se llevó a cabo un examen más exhaustivo del pecio 41CF184, en un momento en que el barco había quedado expuesto nuevamente. Steve Hoyt visitó el pecio en mayo, casi tres años después de su primera visita. Esta vez Hoyt registró extensamente muchos de los atributos básicos para el diagnóstico del buque. Sugirió que la eslora total (LOA) era de $22 \mathrm{~m}$ (72.2 pies) con una manga máxima de $7.7 \mathrm{~m}$ (25.3 pies). Dibujó el yugo en detalle y determinó que su anchura medía era de $4.7 \mathrm{~m}$ (15.5 pies) a partir de la de la amplitud de las tablas del forro interior y de la cubierta. El mástil principal octogonal medía 43.2 x $44.5 \mathrm{~cm}$ (17 pulgadas X 17.5 pulgadas) de 
plano a plano. La cadena de la vigota era visible en ese momento en la banda de babor. Hoyt se dio cuenta que las tablas del forro interno observadas en la proa en 1999 habían desaparecido (Hoyt 2002a: 1-2). Anteriormente en 1999, Hoyt documentó un grosor y anchura para los genoles de 15.2 x $15.2 \mathrm{~cm}$ (6 x 6 pulgadas) (Hoyt 1999a: 3).

Más tarde, en agosto de 2002, los marine stewards de la THC realizaron la planimetría de las maderas expuestas mediante trilateración (Figura 4). Este trabajo fue realizado en su mayor parte por Andrew Hall, Gary McKee, Tom Oertling, John Luce, y Doug Nowell (Hall et al. 2002; Hoyt 2002b; Oertling 2002). Esta investigación determinó que la eslora conservada del casco del 41CF184 era $21.9 \mathrm{~m}$ (72 pies), con una eslora hipotética entre perpendiculares de $24.1 \mathrm{~m}$ (79 pies) (Oertling 2002: 3). Una revisión de la fotografía de 1999 indica que el casco estaba conservado al nivel de la cubierta o por encima de ella, que es el punto en que la eslora entre perpendiculares (LBP) - distancia desde la parte delantera de la roda hasta la parte posterior de la popa - se calculaba para la matrícula y registro de buques flotantes (Lyman 1945: 226). En este artículo se sugiere que la eslora de matrícula y registro del 41CF184 probablemente no excedía los $22.9 \mathrm{~m}$ (75 pies), y posiblemente era bastante similar a la eslora entre perpendiculares medidas en el casco.
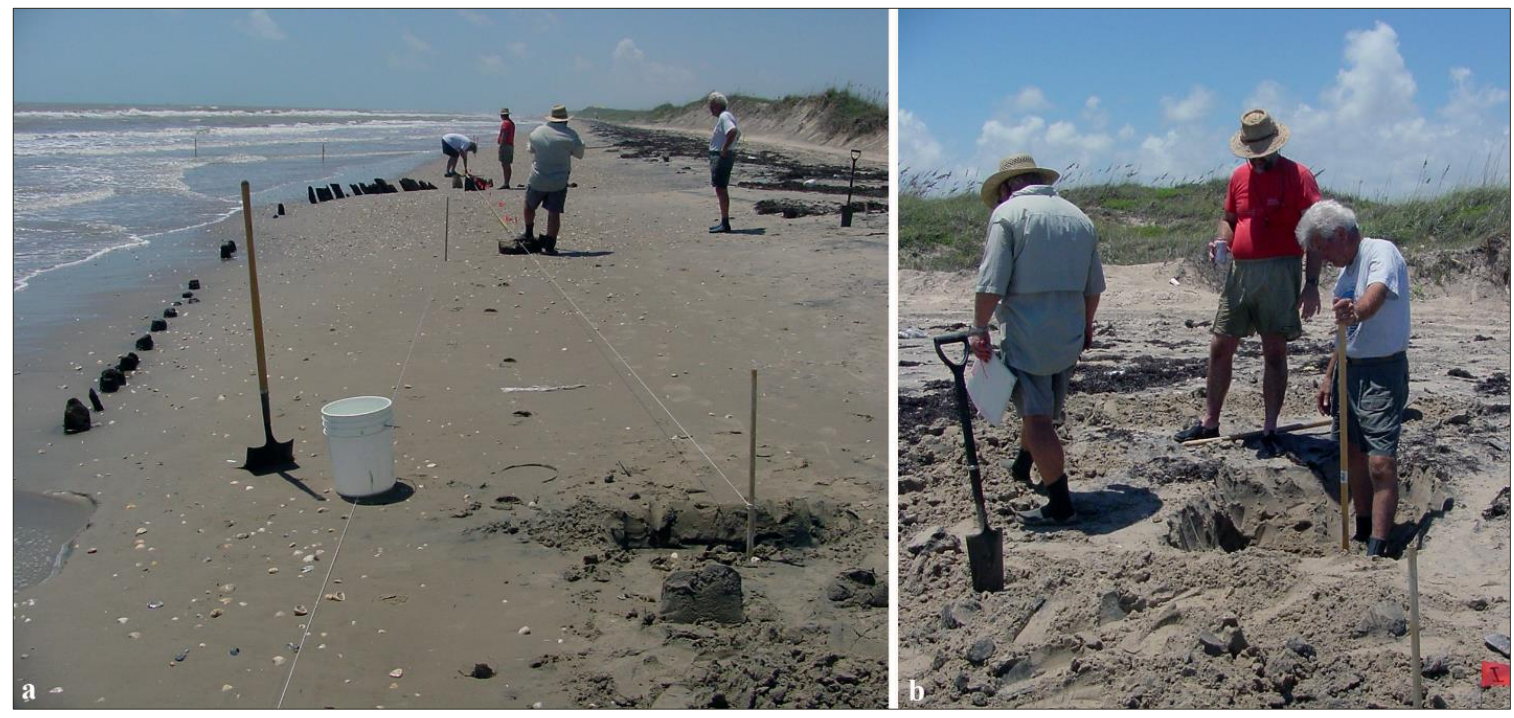

Figura 4. Los marine stewards de la THC realizando la planimetría del pecio 41CF184: (a) posicionamiento de puntos de control; (b) excavando la popa (fotos de Bill Pierson, 2002).

La manga máxima, calculada usando la medida de $3.5 \mathrm{~m}$ (11.5 pies) de la media manga era de 7 m (23 pies) (Oertling 2002: 3). La embarcación estaba unida con cabillas de madera y hierro (Oertling 2002: 2). En 2002, los únicos elementos internos centrales visibles eran el mástil principal y la carlinga del bauprés (también bitas o columnas del bauprés) y se intentó sin éxito excavar y localizar el palo de trinquete. Oertling se centró en dos atributos que ayudaran a datar el pecio: la 


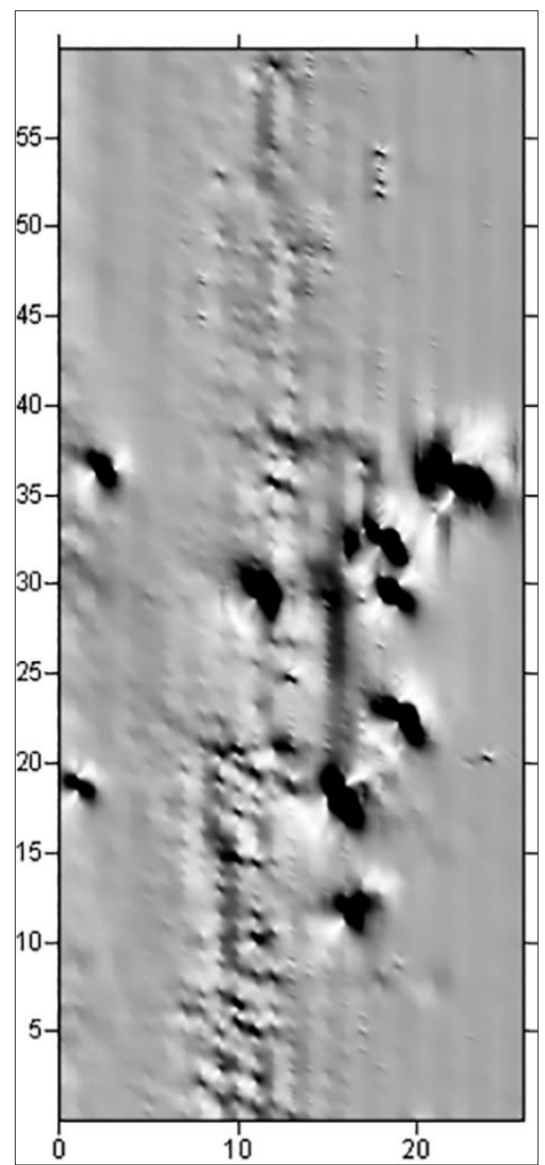

Figura 5. Mapa de la prospección magnetómetrica (Bill Pierson, 2002).

inclinación del palo mayor que era de 5 grados a popa y la disposición semicircular y pronunciado ángulo de los espaldones. Ambas características sugirieron a Oertling (2002: 3) una fecha de construcción entre 1790-1840. Una muestra de madera tomada de un genol (número P30) indicó que se trataba de roble (Oertling 2002: 3).

Además de realizar la planimetría del pecio, el miembro de la THC Bill Pierson realizó una prospección magnetométrica de la playa en la zona del naufragio (Figura 5). Solo una parte pudo ser prospectada debido al oleaje y esto mostró las ubicaciones de los accesorios y pasadores de hierro dentro de un casco unido principalmente con cabillas de madera (Hoyt 2002a: 3).

Se planificó una nueva excavación y planimetría del pecio para junio de 2006, gracias a una colaboración entre la THC y la PAST Foundation. Desafortunadamente, cuando el proyecto estaba a punto de llevarse a cabo, la playa se había erosionado de una forma dramática y el pecio Boca Chica No. 2 se encontraba en la zona intermareal y de oleaje. El proyecto de planimetría de la PAST Foundation nunca se llevó a cabo (Andrew Hall, comunicación personal 2017).

En 2016, la THC adquirió el palo de trinquete que había sido recuperado del pecio en 2010. El informe de la extracción de esta pieza fue compartido por el arqueólogo Mark Willis. Él había sido informado de que el palo fue extraído para tallarlo en forma de pájaro. La THC supo más tarde que el posible artesano reconoció que era el palo de trinquete del pecio, por lo que fue recuperado y almacenado en una tienda de cebos local antes de que cambiara de manos otra vez. Cuando se supo que la tienda de cebos iba a cerrar, el residente local Keith Reynolds preguntó si podía quedarse con el palo de trinquete. En un esfuerzo por encontrar al verdadero dueño del artefacto, Reynolds contactó con Bill Turner, que era el entonces presidente de la Texas Navy Association, quien a su vez lo hizo con la THC (Borgens 2016a: 2). En enero de 2016, Turner y la autora visitaron a Reynolds en Brownsville y recogieron el palo de trinquete. Actualmente ésta es la única pieza del pecio del pecio conservada por la THC. 
Los restos del palo de trinquete corresponden al zoquete, básicamente la parte inferior del mástil, que se insertaría en la sobrequilla. Se cree que pesa más de 200 libras y, aunque está muy dañado por la acción del Teredo, aún conserva su superficie original de los 38 a 50 cm (15.0-19.7 pulgadas) inferiores. El mástil tenía una forma octagonal, como el palo mayor, con una distancia entre planos de $46.6 \mathrm{~cm}$ (18.3 pulgadas) en la base; las caras de octágono son irregulares y con una anchura variable entre 12.8 y $21.2 \mathrm{~cm}$ (5.0 a 8.3 pulgadas). En la base del mástil había una cinta de hierro de $9.2 \mathrm{~cm}$ de altura y $2.7 \mathrm{~cm}$ (3.6 y 1.1 pulgadas) de anchura. La altura total conservada del palo de trinquete es de $144.7 \mathrm{~cm}$ (4.8 pies), incluyendo los $129.8 \mathrm{~cm}$ (4.3 pies) del mástil de y los $14.9 \mathrm{~cm}$ (5.9 pulgadas) de la mecha (Borgens y Cabading 2016). La altura de este artefacto sugiere que la profundidad conservada hasta la base de la quilla era aproximadamente de $2.1 \mathrm{~m}$ (7 pies), o incluso mayor, cuando el pecio se expuso en 2002, ya que el mástil habría estado unido a la sobrequilla que se superpone a las cuadernas y la quilla. En ese momento, la mayoría de las cuadernas ya no se conservaban hasta su terminación natural tal y como era evidente en la fotografía de 1999. Los análisis de las muestras de madera realizados por Macrobotanical Analysis para la THC en 2016, determinaron que el palo de trinquete estaba hecho de ciprés calvo o ciprés de los pantanos (Taxodium distichum), una madera local predominante en los estados costeros del sur de los Estados Unidos (Steffy 1994: 257; Bush 2016). Los mástiles podían dañarse fácilmente y eran reemplazables, por lo tanto, el origen de la madera solo determina de manera concluyente el origen del mástil en sí, que puede o no representar dónde fue construido el barco.

Una consideración importante para deducir la edad y la posible función de un barco histórico es la presencia del forro de cobre. Hasta el momento, no se ha encontrado ninguna evidencia de la presencia de forro de cobre en el pecio 41CF184 o clavazón de cobre asociada a barcos con forro. El forro de cobre surgió en la década de 1760 como una tecnología militar para forrar y proteger la obra viva de los buques militares del daño causado por el teredo y los organismos marinos que adhieren al casco. Gran Bretaña fue líder en el desarrollo de esta tecnología, siendo el primero en forrar con cobre un buque, el HMS Alarm, en 1761, y tenía más de 20 naves forradas en 1777 (Staniforth 1985: 23-24). Francia y los Estados Unidos forraron sus primeros buques militares Le Gorée y Alliance en 1767 y 1781, respectivamente (Boudriot 1986: 241; Steffy 1994: 175). La adopción del forro de cobre para proteger el casco fue gradual debido a la corrosión galvánica de los clavos de hierro subyacentes. Una vez que fue desarrollada con éxito una "aleación" de clavos de cobre a finales de la década de 1780, el forro de cobre se generalizó. En 1812 era considerada una práctica común en la construcción de buques británicos (Staniforth 1985: 25; Pering 1812: 36).

El forro de cobre empezó a utilizarse en la Marina de los Estados Unidos más tarde, y solo se convirtió en una práctica regular a principios del siglo XIX. Aunque los EE. UU. fabricaban su 
propio cobre desde 1815, eran incapaces de producir las cantidades necesarias y todavía en 1850 seguían importando este producto de Gran Bretaña - el suficiente para forrar 600 buques (Kauffman 1968: 117; Ronnberg 1980: 125). En 1832, G. F. Muntz patentó una nueva aleación para el forro de cobre ( 60 por ciento de cobre y 40 por ciento de zinc), aunque su uso solo comenzó a sustituir al cobre regular a mediados del siglo XIX (Staniforth 1985: 23, 27). El uso de la tecnología de forro de cobre se extendió gradualmente a barcos mercantes y de recreo, pero desde 
principios hasta mediados del siglo XIX esto todavía suponía un coste añadido considerable a la construcción y mantenimiento de las embarcaciones. Las embarcaciones para alquiler anunciadas en los periódicos fomentaron el uso del cobre como en el caso del Mexicano cuyo casco estaba
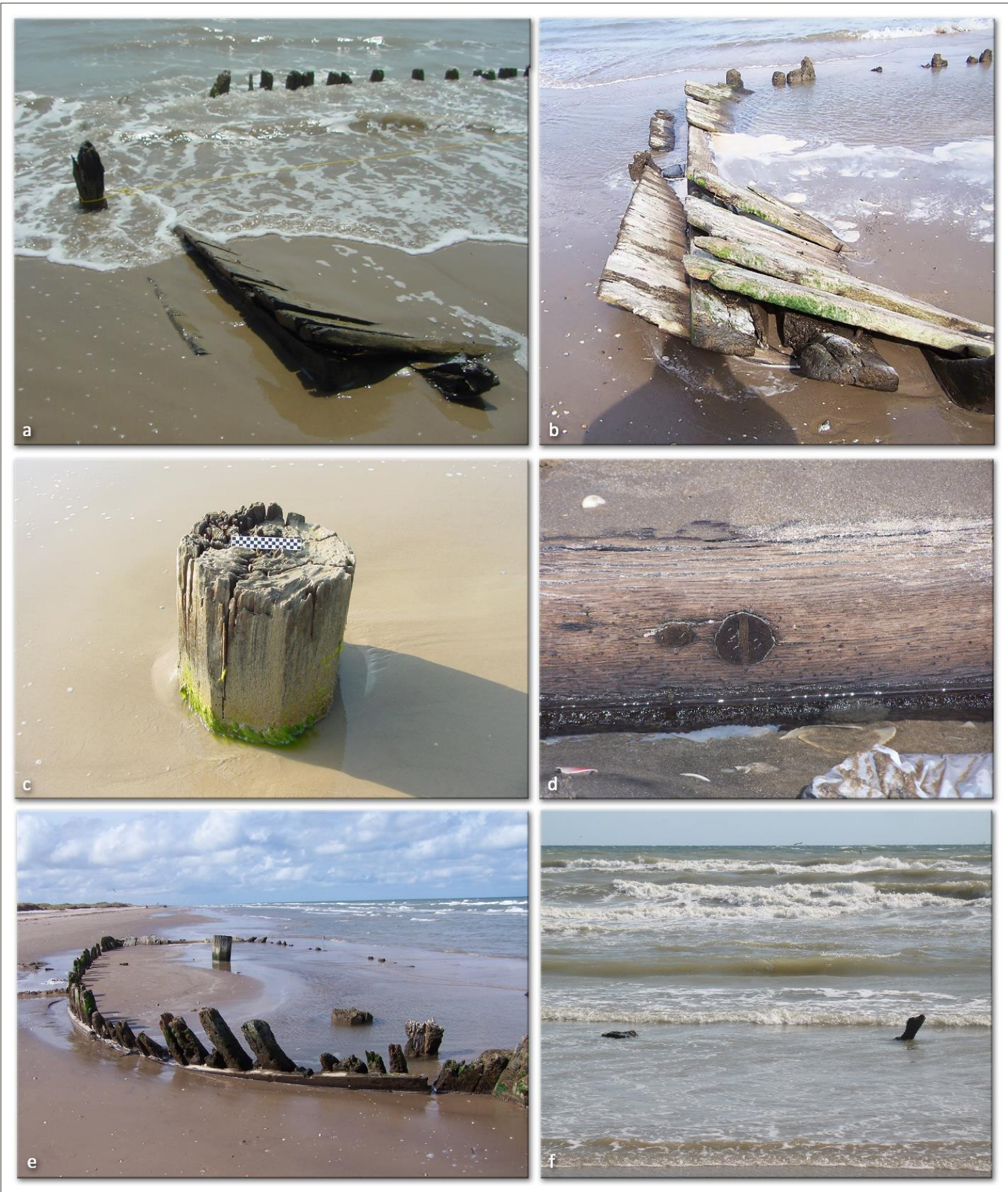

Figura 6. Detalles del pecio 41CF184 desde 1999: (a) yugo en 2002 (foto de Steve Hoyt, 2002); (b) yugo en 2005 más expuesto, pérdida de maderas y detalles de las aletas y forro exterior (foto de Kay Polt, 2005); (c) palo mayor octogonal en 2002 (foto de Steve Hoyt, 2002); (d) cabilla de madera con cuña (foto de Kay Polt, 2005); (e) vista general del pecio en septiembre de 2005 mostrando los dos mástiles, la carlinga del bauprés, el forro exterior del casco, y (esquina derecha) la roda (foto de Kay Polt, 2005); (f) solo la roda y el palo de trinquete eran visibles en octubre de 2009, lo que demuestra una pérdida sustancial y la rápida degradación de las maderas restantes (foto de Jeff Durst, 2009). 
unido y forrado con cobre (New Orlean Bee [NOB] 1836a), ya que aludía a una embarcación de más calidad y mejor mantenida.

Como regla general, la aparición del forro de cobre indica generalmente una fecha de uso o fabricación para un pecio de entre finales del siglo XVIII y finales del siglo XIX. En pecios de finales del siglo XVIII y principios del siglo XIX esto puede sugerir una función militar, ya que sucedió antes de que se adoptara para su uso comercial a gran escala. Además, la presencia de metal Muntz suele utilizarse para determinar fechas previas o posteriores a mediados del siglo XIX. La ausencia de forro también puede indicar fechas anteriores a la década de 1780, pero esto debe ser acompañado de otra evidencia ya que con frecuencia los barcos construidos de forma más económica no utilizaban cobre. La ausencia de forro en 41CF184 sugiere una embarcación no militar de orígenes quizás más humildes.

\section{Monitorización Fotográfica}

Mucho de lo que se ha aprendido acerca del pecio, aparte de la planimetría realizada en 2002, se conoce gracias a la monitorización fotográfica (Figura 6). Con anterioridad a 2010, los archivos de la THC para el pecio 41CF184 contenían imágenes de 1999, 2002-2006, 2008 y 2009. En 2016, Kay Polt del Power Squadron, donó fotografías adicionales que ella había hecho en 2002, 2003 y 2005. Más tarde, en 2017, la residente en Harlingen Rebecca Lozano proporcionó las fotografías más antiguas que el THC tiene en estos momentos en su archivo, y que se remontan a mediados de la década de 1990 (Figura 7). La THC visitó la ubicación del 41CF184 en 2010 y 2016 pero el pecio no estaba visible, por lo que no se pudo documentar fotográficamente (Borgens 2016a: 4).

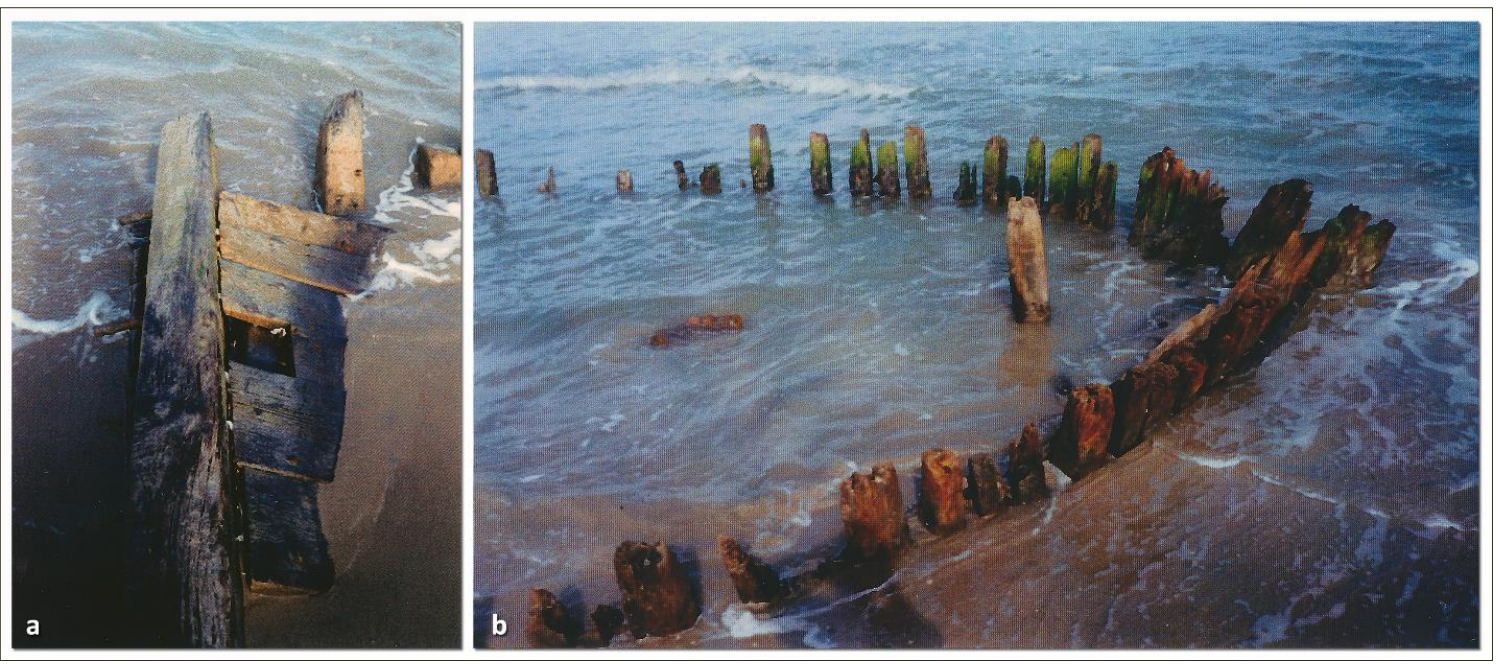

Figura 7. Detalles iniciales del pecio 41CF184: (a) yugo a babor y (b) proa con el palo de trinquete y carlinga del bauprés visibles (fotos de Rebecca Lozano, ca. 1995). 
Las imágenes de Polt se usaron para ilustrar un artículo en línea de la Texas Navy Association que proponía al Montezuma para la identificación del pecio 41CF184 (Drake 2005) - este artículo ya no está disponible en línea. Las fotos de la THC de 1999 y mayo de 2002 junto con las imágenes de Polt de septiembre de 2005 proporcionan algunas de las mejores imágenes del pecio cuando la mayoría de los elementos superiores ahora enterrados eran visibles. Una serie de fotografías tomadas por Hoyt en 2002 capturaron el recorrido de todas las cuadernas de babor y estribor desde el punto de vista de la línea de crujía. Las fotos de Lozano de 1995 son los primeras en el archivo

que muestran el palo de trinquete expuesto - este elemento estaba a menudo enterrado bajo el sedimento. Las imágenes de 2005 de Polt muestran importantes detalles del armazón y proporcionan la mejor documentación de una de las cabillas de madera. Esto demuestra que los extremos de las cabillas de madera se finalizaban con una cuña que bisecaba la circunferencia de la cabeza.

En 2016, la autora amplió la planimetría del pecio realizada por Hall de 2002 incluyendo el yugo documentado por Hoyt en 2002 e interpolando luego la posición de los extremos de las restantes cuadernas, el forro exterior, el forro interior de la proa, y el palo de trinquete a partir de las fotografías (Figura 8). El espacio entre las parejas de cuadernas dobles, según se deducía de las imágenes, era aproximadamente $15.2 \mathrm{~cm}$ (6.0 pulgadas) (Borgens 2016b: 18).

\section{Comparativa Estadística De Los Buques De Nueva Orleans}

En 2006, la autora creó una base de datos del volumen 1 (1804-1820) de los Registros y Matrículas de Nueva Orleans (Survey of Federal Archives 1941) que puede usarse para el análisis estadístico comparativo de los tamaños de los barcos que hubieran podido frecuentar este importante puerto histórico del Golfo a principios del siglo XIX. Esta información se ha utilizado en otros estudios, en particular en el proyecto del pecio de Mardi Gras en el que se generaron promedios para los tamaños de los buques (Ford et al. 2008, Ford et al. 2010; Horrell y Borgens 2017). A partir de estos datos, la eslora media y la manga máxima para todas las goletas en el volumen 1 fueron 18.2 x $5.4 \mathrm{~m}(59.6 \mathrm{x}$ 


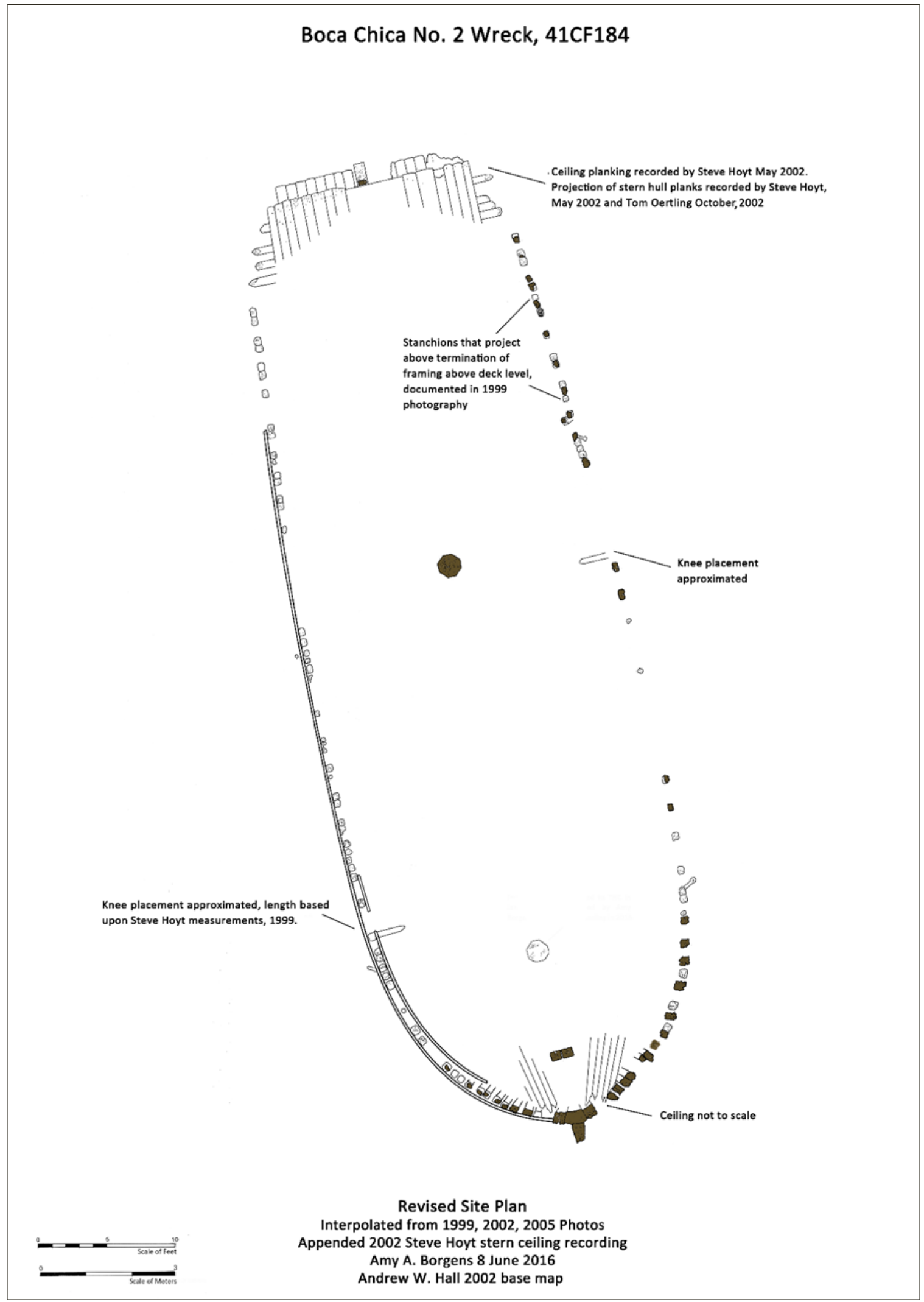

Figura 8. Planimetría del pecio revisada. Las maderas representadas en el plano de 2002 están destacadas (Borgens y Hall, 2016). 
17.7 pies) y 23.3 x $6.9 \mathrm{~m}$ (76.3 x 22.8 pies) para bergantines (Borgens 2008: 58, Tabla 4.2). Por lo tanto, el tamaño del casco del 41CF184 se corresponde estrechamente con el del bergantín mercante medio registrado y matriculado en Nueva Orleans entre 1804 y 1820.

Casi la mitad de las 924 entradas del volumen 1 eran de buques de dos mástiles; sin embargo, esa información no estaba disponible para el $9 \%$ de las embarcaciones. Basándose en la eslora entre perpendiculares conservada de $21.9 \mathrm{~m}$ (72 pies) y una eslora hipotética entre perpendiculares de $22.9 \mathrm{~m}$ (75 pies), se compararon las entradas en el volumen 1. Para barcos de dos mástiles de New Orleans con una eslora comprendida entre 21.9-22.9 m (72-75 pies) $(n=29)$ : 14 eran goletas, 14 eran bergantines, y había un solo paquebote. Todos los buques de estas categorías, menos dos, aparecían enumerados con una sola cubierta - ambas excepciones correspondían a bergantines. Los barcos de vela de dos mástiles dentro de este rango de tamaño tenían una popa cuadrada. La media para embarcaciones de vela dentro de este rango es específicamente de 22.3 x $6.6 \mathrm{~m}$ (73.3 x 21.7 pies). El tonelaje de buques con esta eslora es bastante variable, oscilando entre 44 y 169 toneladas de desplazamiento, con un promedio de 127.9. El puntal variaba entre 1.2 y $3.0 \mathrm{~m} \mathrm{(4 \textrm {a }}$ 10 pies) con un promedio de $2.8 \mathrm{~m}$ (9.1 pies). De acuerdo con los datos de Nueva Orleans para 1804-1820 y más específicamente para el rango de tamaño de 21.9-22.9 m (72-75 pies), el pecio $41 \mathrm{CF} 184$ se corresponde igualmente con un bergantín o goleta mercante de dos mástiles y una sola cubierta. El factor distintivo entre un bergantín y una goleta era típicamente el tipo de aparejo más que la forma del casco.

La relación eslora-manga del casco conservado del pecio 41CF184 es 3.1: 1; la relación de eslora-manga ajustada para $22.9 \mathrm{~m}$ (75 pies) es 3.4: 1. La relación eslora-manga para la goleta media registrada y matriculada es de 3.4: 1 y para el bergantín de 3.3: 1. El promedio de la relación para barcos de vela en general dentro del rango de 21.9-22.9 m (72-75 pies) es 3.4. En comparación, la relación eslora-manga para los bergantines de 83 pies de la Marina de Texas (San Antonio, San Bernard y San Jacinto) botados en 1839 era de 3.9: 1; la de los bergantines de 110 pies Archer y Wharton también era 3.9 (Dawson y Williams 1839). Básicamente, los barcos de guerra suelen tener más eslora que manga en comparación con los barcos mercantes.

En resumen, la hipótesis es que el pecio $41 \mathrm{CF} 184$ es una goleta de dos mástiles, casco de madera, cuadernas dobles, y principalmente unido por medio de cabillas de madera y datado entre finales del siglo XVIII y mediados del siglo XIX. Es de construcción robusta y la relación total eslora-manga es aproximadamente 3.4: 1, que es más coherente con un buque mercante "más voluminoso" para el transporte de carga y no necesariamente la típica de los buques de guerra de 
la época más finos, con casco más afilado. La ausencia de forro de cobre en el 41CF184 en este período también sugiere un uso mercantil y no una función militar.

\section{EXAMINANDO AL MONTEZUMA COMO CANDIDATO PARA EL PECIO}

La creencia de que el 41CF184 es el buque de guerra Montezuma ha persistido durante mucho tiempo, a pesar de que la evidencia demuestra lo contrario. Desafortunadamente, esto ocurre a menudo con pecios históricos, cuando el folclore local puede llegar a asociar inmediatamente un yacimiento arqueológico con el naufragio más famoso de la zona. En general, la mitología local suele asociar los pecios texanos con galeones españoles, naufragios de la Guerra Civil o los barcos piratas de Jean Lafitte. La pregunta aquí es ¿qué se sabe actualmente sobre el Montezuma para sugerir su candidatura para el pecio Boca Chica No. 2?

Esto comienza como un cuento de cuatro (tal vez cinco) Moctezuma/Montezumas/Bravos, todos los cuales parece que se han combinado entre sí a lo largo de los años. Tanto la autora como Steve Hoyt desarrollaron de forma independiente ejes cronológicos que resumen la historia del Montezuma en el Golfo y relatan los cambios de los nombres de los buques. Estos ejes cronológicos aparecen combinados en la Tabla 1.

\section{El Primer Bravo (1825 - Ca. 1835)}

La primera documentación de un buque militar mexicano con este nombre aparece a mediados de la década de 1820. Fue uno de los tres barcos comprados a Inglaterra en 1824, poco después de la independencia de México (Bonilla 1946: 82; Bidwell 1960: 331). Originalmente era el yate con aparejo de bergantín 322 27/94 Ariel, construido en el río Támesis en 1824 y registrado en Londres a nombre del Earl de Harborough (Bidwell 1960: 331; Andreas von Mach, comunicación personal 2017 y 2018). Probablemente llegó a México en otoño de 1825, casi al mismo tiempo de la entrega del Victoria en agosto y el Avend Prindien (que pasó a llamarse Libertad) en septiembre (Bonilla 1960: 349). En 1825, el Ariel, rebautizado como Bravo, fue uno de varios buques militares que protegían San Juan De Ulúa, una isla fortificada frente a Veracruz (Bonilla 1946: 98). En 1826, el capitán David Porter de los Estados Unidos abandonó su comisión en la Marina de los Estados Unidos para servir como comodoro de la Marina mexicana. Este bergantín formaba parte de la flota mexicana cuando tomó el mando.

En sus memorias, el hijo del comodoro Porter, David Dixon Porter, un guardiamarina de la Marina Mexicana, menciona que el Bravo portaba 14 carronadas de 24 libras cuando fue 
inspeccionado por primera vez por su padre en Veracruz en 1825 (Porter 1875: 352; Long 2014: 265). Otras fuentes mencionan 18 cañones, lo que parece ser la descripción más consistente de su armamento, y 20 carronadas (New Times 1827: 2; Bidwell 1946: 444; Bonilla 1946: 98). A finales de diciembre de 1826, Porter trasladó la flota mexicana a los Cayos de Florida donde quedó estacionada y estableció de forma temporal el cuartel general de su planeada ofensiva para capturar buques españoles frente a Cuba. Los barcos Libertad, Victoria y Bravo pronto empezaron a capturar presas y en represalia las fuerzas españolas bloquearon la flota mexicana en Cayo Hueso. Los barcos de Porter pudieron esquivar el bloqueo y finalmente capturaron 21 presas mientras estaban estacionados en esta área (Ward 1828: 307-308; Bonilla 1946: 102; Viele 1999: 105-106). Las actividades de la Marina mexicana en Cayo Hueso desafiaban la neutralidad de los EE. UU. e interferían en el comercio regional entre los EE. UU. y Cuba. Cuando el presidente John Quincy Adams firmó un proyecto de ley que prohibía la entrada de buques apresados en Cayo Hueso (y, por lo tanto, que vendieran sus bienes), la principal forma de pago de Porter a sus tripulaciones fue suprimida. Después de permanecer cinco meses en los Cayos, la flota de Porter viajó a Nueva Orleáns para recoger el recién adquirido bergantín mexicano Guerrero y solicitar una tripulación antes de regresar a Veracruz (Viele 1999: 114-115). 
Tabla 1. Resumen del eje cronológico de los diversos buques con los nombres de Ariel, Bravo, General Bravo, Montezuma, y Moctezuma

\begin{tabular}{|c|c|c|}
\hline Fecha & Evento & Nombres \\
\hline 1824 & $\begin{array}{l}\text { El bergantín de guerra Bravo es comprado a Inglaterra en } 1824 \text { y habiendo sido construido } \\
\text { anteriormente como yate para un aristócrata y bautizado como Ariel (Bidwell 1960: 331). } \\
\text { Según Bonilla (1946: 23) la fecha de compra es 1823. }\end{array}$ & Ariel \\
\hline $\begin{array}{l}\text { Julio de } \\
1824\end{array}$ & $\begin{array}{l}\text { Más de } 20 \text { yates reales del Royal Yacht Club, incluido el yate desarmado Ariel, se unieron al } \\
\text { escuadrón del comodoro Lord Yarborough antes de la reunión en Plymouth (London St. } \\
\text { James and General Evening Post 1824:4) }\end{array}$ & \\
\hline $\begin{array}{l}26 \text { de } \\
\text { agosto de } \\
1824\end{array}$ & El yate de Harborough avistado al oeste de Deal (Courier 1825:3). & \\
\hline 1824 & $\begin{array}{l}\text { Bidwell supone que el Ariel fue comprado en Inglaterra alrededor de agosto de } 1824 ; \text { sin } \\
\text { embargo, también reconoce que el Victoria y la Bravo no se ajustan a la descripción "dos } \\
\text { [fragatas] de 44" de José Mariano de Michelena en una carta del } 31 \text { de agosto de } 1824 \\
\text { (Bidwell 1960:331). Bonilla (1946: 23) erróneamente tiene } 1823 \text { como la fecha de compra. }\end{array}$ & Ariel \\
\hline $\begin{array}{l}6 \text { de agosto } \\
\text { de } 1825\end{array}$ & $\begin{array}{l}\text { Un índice de documentos en los archivos ingleses relativos a México menciona una carta } \\
\text { francesa del } 6 \text { de agosto de } 1825 \text { que proporciona información sobre los barcos Avend- } \\
\text { Prindien y Ariel (Grajales 1969: 84). Estos eran dos de los tres barcos comprados a través de } \\
\text { nuevos préstamos negociados con casas de crédito inglesas. E1 Avend-Prindien pasó a llamarse } \\
\text { Libertad y se esperaba que arribara en enero, pero no llegó a México hasta el } 13 \text { de } \\
\text { septiembre (Bidwell 1960: } 349 \text { ). Las tres embarcaciones arribaron a México en otoño de } \\
\text { 1825, ya que el Victoria llegó a México el } 18 \text { de agosto de } 1825 \text { después de paradas en Nueva } \\
\text { York y Jamaica, y la Bravo arribó el } 20 \text { de septiembre (Bidwell 1960: } 349 \text { ). }\end{array}$ & Ariel \\
\hline $\begin{array}{l}\text { Agosto } \\
1825\end{array}$ & $\begin{array}{l}\text { El yate de Lord Harborough fue buscado por error por espíritus y contrabando por un oficial } \\
\text { del "Servicio Preventivo." Cuando Lord Harborough cuestionó el motivo de la búsqueda, el } \\
\text { teniente Graham lo desafió a un duelo. Graham fue condenado por provocar el duelo y el } \\
\text { evento fue utilizado como un ejemplo de abuso de poder por parte de los militares. Se } \\
\text { describió que el yate [que se suponía era el Ariel] parecía un barco pesquero como } \\
\text { justificación de por qué se buscó, ya que no se parecía al barco de un noble. (Kent and Essex } \\
\text { Mercury 1825:4). }\end{array}$ & \\
\hline 1825 & $\begin{array}{l}\text { El Ariel fue equipado como buque de guerra en Gravesend, Inglaterra, en el otoño de } 1825 \text {, } \\
\text { durante un período de tres semanas (York Herald 1825, von Mach, comunicación personal } \\
\text { 2018). }\end{array}$ & Ariel \\
\hline $\begin{array}{l}\text { Julio de } \\
1825\end{array}$ & $\begin{array}{l}\text { El Ariel, maestro Dillon, desembarca de Gravesend, Inglaterra el } 9 \text { de julio a Nueva York, } \\
\text { deteniéndose en Deal el } 12 \text { de julio (London Lloyd's List [LLL] } 1825 \mathrm{a}: 1 ; 1825 \mathrm{~b} \text { ). E1 } 29 \text { de } \\
\text { julio, el Ariel continuaría su viaje a Nueva York, ahora partiendo de Falmouth con el barco } \\
\text { Arve Prinsen (LLL 1825c). }\end{array}$ & Ariel \\
\hline 1825 & $\begin{array}{l}\text { La Bravo y el Libertad, anteriormente los Ariel y Aven Prinsen, salen de Falmouth, Inglaterra } \\
\text { (Michelena 1825; von Mach, comunicación personal 2018). }\end{array}$ & Ariel, Bravo \\
\hline $\begin{array}{l}20 \text { de } \\
\text { septiembre } \\
1825\end{array}$ & $\begin{array}{l}\text { El Victoria llega a México el } 18 \text { de agosto de } 1825 \text { después de detenerse en Nueva York y } \\
\text { Jamaica; La Bravo llegó el } 20 \text { de septiembre (Bidwell 1960: 349). }\end{array}$ & Bravo \\
\hline $\begin{array}{l}\text { Septiembre } \\
\text { de } 1825\end{array}$ & $\begin{array}{l}\text { E1 Ministerio de Hacienda (ministro de Hacienda), Ignacio Esteva, inspeccionó la marina y } \\
\text { comentó la débil condición de la Bravo (Escamilla 2008: 245). }\end{array}$ & Bravo \\
\hline $\begin{array}{l}5 \text { de } \\
\text { octubre de } \\
1825\end{array}$ & $\begin{array}{l}\text { Uno de los varios barcos que recibieron órdenes de atacar a los barcos españoles avistados en } \\
\text { Veracruz, incluyendo el Libertad, los bergantines Victoria y Bravo, las goletas Papaloapan, } \\
\text { Tampico y Orizaba, y la balandra Chalco (Bonilla 1946: 94). }\end{array}$ & Bravo \\
\hline $\begin{array}{l}\text { Noviembre } \\
\text { de } 1825\end{array}$ & $\begin{array}{l}\text { La lancha del Bravo se acercó a la fortaleza española en San Juan de Ulúa para ver hasta } \\
\text { donde se podrían aproximar sin ser detectados (Bidwell 1946: 370). }\end{array}$ & Bravo \\
\hline 1826 & $\begin{array}{l}\text { Otro documento en los archivos ingleses acerca de México proporciona información general } \\
\text { sobre las fragatas Libertad, Ariel y Victoria (Grajales 1969: 103). En esta coyuntura, la Ariel es } \\
\text { formalmente parte de la Marina mexicana, aunque no se menciona al Bravo en esta carta. }\end{array}$ & Ariel \\
\hline $\begin{array}{l}\text { Mayo de } \\
1826\end{array}$ & $\begin{array}{l}\text { El nuevo Comodoro Porter llega a Veracruz y observa la marina mexicana existente: la } \\
\text { pequeña fragata Libertad de } 32 \text { cañones, en su mayoría carronadas; el viejo bergantín Victoria } \\
\text { con } 18 \text { cañones de } 18 \text { libras; Guerrero; el bergantín Bravo con } 14 \text { carronadas de } 24 \text { libras; } \\
\text { Herman, un bergantín-goleta de } 5 \text { cañones y dos pequeñas goletas estacionadas en Campeche } \\
\text { (Porter } 1875: 348,352) \text {. }\end{array}$ & Bravo \\
\hline $\begin{array}{l}\text { Enero de } \\
1827\end{array}$ & Registrado como un barco de la Marina mexicana (Ward 1828: 307-308; Bonilla 1946: 109). & \\
\hline $\begin{array}{l}\text { Diciembre } \\
\text { de } 1826\end{array}$ & $\begin{array}{l}\text { El Bravo llega a Cayo Hueso en diciembre como parte de la empresa de la flota mexicana } \\
\text { para capturar presas españolas en la costa de Veracruz (Viele 1999: 107). }\end{array}$ & Bravo \\
\hline
\end{tabular}




\section{Tabla 1. Resumen del eje cronológico de los diversos buques con los nombres de Ariel, Bravo, General Bravo, Montezuma, y Moctezuma}

\begin{tabular}{|c|c|c|}
\hline Fecha & Evento & Nombres \\
\hline $\begin{array}{l}\text { Marzo de } \\
1827\end{array}$ & $\begin{array}{l}\text { Registrado como parte de la flota mexicana cerca de Cayo Hueso con } 18 \text { cañones y una } \\
\text { tripulación de } 100 \text { hombres. También se menciona a la Libertad de } 40 \text { cañones y } 250 \\
\text { hombres), el Victoria ( } 18 \text { cañones, } 80 \text { hombres) y una goleta. La tripulación de esta flota } \\
\text { estaba compuesta por } 2 / 3 \text { de "indios" y } 1 / 3 \text { de americanos e ingleses (New Times } 1827: 2 \text { ). }\end{array}$ & \\
\hline $\begin{array}{l}25 \text { de abril } \\
\text { de } 1827\end{array}$ & $\begin{array}{l}\text { El Bravo capturó al Jovena María en Salt Key Bank, que está cerca de las Bahamas entre los } \\
\text { Cayos de Florida y Cuba (LLL 1827: 1). }\end{array}$ & Bravo \\
\hline 1828 & $\begin{array}{l}\text { El Bravo formaba parte de la marina que operaba en la costa de Cuba y había capturado } 13 \\
\text { presas (Bonilla 1946: 102). }\end{array}$ & Bravo \\
\hline $\begin{array}{l}31 \text { de julio } \\
\text { de } 1828\end{array}$ & $\begin{array}{l}\text { La débil fuerza de la Marina mexicana descrita tal y como apareció en Veracruz el } 31 \text { de } \\
\text { julio de 1828: la Congress de } 64 \text { cañones, la Libertad de 36, el Bravo de } 18 \text { cañones y dos } \\
\text { goletas (London Morning Post 1828: 3). }\end{array}$ & Bravo \\
\hline $\begin{array}{l}4 \text { de } \\
\text { septiembre } \\
\text { de } 1832\end{array}$ & $\begin{array}{l}\text { Se informa desde Nueva Orleans que la goleta mexicana Montezuma de Tampico, del capitán } \\
\text { Villareal, fue capturada por la Grampus, del capitán Tatnall, con } 37 \text { soldados y una } \\
\text { tripulación de } 43 \text { hombres (British Traveler and Commercial Law and Gazette 1832: } 2 \text {; } \\
\text { Washington National Intelligencer: } 1832: 3 \text {; Niles' Weekly Register 1832: 82-83). Fue } \\
\text { capturada cerca del río Tampico por los actos de piratería cometidos cerca de Matanzas. La } \\
\text { Montezuma fue ilegalmente equipada por los generales mexicanos como parte de un } \\
\text { levantamiento contra el gobierno mexicano. Llevaba un cañón de pivote y otros dos cañones } \\
\text { (Jones 1878: } 39 \text { ). Villareal fue declarado culpable de piratería en los tribunales de los Estados } \\
\text { Unidos y el barco no fue entregado a México como se solicitó. }\end{array}$ & Montezuma \\
\hline 1833 & $\begin{array}{l}\text { La goleta de transporte Montezuma, del capitán Don Tomas Marin, viajó a Matamoros con } \\
\text { tropas y en noviembre viajó a Nueva Orleans con tropas (Bonilla 1946: 118). }\end{array}$ & Montezuma \\
\hline $\begin{array}{l}17 \text { de abril } \\
\text { de } 1834\end{array}$ & $\begin{array}{l}\text { Las goletas de guerra Moctezuma y Consolation ( } 79 \text { toneladas) y la goleta de } 111 \text { toneladas de } \\
\text { la embarcación piloto la Correo de Tampico llegan a Veracruz (Procurador del Pueblo 1834; } \\
\text { von Mach, comunicación personal 2018). }\end{array}$ & Moctezuma \\
\hline 1835 * & $\begin{array}{l}\text { En 1835, la marina de } 1829 \text { (cuando Porter partió) se reducía al bergantín Veracruzano y "la } \\
\text { goleta" Moctezuma. Según Bonilla, esto motivó las compras de } 1836 \text { de el bergantín Vencedor } \\
\text { del Álamo y los buques de guerra Iturbide, Libertador, Mexicano, General Bravo, General Cos, y } \\
\text { General Urrea. (Lerdo de Tejada 1857: 5; Bonilla 1946: 118). El presupuesto para } 1835 \text { fue de } \\
\$ 826,584 \text { (Bonilla 1946: 118). }\end{array}$ & $\begin{array}{l}\text { Moctezuma, } \\
\text { General Bravo }\end{array}$ \\
\hline $\begin{array}{l}3 \text { de mayo } \\
\text { de } 1835\end{array}$ & $\begin{array}{l}\text { Confiscación de la goleta estadounidense Martha de Nueva Orleans por John Calva, primer } \\
\text { teniente a cargo de la goleta mexicana de guerra Montezuma. (Washington Globe 1835: } 2 \text {; } \\
\text { Forysth 1836). }\end{array}$ & Montezuma \\
\hline $\begin{array}{l}7 \text { de mayo } \\
\text { de } 1835\end{array}$ & $\begin{array}{l}\text { Algunos pasajeros que viajaban en el buque de guerra Moctezuma en } 1835 \text { no tenían pasaportes } \\
\text { (Tenorio } 1835 \mathrm{a} \text { ). }\end{array}$ & Moctezuma \\
\hline $\begin{array}{l}18 \text { de } \\
\text { mayo de } \\
1835\end{array}$ & Llegada de la goleta de guerra Moctezuma con tropas y dinero (Tenorio $1835 \mathrm{~b}$ ). & Moctezuma \\
\hline $\begin{array}{l}5 \text { de julio } \\
\text { de } 1835\end{array}$ & $\begin{array}{l}\text { Carta de Eduardo Gritten a Domingo de Ugartechea en la que declara su convicción de que } \\
\text { un barco estadounidense estaba buscando expresamente a la goleta de guerra nacional } \\
\text { Moctezuma (Gritten 1835: 204). }\end{array}$ & Moctezuma \\
\hline $\begin{array}{l}\text { Septiembre } \\
\text { de } 1835\end{array}$ & $\begin{array}{l}\text { La goleta de guerra Montezuma de } 4 \text { cañones se enfrenta con el Ingham. La Montezuma tiene } \\
\text { una tripulación de } 50 \text { hombres mientras que el Ingham tiene } 4 \text { cañones y solo } 24 \text { hombres. El } \\
\text { Ingham escapó hacia la costa y se afirma que comenzó el ataque (London St. James Chronicle } \\
\text { y General Evening Post } 1835: \text { ). }\end{array}$ & Montezuma \\
\hline $\begin{array}{l}2-9 \text { de } \\
\text { octubre de } \\
1835\end{array}$ & $\begin{array}{l}\text { La goleta de guerra Montezuma estaba en Veracruz preparándose para llevar armas y } \\
\text { municiones al General Cos, pero no estuvo lista a tiempo para navegar con la carga; se } \\
\text { sospecha que éstas serán desembarcadas en la Bahía de Matagorda. Hubo un embargo } \\
\text { temporal en Veracruz del } 2 \text { al } 9 \text { de noviembre [posiblemente para mantener esto información } \\
\text { en secreto...] (London Public Ledger 1835: 3). }\end{array}$ & Montezuma \\
\hline $\begin{array}{l}28 \text { de } \\
\text { octubre de } \\
1835\end{array}$ & $\begin{array}{l}\text { Informe que la goleta de guerra "Montazuma," ahora Bravo, recibió la orden de navegar a } \\
\text { Aransas sin tropas (Bryan 1835). }\end{array}$ & $\begin{array}{l}\text { Montazuma, } \\
\text { Bravo }\end{array}$ \\
\hline $\begin{array}{l}28 \text { de } \\
\text { octubre de } \\
1835 .\end{array}$ & $\begin{array}{l}\text { Un crucero mexicano está "frente a esta costa" (la carta es de Quintana) y ha sido visto } \\
\text { durante los dos días anteriores - disparó un tiro sobre Velasco que no llegó a la orilla. Brinkley } \\
\text { (editor) asume que este es la goleta de guerra Montezuma (McKinney y Williams 1835a). }\end{array}$ & Montezuma \\
\hline
\end{tabular}


Tabla 1. Resumen del eje cronológico de los diversos buques con los nombres de Ariel, Bravo, General Bravo, Montezuma, y Moctezuma

\begin{tabular}{|c|c|c|}
\hline Fecha & Evento & Nombres \\
\hline $\begin{array}{l}4 \text { de } \\
\text { noviembre } \\
\text { de } 1835\end{array}$ & $\begin{array}{l}\text { La goleta de guerra Moctezuma disparó sobre Velasco y se devolvieron los disparos de cañón } \\
\text { desde la costa, y la Moctezuma se retiró. El día } 28 \text { voluntarios a bordo del corsario San Felipe } \\
\text { salieron en su persecución, primero hacía Galveston y luego en dirección a Matagorda donde } \\
\text { lo encontraron anclado. El San Felipe esperó a que la mar se calmara para comenzar el ataque, } \\
\text { pero en cambio naufragó en la costa. La Moctezuma y el San Felipe, encallado, intercambiaron } \\
\text { disparos (Fisher 1836; McKinney 1835a; Potencias 2006: 80). }\end{array}$ & $\begin{array}{l}\text { Montazuma, } \\
\text { Moctezuma, } \\
\text { Montezuma, } \\
\text { Bravo }\end{array}$ \\
\hline $\begin{array}{l}9 \text { de } \\
\text { noviembre } \\
\text { de } 1835\end{array}$ & $\begin{array}{l}\text { McKinney está en Matagorda, preparando otro barco para ir tras la goleta de guerra } \\
\text { Montezuma (El corsario San Felipe se perdió alrededor del } 6 \text { de noviembre). McKinney cree } \\
\text { que un barco llamado Crawford causó el naufragio del San Felipe ya que la Montezuma estaba } \\
\text { en Brazos Santiago el dia } 28 \text {. El Veracruzana está también en la costa de Matagorda y quieren } \\
\text { dos comisiones más (McKinney y Williams } 1835 \mathrm{~b} \text { ). }\end{array}$ & Montezuma \\
\hline $\begin{array}{l}14 \text { de } \\
\text { noviembre } \\
\text { de } 1835\end{array}$ & $\begin{array}{l}\text { Menciona que la goleta Montezuma y el bergantín "Vera Cruzana" (en la costa de Galveston) } \\
\text { están navegando en el Golfo. La Montezuma estuvo en Brazos Santiago según Información } \\
\text { recibida hace seis días. También se menciona, tal vez erróneamente, que el San Felipe fue } \\
\text { recuperado (McKinney 1835b). }\end{array}$ & Montezuma \\
\hline $\begin{array}{l}19 \text { de } \\
\text { noviembre } \\
\text { de } 1835\end{array}$ & $\begin{array}{l}\text { La goleta de guerra Bravo hace encallar a la goleta Hannah Elizabeth y sube a bordo una } \\
\text { tripulación de presa (Fannin 1835: 158-159; Dienst 1909a: 184). Otro relato llama a este } \\
\text { buque General Bravo (Tornel 1836). Cinco estadounidenses son apresados por la fuerza y } \\
\text { encarcelados en Brazos Santiago (Smith 1835: 173). Las autoridades mexicanas argumentan } \\
\text { que sus acciones estaban justificadas ya que la Hannah Elizabeth llevaba un cañón y armas de } \\
\text { contrabando y (Guerra 1835: 188). La goleta William Robbins recupera la Hannah Elizabeth y } \\
\text { captura su tripulación de presa. El teniente mexicano dice que pertenece al Bravo y no a la } \\
\text { goleta de guerra Montezuma. Doce tripulantes mexicanos fueron capturados, y uno murió por } \\
\text { enfriamiento y embriaguez (Fisher 1835). }\end{array}$ & $\begin{array}{l}\text { Bravo, } \\
\text { General } \\
\text { Bravo }\end{array}$ \\
\hline $\begin{array}{l}8 \text { de enero } \\
\text { de } 1836\end{array}$ & $\begin{array}{l}\text { Otra mención acerca de la goleta mexicana de guerra Moctezuma estando en la bahía de } \\
\text { Galveston y que Texas no tiene una marina para hacer frente su presencia - la goleta } \\
\text { Invincible es ofrecida por McKinney y Williams. Se aconseja y autoriza al gobernador a dar a } \\
\text { Thomas F. McKinney una carta nombrándolo comandante de la Invincible como buque de } \\
\text { guerra nacional. Se solicitan voluntarios (Barrett 1836; Telegraph and Register 1836: 2). }\end{array}$ & Moctezuma \\
\hline $\begin{array}{l}3 \text { de abril } \\
\text { de } 1836\end{array}$ & $\begin{array}{l}\text { Según un relato mexicano de Matamoros, la goleta de guerra Bravo, antes llamada } \\
\text { Montezuma, comandada por el capitán Davis, y la goleta Correo Secundo (antes New Castle, del } \\
\text { capitán Watkins) se estaban preparando para transportar tropas y suministros para Copano. } \\
\text { La Correo fue comprada por México y estaba bajo el mando del capitán Thompson. Estaba } \\
\text { armada con dos cañones. El teniente Levenue [sic] de la balandra Invincible es hecho } \\
\text { prisionero. El relato de Pierce usa el nombre Correo de México en lugar de Correo Secundo, } \\
\text { aunque éstos son el mismo barco (New Albany Gazette 1836: 2; Pierce 1917: 22). La Bravo } \\
\text { encalla y recibe los disparos de la Invincible (Hall 1835). El capitán Davis de la Bravo } \\
\text { menciona que su embarcación apenas sufrió daños. El oficial del puerto de Matamoros se } \\
\text { refiere a este barco como el General Bravo (Espino 1835). Zimmerman, un miembro de la } \\
\text { tripulación de la Invincible, afirma que el costado de estribor de la Montezuma estaba } \\
\text { destrozado hacia dentro (Zimmerman 1836). }\end{array}$ & $\begin{array}{l}\text { Montezuma, } \\
\text { Bravo, } \\
\text { General } \\
\text { Bravo }\end{array}$ \\
\hline $\begin{array}{l}\text { Abril de } \\
1836\end{array}$ & $\begin{array}{l}\text { Según Dienst, la goleta de guerra Bravo es una de las tres embarcaciones mexicanas que se } \\
\text { enfrentaron a la goleta Independence con un desenlace igualado (Dienst 1909a: 189). Es } \\
\text { probable que esto sea un error, ya que la acción naval de la Bravo de abril de } 1836 \text { involucró a } \\
\text { la goleta de guerra Invincible (no al Independence) e incluyó dos y no tres buques navales. }\end{array}$ & $\begin{array}{l}\text { Segundo } \\
\text { Bravo }\end{array}$ \\
\hline $\begin{array}{l}5 \text { de abril } \\
\text { de } 1836\end{array}$ & $\begin{array}{l}\text { El general Filosola menciona que los buques Correo y Segundo Bravo están listos para partir de } \\
\text { Matamoros (Filosola 1849: 242). }\end{array}$ & $\begin{array}{l}\text { Segundo } \\
\text { Bravo }\end{array}$ \\
\hline $\begin{array}{l}16 \text { y } 17 \text { de } \\
\text { mayo de } \\
1836\end{array}$ & $\begin{array}{l}\text { El } 16 \text { de mayo, una carta enviada por Filosola al comandante del buque Segundo Bravo trata } \\
\text { las órdenes enviadas a Matamoros en la goleta Correo Segundo. Otra carta de Filosola del } 17 \\
\text { de mayo menciona que los buques Segundo Bravo y Correo Segundo deben recoger comida para } \\
\text { el ejército (Filosola 1849: 291-292). }\end{array}$ & $\begin{array}{l}\text { Segundo } \\
\text { Bravo }\end{array}$ \\
\hline $\begin{array}{l}\text { Junio de } \\
1836 \text { * }\end{array}$ & $\begin{array}{l}\text { Un resumen de los gastos gubernamentales durante } 12 \text { años hasta el } 30 \text { de junio de } 1836 \\
\text { menciona tanto a la goleta Moctezuma como el bergantín Bravo (México Ministerio de } \\
\text { Hacienda 1837). }\end{array}$ & $\begin{array}{l}\text { Moctezuma, } \\
\text { Bravo }\end{array}$ \\
\hline
\end{tabular}


Tabla 1. Resumen del eje cronológico de los diversos buques con los nombres de Ariel, Bravo, General Bravo, Montezuma, y Moctezuma

\begin{tabular}{|c|c|c|}
\hline Fecha & Evento & Nombres \\
\hline $\begin{array}{l}\text { Julio de } \\
1836\end{array}$ & $\begin{array}{l}\text { Según los documentos de Nueva Orleans de julio de 1836, el buque Bravo se perdió en el } \\
\text { camino de Matamoros a Veracruz con toda su tripulación a bordo excepto el capitán } \\
\text { Thompson y dos marines (Dienst 1909a: 139). Un relato diferente dice que el barco perdido } \\
\text { es la goleta Correo Secundo (London Shipping Gazette 1836: 1). }\end{array}$ & Bravo \\
\hline $\begin{array}{l}20 \text { de julio } \\
\text { de } 1836\end{array}$ & $\begin{array}{l}\text { Carta de la oficina del Secretario de Guerra y de la Marina que menciona la comisión para } \\
\text { Thompson la goleta de guerra Bravo, el pago de la tripulación del buque y también } \\
\text { suministros para Matamoros. El documento enumera el armamento y la tripulación del } \\
\text { escuadrón de aquel momento que consiste en los bergantines Iturbide, Libertador y Vencedor } \\
\text { del Álamo, la goleta-bergantín Fama (General Urrea), la goleta Bravo con un cañón de pivote } \\
\text { de } 16 \text { libras y cuatro carronadas de } 9 \text { libras. La Bravo tiene una tripulación de } 60 \text { hombres } \\
\text { con } 10 \text { soldados y un sargento de guarnición. También se mencionan dos buques } \\
\text { comprados en Yucatán: el General Terán y la goleta Hidalgo y dos barcos de vapor de } 50 \\
\text { caballos de potencia armados cada uno con un cañón de } 16 \text { libras (Secretaria de Guerra y } \\
\text { Marina 1836). }\end{array}$ & Bravo \\
\hline $\begin{array}{l}\text { Agosto de } \\
1836\end{array}$ & $\begin{array}{l}\text { "La Flota mexicana compuesta por el bergantín Fama y la goleta Bravo estaban en Vera } \\
\text { Cruz el } 9 \text { de agosto de } 1836 \text { - se estaban preparando para realizar una navegación" (Boston } \\
\text { Morning Post [BMP] 1836: 2) }\end{array}$ & Bravo \\
\hline $\begin{array}{l}11 \text { de } \\
\text { febrero de } \\
1837\end{array}$ & $\begin{array}{l}\text { La goleta militar Bravo, con el infame capitán Thompson, arribó a Sisal para embarcar al } \\
\text { General Toro - comandante general de Yucatán. Thompson fue } 10 \text { leguas tierra adentro a } \\
\text { la capital "Menda" [sic, Mérida] (BMP 1837a: 2). }\end{array}$ & Bravo \\
\hline $\begin{array}{l}12 \text { y } 16 \text { de } \\
\text { abril de } \\
1837\end{array}$ & $\begin{array}{l}\text { La balandra de guerra USS Natchez se enfrenta al General Urea, el bergantín General Terán y } \\
\text { la goleta de guerra Bravo en Brazos Santiago sobre la disputa por las goletas } \\
\text { estadounidenses detenidas (Hill 1987: 70-71). }\end{array}$ & Bravo \\
\hline $\begin{array}{l}9-17 \text { de } \\
\text { abril de } \\
1837\end{array}$ & $\begin{array}{l}\text { La goleta de guerra Bravo "prácticamente bloqueado" en la desembocadura del río Bravo } \\
\text { (río Grande) durante el enfrentamiento con el buque Natchez - esto fue probablemente en } \\
\text { Brazos Santiago y no en el río Bravo (río Grande) (Cerro 1987: 71). }\end{array}$ & $\begin{array}{l}\text { General } \\
\text { Bravo }\end{array}$ \\
\hline $\begin{array}{l}9 \text { de julio } \\
\text { de } 1837\end{array}$ & $\begin{array}{l}\text { Informe sobre como el capitán Thompson y su teniente abandonaron la goleta de guerra } \\
\text { Bravo y se dirigieron en un bote abierto hacia el norte, hacia Texas, desde México (BMP } \\
1837 \text { b: 2). }\end{array}$ & \\
\hline $\begin{array}{l}\text { Agosto de } \\
1837\end{array}$ & En el puerto de Veracruz con los buques General Terán y el Independence (Cerro 1987: 87). & $\begin{array}{l}\text { General } \\
\text { Bravo }\end{array}$ \\
\hline $\begin{array}{l}28 \text { de } \\
\text { agosto de } \\
1838\end{array}$ & $\begin{array}{l}\text { El buque armado General Bravo forma parte de una flotilla que llega a Campeche y que } \\
\text { también incluye los bergantínes Fama y Vencedor del Álamo (Bonilla 1946: 118). }\end{array}$ & $\begin{array}{l}\text { General } \\
\text { Bravo }\end{array}$ \\
\hline $\begin{array}{l}\text { Abril de } \\
1842\end{array}$ & $\begin{array}{l}\text { Lo construye Green and Wigrams en Inglaterra. Un buque de madera pesada de } 1111 \\
\text { toneladas de desplazamiento, montando un Paixhan de } 68 \text { libras, dos cañones largos de } 32 \\
\text { libras, cuatro carronadas de } 32 \text { libras y un cañón pequeño de } 9 \text { libras (Hill 1987: 172-173). }\end{array}$ & Moctezuma \\
\hline $\begin{array}{l}30 \text { de abril } \\
\text { de } 1843\end{array}$ & $\begin{array}{l}\text { Batalla con el buque de guerra Austin y Wharton en Campeche. Mueren el comandante y } \\
\text { veinte tripulantes de la goleta de guerra Moctezuma. La flota mexicana se retira (Hill 1987: } \\
\text { 183-188). }\end{array}$ & Moctezuma \\
\hline $\begin{array}{l}16 \text { de } \\
\text { mayo de } \\
1843\end{array}$ & $\begin{array}{l}\text { Segundo enfrentamiento con el Austin y el Wharton. La flota mexicana es derrotada } \\
\text { (Jordania 2006: 263-261). }\end{array}$ & Moctezuma \\
\hline 1846 & Embargado por Inglaterra por la falta de pago (Scheina 1969: 262) & Moctezuma \\
\hline
\end{tabular}

* en amarillo se indica la fila donde se menciona a más de un barco. 


\section{E1 Transporte Armado Mexicano Moctezuma (1832)}

Mientras el bergantín Bravo estaba todavía en activo, una goleta con el nombre de Montezuma entró en escena. A principios de agosto de 1832, la goleta armada Montezuma, bajo el mando del capitán Pedro Villareal, detuvo y robó a la goleta estadounidense William A. Turner cerca de Matanzas, Cuba (British Traveler and Commercial and Law Gazette 1832: 2; Niles Weekly Register 1832: 82-83). Estaba armada con 3 cañones, uno de los cuales era un cañón pesado pivotante (Jones 1878: 39). Más tarde, en octubre, la goleta de guerra estadounidense Grampus capturó la Montezuma frente a Tampico en represalia por su acción contra la William A. Turner. Cuando fue capturado, la Montezuma estaba siendo utilizada como transporte de tropas y llevaba a bordo 40 soldados, además de una tripulación de 36 hombres. Fue juzgada en Nueva Orleans (Washington National Intelligencer 1832: 3; Jones 1878: 39-41).

El gobierno de los Estados Unidos supo no se trataba de una goleta militar mexicana oficial, sino que había sido equipada ilegalmente como buque armado por oficiales militares, incluido Santa Anna, como parte de un levantamiento contra el gobierno mexicano. México solicitó que el buque le fuera entregada a su cónsul. Esto fue denegado en octubre de 1832, alegando que no era un buque oficial del gobierno mexicano y que había cometido un acto de piratería (Livingston 1832; Montoya 1832). El 1 de octubre de 1832, el buque fue condenado por la Corte del Distrito de los Estados Unidos y vendido; pasó a llamarse Annette y fue registrado al mes siguiente en Nueva Orleans por unos nuevos propietarios, Alexander Baron y el capitán Henry L. Thompson, más tarde comodoro de la Marina de Texas. Según el registro, la Annette era una embarcación de $6137 / 95$ toneladas, 17.32 × 5.43 × 2.16 m (56.83 x 17.83 x 7.08 pies $)$ y tenía una sola cubierta, dos mástiles, una popa cuadrada y proa plana (Survey of Federal Archives1942: 9; Andreas von Mach, comunicación personal 2018).

Durante el mismo período, en 1833, el autor Juan de Dios Bonilla (1946: 118) menciona una goleta llamada Montezuma que, bajo el mando de Don Tomas Marín, transportaba tropas a Matamoros y luego a Nueva Orleans en noviembre. No está claro si esta embarcación es la goleta recientemente capturada de acuerdo con una información histórica inexacta en relación con las fechas del posterior transporte de tropas o si se trata de otro barco del mismo nombre utilizado para el mismo propósito tras la captura de la Montezuma. 


\section{La Nueva Amenaza Moctezuma/Montezuma, Alias Bravo/General Bravo (1834-1836)}

E1 3 de mayo de 1835, un barco referido tanto como Moctezuma y Montezuma se apoderó de la goleta de Nueva Orleans Marta en la bahía de Galveston y la llevó a Veracruz. El teniente primero John Calva del Montezuma fue acreditado con la captura (Washington Globe 1835: 2). Días después, en cartas del 7 y 18 de mayo, el comandante mexicano en Anáhuac, Antonio Tenoria, comentó la llegada del Moctezuma con tropas y dinero y mencionó que algunos de los pasajeros no tenían pasaportes (Tenoria 1835a; 1835b). Estos relatos de mayo de 1835 son una indicación temprana de la actividad de un nuevo buque con este nombre. El Moctezuma parece haber sido llamado alternativamente Montezuma, Bravo, General Bravo y posiblemente Segundo Bravo a lo largo de los años siguientes.

¿Es esta goleta Moctezuma el antiguo bergantín Bravo o una embarcación totalmente nueva? Se sabe menos de las actividades del bergantín Bravo durante estos años sin que la autora haya descubierto ninguna referencia al mismo después de 1836. En este momento, el bergantín Bravo y la goleta Moctezuma coexisten brevemente y figuran en el resumen naval oficial de los gastos durante los 12 años anteriores a 1836 (México Ministerio de Hacienda 1837). El autor Robert Scheina (1970: 47) menciona que la goleta Moctezuma ya era parte de la Marina cuando se adquirieron nuevos barcos en 1835. Esto se basa probablemente en una historia de 1857 en Veracruz (Lerdo de Tejada 1857: 417) que afirma que la Marina de Porter de 1829 casi había desaparecido en 1835, excepto la goleta Moctezuma y el bergantín Veracruzana. Scheina y Lerdo de Tejada solo pueden estar refiriéndose al bergantín Bravo y no a la goleta Moctezuma, ya que la goleta de este último nombre aparece por primera vez en 1834 y no parece que forme parte de la flota de la década de 1820. En este momento, el bergantín Bravo habría estado al servicio de México durante una década posteriormente a su uso en Inglaterra - podría haber sido licenciado en este momento y puesto fuera de servicio. Curiosamente, los informes mexicanos se refieren a la nueva goleta como Moctezuma, mientras que los informes estadounidenses y texanos a menudo, y posiblemente por error, llaman a esta embarcación Montezuma. En la siguiente argumentación se utilizará el nombre Moctezuma.

Un artículo de periódico de 1834 informa sobre la llegada de las goletas de guerra Moctezuma y Consolation (79 toneladas) y la goleta piloto Correo de Tampico de 111 toneladas, con la armada el 17 de abril. Consolation y Correo de Tampico llevaban tripulaciones de 11 y 8 hombres respectivamente (Procurador del Pueblo 1834; Andreas von Mach, comunicación personal 2018). Según la Memoria del Secretario de Estado y del Despacho de la Guerra publicado en México, en 1834, la Moctezuma estaba armada con una culebrina de 12 libras y dos cañones de 8 libras; llevaba 
a bordo cuatro oficiales y una tripulación de 33 hombres. Había sido armada recientemente en Nueva Orleans (Andreas von Mach, comunicación personal 2018).

A finales de 1835, la Moctezuma comenzó a navegar regularmente a lo largo de la costa desde el río Bravo (río Grande) hasta Galveston y dentro de la Bahía de Galveston, alarmando a los líderes revolucionarios. Texas todavía tenía que declarar su independencia (en marzo siguiente) así que México reconocía como acciones ilegales la innegable escalada de las hostilidades y los movimientos no disimulados, tanto para proporcionar voluntarios texanos como reclutar corsarios. La "nueva" goleta Moctezuma se convirtió en una amenaza inmediata para el comercio de Texas y Estados Unidos a lo largo de la costa de Texas, ya que intentó disuadir las actividades revolucionarias y evitar el envío de suministros de contrabando a Texas. La presencia de la Moctezuma, y en menor medida la del Veracruzano, fueron una influencia directa para la formación de la Marina de Texas de 1836.

En junio, la Moctezuma, bajo el mando del teniente Calvi, fue atacada por el guardacostas estadounidense Ingham, aunque hay un debate sobre qué embarcación efectuó el primer disparo. El guardacostas estaba estacionado en Texas con el fin de monitorear las amenazas que se percibían por parte de México contra la navegación estadounidense, agravadas por la captura de la Martha a principios de marzo por parte de la Moctezuma. La "goleta construida como clíper" Moctezuma fue vista frente a Brazos Santiago el 14 de junio y, según relatos estadounidenses, rápidamente se acercó al Ingham y abrió fuego. Este disparo también fue interpretado como una "señal" por el guardacostas. La Moctezuma se retiró, arrojando por la borda objetos pesados para aligerar su carga y cruzar la barra. Los dos barcos continuaron el intercambio de disparos hasta que Calvi encalló inadvertidamente en la barra. El Capitán Jones del Ingham decidió no hundir la dañada Moctezuma mientras estaba encallada (Wells 1998: 469-472). El resumen de un periódico sobre este enfrentamiento decía que la Moctezuma montaba cuatro cañones y una tripulación de 24 hombres (London St. James Chronicle y General Evening Post 1835: 4).

En octubre, la ahora recuperada goleta mexicana, disparó un tiro contra la ciudad y el fuerte de Velasco (McKinney y Williams 1835a) y en noviembre persiguió, encalló y capturó en el paso del Cavallo a la goleta estadounidense Hannah Elizabeth con un cargamento de armas de contrabando (Fannin 1835; Fisher 1835). La Moctezuma provocó entonces de forma indirecta que el corsario texano San Felipe encallara en la península de Matagorda antes de aproximarse y abrir fuego sobre ella (Fleury 1874; Wilson 1874).

Las conversaciones para crear formalmente una Marina con el fin contrarrestar esta actividad comenzaron de forma inmediata. El 9 de noviembre, se informó que Thomas McKinney estaba 
equipando un barco para perseguir a la Moctezuma (McKinney 1835a). Días después, se solicitaron comisiones (para corsarios) para proteger la costa de la Moctezuma y el Vera Cruzana (General Council 1835: 8). El 8 de enero, McKinney ofreció la Invincible para servir en la nueva Marina y además el gobernador fue autorizado a dar a McKinney una carta de nombramiento como comandante de la goleta como "un buque de guerra nacional" (Barrett 1836). El 9 de enero, se solicitaron voluntarios, probablemente para tripular el buque, con el fin de perseguir a la Moctezuma y el día 11 se anunció oficialmente la compra del buque de guerra (McMullen 1836; Telegraph and Register 1836: 2). Siguieron otras adquisiciones para la Marina en enero, incluyendo el Brutus, el antiguo guardacostas Ingham, rebautizado Independence, y el ex corsario William Robbins - recientemente rebautizado como Liberty (Powers 2006: 52-53). El capitán y la tripulación de la Invincible sentían que su misión era capturar a la esquiva Moctezuma y buscaron en vano avistarla.

En abril, las fuentes históricas muestran que la Moctezuma/Montezuma pasó a llamarse Bravo y estaba bajo el mando del capitán Fernando Davis. Iba en convoy con la recientemente adquirida goleta de guerra de dos cañones Correo Secundo (comandada por el infame Capitán Thomas M. Thompson) que estaba preparándose para transportar tropas y suministros a Copano, en preparación de un avance militar mexicano contra los revolucionarios tejanos. Las Bravo y Correo Secundo estaban en Brazos Santiago, el puerto oceánico de la ciudad fluvial de Matamoros, situado a $88.5 \mathrm{~km}$ (55 millas) de la desembocadura del río Bravo (río Grande). Este río desembocaba en el Golfo de México en una ubicación aproximadamente 12.9 km (8 millas) al suroeste del paso Brazos Santiago. Antes de la navegación regular a vapor, las mercancías destinadas a Matamoros se enviaban al puerto de Brazos Santiago y luego se transportaban por tierra a través de dos caminos de playa accesibles durante la marea baja. Gabarras transportaban pasajeros y carga a tierra firme durante la marea alta e inundaciones (Powers 2006: 77-78). Es en este momento de la historia en que la Invincible se encuentra con la Bravo después de tres meses de búsqueda. Lo que sucede a continuación todavía se sigue debatiendo.

Los hechos básicos e indiscutibles de este caso son los siguientes: la Bravo estaba desatendida (la Correo estaba probablemente anclada en el puerto) y reparando su timón que había sido dañado en la barra. El capitán Thompson del Correo está ayudando a cambiar el timón. La Invincible, con bandera americana, se acerca al buque y lo reconoce como su némesis Moctezuma/Bravo. El oficial Living convence al capitán Jeremiah Brown, en contra su buen juicio, para que le permita ir a la Bravo disfrazado de oficial de guardacostas estadounidense para obtener información sobre las actividades mexicanas. Living es llevado a la Bravo en el bote del barco y es retenido a bordo mientras la Bravo envía su lancha, con el capitán Thompson, a la Invincible para confirmar los 
papeles de Living. El capitán Brown reconoce a Thompson y abre fuego sobre la lancha y después sobre la Bravo, una vez la Marina mexicana ha desembarcado a Living. La Bravo intenta retirarse, pero sin un timón operativo encalla todavía más en la barra y es atacada por la Invincible (figura 9). Durante el combate, la Invincible nota como se aproxima el bergantín Pocket y sale en su persecución - el Pocket es capturado y llevado a Galveston por la Invincible.

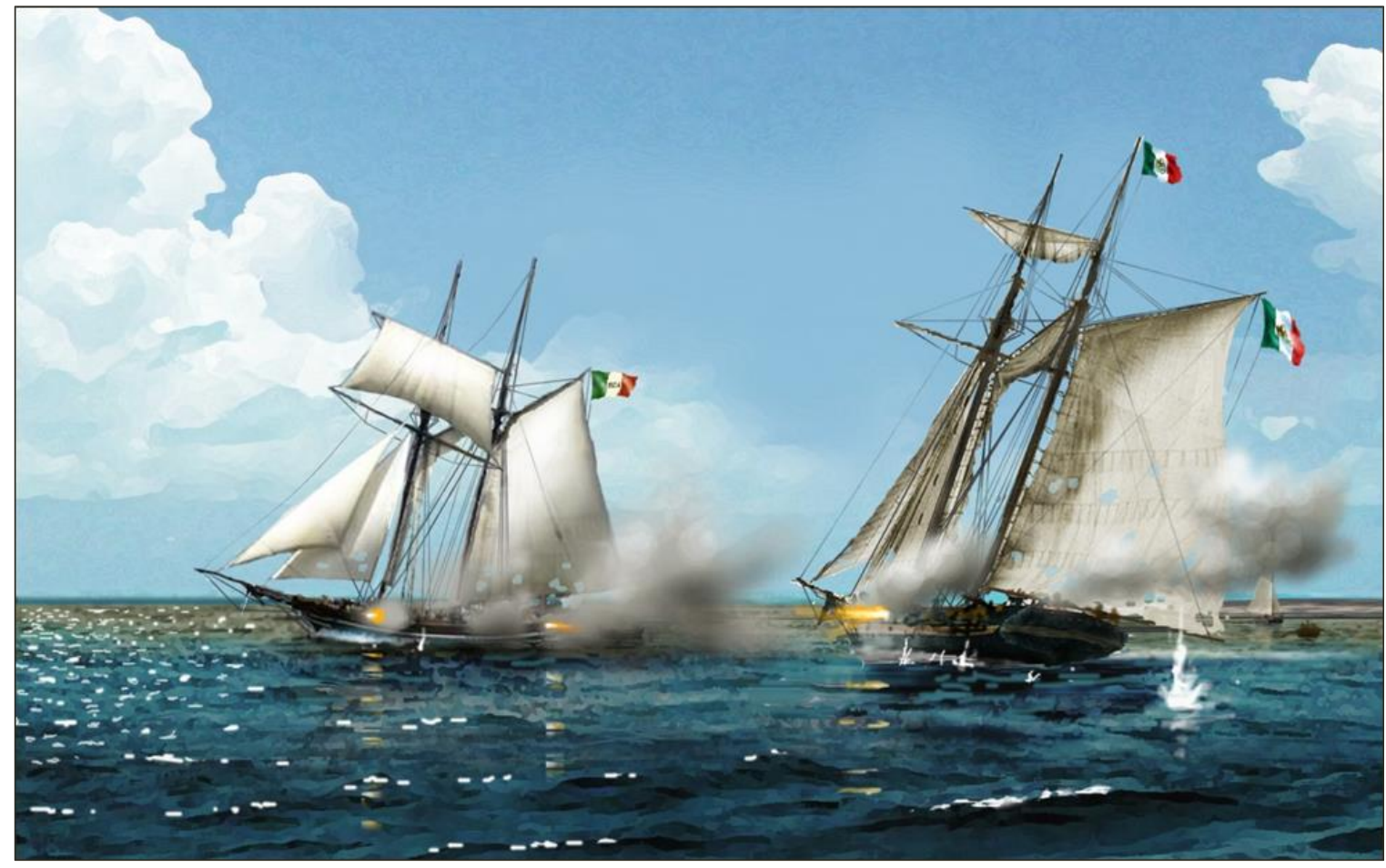

Figura 9. Combate frente a Brazos Santiago, 3 de abril de 1836; La Invincible contra la Bravo por Peter Rindlisbacher (2017).

El principal relato mexicano de esta operación ofrece una perspectiva ligeramente diferente sobre la partida de la Invincible de la batalla - es descrita como una retirada en contraposición a un cambio de las prioridades militares de la Invincible (la versión texana de los acontecimientos), es decir, la captura de un bergantín desconocido a tres a cuatro millas de distancia en vez del hundimiento definitivo de la Bravo. El capitán Davis de la Bravo, en su informe a José María Espino, el capitán del puerto de Matamoros, reconoció que la Bravo era vulnerable cuando estaba encallada en la barra, pero describió a la Invincible retirándose debido a los refuerzos que se aproximaban en la forma del barco armado Correo y a la ajustada posición de la artillería terrestre (Espino 1836). Quizás Jeremiah Brown pensó que la Invincible, ligeramente dañada, era más capaz de capturar a un bergantín desarmado en lugar de prolongar un enfrentamiento armado contra la Correo, la Bravo y su cañón de pivote y la artillería costera. 
Dos hechos importantes de este suceso son muy debatidos: dónde ocurrió este enfrentamiento y si la Bravo se hundió. Testigos discrepantes y relatos indirectos de la "batalla" se presentan en la Tabla 2, ordenados cronológicamente según el informe histórico. La mayoría de las veces, los relatos tempranos sitúan el enfrentamiento naval en Brazos Santiago mientras los autores posteriores al siglo XIX lo sitúan en la desembocadura del río Bravo (río Grande). Esto puede ser, en parte, debido a la interpretación equivocada de la geografía de Texas y quizás al no reconocer que el puerto oceánico de Matamoros no estaba situado en este momento en la desembocadura del río sino a 8 millas más al noreste en el puerto y paso de Brazos Santiago. Algunos informes mencionan a la artillería disparando sobre la Invincible y esto, en sí mismo, sitúa 


\section{Tabla 2. Relatos del hundimiento de la Bravo.}

Volumen $5(2018 / 2019)$

\begin{tabular}{llll}
\hline Fuente & Resumen del relato & Ubicación* $^{*}$ & Desenlace \\
\hline William Gray, 1836 & De acuerdo con el relato de su diario del 7 de abril de 1836, William Gray estaba a bordo la goleta de & BS & Inutilizada \\
(1909: 154-155) & guerra Brutus cuando la Invincible se le aproximó regresando de Brazos Santiago con la presa del & \\
& Pocket. A Gray le dijeron que cuando la Invincible se encontró con la Montezuma, "ahora llamada \\
& Bravo," tanto Davis como Thompson estaban a bordo. La Bravo encalló y fue "inutilizada" y no pudo ser \\
& abordada debido a las aguas poco profundas y la presencia de 1,000 tropas mexicanas en la playa. El \\
& relato menciona que el teniente Living se quedó a bordo de la Bravo, pero la tripulación de la lancha que \\
& esperaba partió cuando comenzó el enfrentamiento. Esto ocurrió el 3 de abril que era Pascua. &
\end{tabular}

Walter Zimmerman, Walter Zimmerman, quien había formado parte de la expedición del general Mexia a Tampico, se alistó - - Hundida

1836 como tripulante en la Invincible. Describió la Montezuma como superior en hombres y armas. Según

Zimmerman, después de un combate de 2 horas el "El enemigo se hundió con su costado de babor completamente destrozado". Persiguió a un bergantín mercante [Pocket] después de que la Montezuma se hundiera, creyendo que era un buque armado de 18 cañones. Hay problemas con esta fuente ya que la Invincible tenía más tripulación y casi el doble de cañones.

Relato periodístico Este relato menciona que la Invincible se acercó al bergantín mexicano [Bravo] y realizó una consulta, BS BS retirada

de 1836 (reimpreso luego envió un bote para reunirse. La Invincible intercambió disparos con el buque mexicano [Bravo]

en Dienst 1909b: "que efectuó varios disparos" - la goleta con la bandera mexicana cayó a sotavento hacia la costa y "el

253) otro barco [Invincible] orzó y fue a por el bergantín [Pockef], que estaba a unas tres o cuatro millas de distancia."

Covington Western "La goleta armada de Texas, Invincible, del capitán Brown, se encontró con la goleta mexicana

Constelación (1836: Montezuma, anclada frente a Brasos [sic] de Santiago. Inmediatamente se produjo un enfrentamiento,

2) acción que duró varias horas, y que terminó en el hundimiento de la Montezuma, antes de que pudiera alcanzar la costa adonde huía. La última vez que se la vio, sus mástiles estaban bajo el agua. La goleta se estaba preparando para transportar unos dos mil hombres a la Bahía de Galveston; la expedición está ahora destruida. La Invincible sufrió algunos daños en sus velas y aparejos, pero no tuvo ningún un hombre herido. El destino de la tripulación de la Montezuma es desconocido."

\begin{tabular}{|c|c|c|c|}
\hline $\begin{array}{l}\text { London Morning } \\
\text { Post (1836: 5) }\end{array}$ & $\begin{array}{l}\text { "Se informa que tuvo lugar un enfrentamiento naval entre la goleta mexicana Montezuma, y la goleta } \\
\text { texana Invincible, frente a Brasos [sic] de Santiago, que terminó con el hundimiento de la primera, } \\
\text { después de una lucha de varias horas". }\end{array}$ & BS & Hundida \\
\hline $\begin{array}{l}\text { José María Espino, } \\
1836\end{array}$ & $\begin{array}{l}\text { El capitán del puerto de Matamoros (Espino) transmite la información remitida por el capitán Fernando } \\
\text { Davis de la Bravo. Mientras estaban reparando el timón de la Bravo, un barco estadounidense se acercó } \\
\text { y un oficial del barco estadounidense subió a bordo de la Bravo queriendo hablar con el puerto. Él } \\
\text { describe el barco [Invincible] disparando sobre Thompson en la lancha y también a la Bravo. Levine [sic] } \\
\text { fue tomado prisionero una vez que fueron atacados [por la Invincible]. Bravo solo sufrió un disparo a } \\
\text { popa y daños en el aparejo. La batalla, que duró más de una hora, se interrumpió cuando el otro barco } \\
\text { partió en persecución de otro bergantín. La carta insinúa que tanto el acercamiento de la Correo y la } \\
\text { potencia de fuego desde la playa alentó la retirada de la nave de guerra [Invincible]. }\end{array}$ & BS & $\begin{array}{l}\text { A flote y } \\
\text { encallada en } \\
\text { el lado norte } \\
\text { de la barra - sólo } \\
\text { recibió un disparo } \\
\text { en la popa }\end{array}$ \\
\hline $\begin{array}{l}\text { Edward Hall (Powers } \\
\text { 2006: 80) }\end{array}$ & $\begin{array}{l}\text { Ed Hall fue informado por un testigo ocular de que "la Montezuma está en la barra y está tan dañada } \\
\text { como para ser abandonada: sus armas llevadas a tierra y montadas en otras embarcaciones." }\end{array}$ & - & Abandonada \\
\hline $\begin{array}{l}\text { General Filosola, } \\
1836(1849: 242, \\
290-292)\end{array}$ & $\begin{array}{l}\text { El } 5 \text { de abril se informó que la Segundo Bravo y la Segundo Correo están completamente listas para } \\
\text { dejar Brazos Santiago }\end{array}$ & BS & \\
\hline $\begin{array}{l}\text { Morning Chronicle } \\
\text { (1836a: 4) }\end{array}$ & $\begin{array}{l}\text { "La goleta armada de Texas, Invincible, se enfrentó a la goleta mexicana Montezuma, frente a Brasos } \\
\text { Santigo [sic]; la acción terminó con el hundimiento de la Montezuma ". }\end{array}$ & BS & \\
\hline
\end{tabular}

(1836a: 4) Santigo [sic]; la acción terminó con el hundimiento de la Montezuma ". 


\begin{tabular}{|c|c|c|c|}
\hline $\begin{array}{l}\text { David Conrad, } \\
1836 \text { (Powers } \\
\text { 2006: 80) }\end{array}$ & La Bravo, después de encallar se hizo pedazos en los rompientes. & - & $\begin{array}{l}\text { Destrozada; } \\
\text { Hundida }\end{array}$ \\
\hline $\begin{array}{l}\text { Rueben Potter, } \\
1836 \text { (Powers } \\
2006: 80 \text { ) }\end{array}$ & "La Bravo se hundió más rápidamente de lo que se esperaba por un simple golpe." & - & Hundida \\
\hline $\begin{array}{l}\text { Hayes (1974 } \\
\text { [1879]: 146) }\end{array}$ & $\begin{array}{l}\text { La Invincible se encontró con la Montezuma mientras navegaba frente a Brazos Santiago y después de } \\
\text { un enfrentamiento de dos horas, Montezuma "quedo varada y abandonada a punto de hundirse." Hayes } \\
\text { identifica incorrectamente a Thompson como capitán de la Montezuma y que la Invincible regresó a } \\
\text { Galveston para ser reparada después del enfrentamiento y antes de capturar al Pocket - ambos } \\
\text { comentarios no coinciden con otros relatos. }\end{array}$ & BS & Hundiéndose \\
\hline $\begin{array}{l}\text { Bancroft (1889: } \\
272)\end{array}$ & $\begin{array}{l}\text { La Invincible inutilizó a la Bravo y la forzó a encallar. La Invincible solo sufrió daños en el aparejo que fue } \\
\text { reparado. La Invincible salió en persecución del Pocket. }\end{array}$ & - & Dañada \\
\hline $\begin{array}{l}\text { Dienst (1909b: 252- } \\
\text { 253) }\end{array}$ & $\begin{array}{l}\text { La Bravo pierde el timón cruzando la barra en la desembocadura del río Bravo (río Grande). Encalló cerca } \\
\text { de la playa norte y naufragó por una andanada de la Invincible. El relato de Dienst contradice el uso que } \\
\text { hace de una cita directa de un artículo de periódico en el que dice que este enfrentamiento ocurrió en } \\
\text { Brazos Santiago. }\end{array}$ & RG & Naufragada \\
\hline $\begin{array}{l}\text { Fischer (1976: } \\
\text { 133-134) }\end{array}$ & $\begin{array}{l}\text { El relato menciona que la Bravo perdió su timón al cruzar la barra y que Leving [sic] subió a bordo. La } \\
\text { embarcación encalló al no poder maniobrar. Menciona un breve enfrentamiento y que la Bravo fue puesta } \\
\text { fuera de combate por una andanada. Leving y la tripulación desembarcaron. El combate fue interrumpido } \\
\text { por la llegada del Pocket. }\end{array}$ & RG & Fuera de combate \\
\hline Pierce (1917: 22) & $\begin{array}{l}\text { La Invincible llega al puerto de Brazos Santiago y se encuentra con la General Bravo y la Correo de } \\
\text { México con provisiones para las tropas mexicanas cerca de Copano. Livine [sic] es enviado a bordo de la } \\
\text { General Bravo buscando poder ir a tierra para hablar con el Cónsul americano de Matamoros. La } \\
\text { Invincible abrió fuego contra la Bravo cuando la lancha de la Bravo se acercó sin Levine [sic] presente. La } \\
\text { Bravo devolvió el fuego, la Correo se hizo a la vela para atacar a la Invincible, y la artillería mexicana de la } \\
\text { costa abrió fuego contra la Invincible. La Invincible se retiró hacia la barra o paso. }\end{array}$ & BS & Encallada \\
\hline Hill (1987: 51-52) & $\begin{array}{l}\text { La Bravo estaba en convoy en la desembocadura del río Bravo (río Grande) con la Correo Segundo. } \\
\text { Perdió el timón y fue atacada por la Invincible. Después de una hora de combate, el bergantín Pocket es } \\
\text { avistado y la Invincible sale en su persecución. Thomas Thompson estaba a bordo de la Bravo ayudando } \\
\text { a cambiar el timón. El teniente Leving [sic] subió a bordo de la Bravo y Thompson fue enviado en un bote } \\
\text { a la Invincible para hacer las gestiones para que Leving [sic] bajara a tierra. El capitán Brown de la } \\
\text { Invincible reconoció a Thompson y lo dejó subir a bordo y lo encerró debajo de cubierta (esto no se } \\
\text { corresponde con los otros relatos) y disparó una andanada. Sin daños en la Bravo excepto una bala de } \\
\text { cañón en la popa y dos daños menores en el aparejo. La batalla terminó cuando la Invincible salió en } \\
\text { persecución del Pocket. El relato de Hill parafrasea el informe de Espino hasta cierto punto, pero cambia } \\
\text { los detalles (ver arriba). }\end{array}$ & RG & Apenas dañada \\
\hline $\begin{array}{l}\text { Powers (2006: 78- } \\
\text { 81) }\end{array}$ & $\begin{array}{l}\text { La Invincible, portando colores estadounidenses, reconoció y se acercó a la Bravo. Estaba mandada por } \\
\text { Fernando Ricardo Davis, un estadounidense que comenzó como guardiamarina en la Marina de México } \\
\text { en 1823. Living fue llevado a bordo de la Bravo vestido con un el uniforme de guardacostas. Thompson } \\
\text { a bordo de la Bravo creía que el barco desconocido era la Invincible. El capitán Davis envió a Thompson } \\
\text { en un bote del puerto aparejado como una balandra a la Invincible para verificar la historia de Living. } \\
\text { Reconoció al capitán Brown y cambio el rumbo y Brown abrió fuego sobre la Bravo. El bote de la } \\
\text { Invincible fue soltado (aunque Living fue llevado a tierra) y llegado a este punto, la Invencible, disparó } \\
\text { contra la Bravo que intentaba de hacerse a la vela sin timón. La Bravo "se clavó en la barra, donde unos } \\
\text { pocos disparos de la Invincible la llenaron de agua ". La Bravo devolvió algunos tiros y fue abandonada. }\end{array}$ & BS & Abandonada \\
\hline
\end{tabular}


VOLUMEN 5 (2018/2019)

Jordan (2006: 52- La General Bravo y la Segundo Correo Mexicano montaron guardia en la desembocadura del río Bravo RG

Encallada

53) (río Grande) al tener noticias de la inminente invasión mexicana que iba a partir desde Matamoros.

Debían encontrarse con el John M. Brandel, New Castle y Pocket con sus respectivos suministros para

ir en convoy a la Bahía de Matagorda. La Invincible avistó a la Bravo y la Correo frente a Brazos

Santiago, en la desembocadura del río Bravo (río Grande), y reconoció a la Bravo por tener el timón

dañado. Finalmente tiene lugar un cañoneo de poco más de una hora, la Bravo encalla en la

desembocadura del río. La Invencible captura al Pocket.

${ }^{\text {* BS }}$ = Brazos Santiago; RG = desembocadura del río Bravo (río Grande) 
decididamente el suceso en Brazos Santiago cerca de la guarnición mexicana. Living también fue juzgado como espía y ejecutado en Brazos Santiago, y no en Matamoros (Pierce 1917: 22; Powers 2006: 78-81), lo que otorga credibilidad adicional a esta ubicación como el lugar de la batalla. Finalmente, Brown, el capitán de la Invincible, afirma explícitamente que el Pocket fue capturado en Brazos Santiago, lo que no debería dejar lugar a la duda (Brown 1836).

Si se hundió o no realmente la Bravo es más difícil de dilucidar. Relatos de testigos estadounidenses y texanos y los periódicos describen típicamente a la Invincible como la ganadora de este enfrentamiento y la Bravo "hundiéndose," "destrozada por una andanada" y "hecha pedazos" (Tabla 2). Algunos reportajes periodísticos no describen el resultado - solo que la Bravo encalló. No por casualidad, un relato mexicano afirma que la Bravo resultó en gran parte ilesa y que solo recibió un disparo de cañón en la popa (cubierta de popa) y daños menores en el aparejo (Espino 1836; Hill 1987: 51-52). El capitán intentó sacar el barco de la barra, pero un curioso comentario en la carta sugiere que la Bravo podría tener una vía de agua (Espino 1836). El misterio solo se hace mayor cuando un barco a vela llamado Bravo continúa sirviendo de forma activa en la Marina mexicana hasta 1838 - más de un año después de su "hundimiento". La autora revisó el cuaderno de bitácora de un barco llamado Bravo en la colección del Briscoe Center for American History en Austin, Texas (Añorga 1835), pero desafortunadamente, la última entrada está fechada en diciembre de 1835, muchos meses antes de los eventos ocurridos en la costa de Texas.

\section{E1 Rompecabezas De La Bravo Y La Segundo Bravo (1836-1838)}

A pesar de la confianza texana en la pérdida de la Bravo a causa de los disparos de la Invincible, la Bravo aparece más tarde, en 1836-1838, ahora bajo el mando del capitán Thompson, anteriormente de la Correo Mexicano/Segundo Correo. La autora agradece a su colega John Powers (2006) por ser el primer autor que ha encontrado durante la investigación que cuestiona la veracidad de las diferentes versiones de la batalla y reconoce la disparidad entre las versiones del naufragio y la supervivencia de la Bravo después de abril de 1836. Su trabajo fue repasado durante la preparación del presente estudio. A menos que se descubra(n) una(s) carta(s) extremadamente informativa(s), este misterio puede que nunca sea resuelto de manera satisfactoria. Aunque parece que la evidencia pesa más sobre la pérdida irreparable de la Bravo, también hay evidencia que sugiere que, de hecho, no se hundió.

Después del "hundimiento" de la Bravo el 2 de abril, se informó más tarde, el 17 de mayo, que la "Segundo Bravo" y "Segundo Correo" estaban en Brazos Santiago para recoger suministros para el ejército en la Bahía de Copano (Filosola 1849: 290-291). Hubo otras comunicaciones anteriores 
de Filosola del 5 de abril y el 16 de mayo en relación a ambos buques. Powers (2006: n. 37, 247248) sugirió que el nombre Segundo Bravo podría indicar el reemplazo del buque de guerra como explicación ante la disparidad entre estos informes, el problemático desarrollo temporal del enfrentamiento de la Invincible y la referencia al buque de guerra mexicano como "segundo" Bravo.

Una explicación alternativa para el nombre "Segundo", sin embargo, puede ser simplemente que la goleta de 1835 Moctezuma se convirtió en la "segundo" Bravo cuando se le cambió el nombre más tarde ese mismo año, ya que el bergantín Bravo ya era un reconocido buque naval comisionado. El uso de "Segundo" no implica necesariamente una goleta de guerra sustituta del mismo nombre - que técnicamente habría sido el tercero y no el segundo buque de nombre Bravo que servía al gobierno mexicano. Podría haber sido una manera conveniente para diferenciar entre la goleta y el bergantín anterior.

En su informe a Fernando Fernández, comandante del Departamento de Nuevo León y Tamaulipas, el comandante de Matamoros, José María Espino, transmite el relato del enfrentamiento naval. Esta información había sido proporcionada por el capitán Fernando Davis de la Bravo. Dos pasajes clave aluden al estado de la embarcación: (a) la declaración de que la Bravo fue apenas dañada, habiendo recibido un solo disparo a popa con dos tripulantes heridos por una polea rota y (b) que la Bravo estaba encallada en el lado norte de la barra esperando un viento más fuerte; ellos estaban trabajando para salvar el barco, aunque tenía una vía de agua (Espino 1836). El informe del testigo ocular a Edward Hall (Powers 2006: 80) indicando que las armas fueron desmontadas de la Bravo, no significa necesariamente que estaban siendo rescatadas del presunto naufragio y montadas en otros buques. Esta acción era la medida típica tomada para aligerar una embarcación encallada para que pueda ser reflotada retirando los objetos pesados tales como armas, carga y lastre. El cañón pudo haber sido reubicado temporalmente con la intención de reponerlo en la Bravo más tarde. El informe de Espino (1836) que muestra que la Bravo tenía un cañón de pivote y cañones en las bandas es consistente con el armamento descrito en el buque Bravo posterior y todavía en activo en julio de 1836.

Curiosamente, el historiador Alex Dienst (1909a: 139) en sus primeros trabajos sobre la Marina de Texas hace referencia al relato de un periódico anónimo de julio de 1836 en Nueva Orleans que afirma que la Bravo se hundió en su camino desde Matamoros a Veracruz con la pérdida de toda la tripulación con la excepción de Thompson y dos marines. El examen del New Orleans Bee de julio no pudo localizar tal artículo, pero un relato similar del New York Courier and Enquirer (reimpreso en el September London Shipping Gazette 1836: 1) describe exactamente el mismo 
evento, exceptuando que esta desgracia le sucedió a la Correo Secundo. Este último relato es quizás más convincente y creíble considerando que Thompson en este momento era el comandante de la Correo Secundo (Segundo) y no de la Bravo.

Es tentador considerar si Thompson, a su regreso a Veracruz sin un barco a su mando, fue nombrado capitán de la reflotada Bravo; sin embargo, la otra opción sería que le fue dado el mando de un buque totalmente diferente rebautizado como Bravo. Cartas en los archivos mexicanos de julio de 1836 describen a Thompson como comandante de la goleta Bravo (Figura 10a) y también incluyen el sumario de las armas y tripulación como parte de una discusión más amplia de asuntos navales (Figura 10b,10c) que incorpora una lista de la tripulación y armamento de todos los buques de la Marina actual. La Bravo, tal y como se describe en un documento fechado el 20 de julio, estaba armada con un cañón pivote de 16 libras y cuatro carronadas de 9 libras. El de 16 libras no es un "calibre" de cañón común y puede ser un error del autor del documento original. La Bravo, la Hidalgo y otras dos cañoneras fueron descritas equipadas con cañones de 16 libras. Una copia del mismo documento también describe el cañón de pivote de la Bravo como de 16 libras. La Bravo tenía una tripulación de 60 hombres, incluidos 10 soldados y un sargento de guarnición (Reibaud 1836; Secretaria de Guerra y Marina 1836). ¿Es este un buque totalmente diferente al Bravo descrito anteriormente de cuatro cañones y una tripulación de 50 hombres (London St. James Chronicle y General Evening Post 1835: 4), con el cañón de pivote adicional mencionada por el capitán Fernando (Espino 1836)? Es difícil decirlo, especialmente con las identificaciones erróneas y los errores que se producen en las fuentes históricas.

En agosto de 1836, la Bravo y el bergantín Fama (también llamado General Urrea) se preparaban para para una navegación desde Veracruz (BMP 1836: 2). Más tarde, en febrero de 1837, el capitán Thompson llevó al General Sayas a Sisal en la Bravo para reemplazar al General Toro como comandante general del Yucatán (BMP 1837a: 2). La Bravo también estuvo involucrada en lo que se consideró un incidente escandaloso en Brazos Santiago, en abril de 1837, que dio lugar a un intercambio de disparos de cañón entre buques de los EE. UU. y la Marina mexicana. Los mercantes Champion y Louisiana de los Estados Unidos habían sido detenidos en Brazos Santiago y la Marina de los Estados Unidos intervino para asegurar su liberación. El USS Natchez llegó a Brazos Santiago y partió en convoy con el Louisiana.

Al regresar a por el Champion, Natchez se encontró con la flota mexicana compuesta por el General Urrea, la General Teran, y la Bravo. Sin mediar provocación, Natchez capturó el General Urrea el 16 de abril y tanto la Bravo como la artillería del puerto abrieron fuego sobre él, pero ambos estaban a una distancia demasiado lejana como para tener algún efecto. Sin embargo, un 
disparo cayó accidentalmente sobre el buque mercante estadounidense Climax. Esto fue visto por México como una acción hostil de los Estados Unidos. El comodoro Dallas de la Marina de los Estados Unidos viajó a Veracruz con una flota de cinco buques, incluida la USS Constellation, para entregar una disculpa formal al gobierno mexicano (Pierce 1917: 23-24; Hill 1987: 70-71). E1 General Urrea fue devuelto a México. La goleta de guerra "General Bravo" además se menciona como parte de una flotilla que incluye el Fama y el Vencedor del Álamo que llegaron a Campeche a finales de agosto de 1838 (Bonilla 1946: 118).

Durante la guerra de los Pasteles entre México y Francia en 1838-1839, la Marina francesa capturó a toda la flota atlántica de la Marina mexicana en Veracruz el 28 de noviembre de 1838, incluida la corbeta Iguala; los bergantines Irtubide, Libertador y Urrea; y las goletas Terán y Bravo, antes de que las fuerzas francesas regresaran a Francia en marzo de 1839 (Penot 1976: 451; Meed 2001: 109; Jordan 2006: 116). Se cree que todos estos buques eran adquisiciones bastante nuevas,

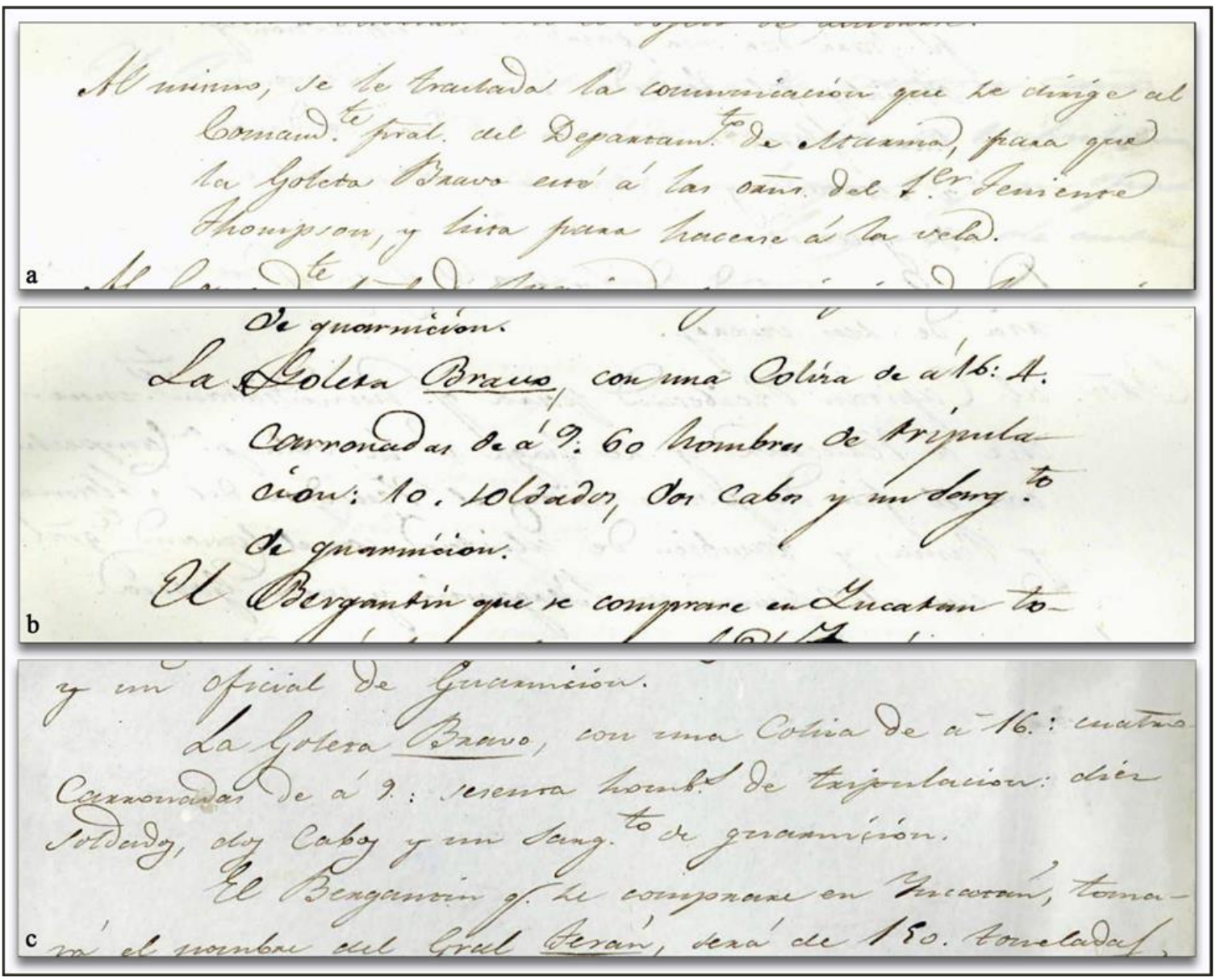

Figura 10. Documentos militares mexicanos que se refieren a la Bravo tras su pérdida en Brazos Santiago en abril de 1836: (a) mencionando a Thompson como comandante de la Bravo y a quien se le pide que prepare la Bravo para navegar; (b) descripción de la Bravo; y C) copia de la descripción de la Bravo. (Secretaria de Guerra y Marina 1836; Reibaud 1836). 
construidas en Baltimore (Jordan 2006: 116; Williams 2010) aunque la fuente original de esta información no está referenciada.

La documentación sugiere que los bergantines Iturbide, Libertador, Urrea y la goleta Bravo fueron devueltos a México en diciembre de 1838, aunque parece que Texas tenía la intención de adquirir estas presas capturadas, como lo demuestra una nueva ley aprobada por el Congreso de Texas en 1838 que autorizaba esta compra (Wells 1988: 4-5; Demerliac 2007: 191). Además, la Memoria del Secretario de Estado y el Despacho de la Guerra de 1839 registra que el Iturbide había sido vendido por los franceses, la Teran y el Urrea habían sido desechados, la Iguala todavía era propiedad de Francia, y la Bravo estaba en Tampico (Andreas von Mach, comunicación personal 2018). Algunos de estas fuentes históricas no concuerdan, por lo que el destino la Bravo después de la conclusión de la guerra de los Pasteles es incierto.

\section{El Montezuma Final (1842-1843)}

En última instancia en 1842, los diferentes barcos de vela Moctezuma, Montezuma, Bravo, General Bravo y Segundo Bravo parece que ya no están en activo. La Marina mexicana adquirió un nuevo buque de guerra de última generación, el barco de vapor Montezuma de 204 pies construido por Greens and Wigrams en Inglaterra y armado con un cañón de proyectiles de 68 libras, dos cañones largos de 32 libras, cuatro carronadas de 32 libras y un cañón pequeño de 9 libras. Estaba equipado con dos motores de 140 caballos de potencia y tenía un desplazamiento de 1,111 toneladas (Hill 1987: 172-173). Participó en la batalla de Campeche en 1843, pero en última instancia México no pudo hacer frente al pago del buque y fue embargado en 1846.

En resumen, cuatro buques armados con los nombres de Moctezuma, Montezuma, Bravo, General Bravo y/o Segundo Bravo estuvieron operando en las costas de Texas y México entre 1825 y 1846 - esta cantidad se amplía a cinco si se cree que la goleta Moctezuma de 1835 verdaderamente se hundió en Brazos Santiago en abril de 1836. Se enumeran en la Tabla 3 para simplificar. 
Tabla 3. Buques armados llamados Bravo, Moctezuma o Montezuma operativos en México a principios del siglo XIX.

\begin{tabular}{|c|c|c|c|c|}
\hline Numero & Nombre(s) & $\begin{array}{l}\text { Tipo de } \\
\text { buque }\end{array}$ & $\begin{array}{l}\text { Periodo } \\
\text { de uso }\end{array}$ & Armamento \\
\hline 1 & AeriallBravo & $\begin{array}{l}\text { El } \\
\text { yate/bergantín }\end{array}$ & $\begin{array}{l}1825- \\
\text { ca. } \\
1835\end{array}$ & $\begin{array}{l}14 \text { carronadas de } 24 \text { libras; } 18 \text { cañones; } 0 \\
20 \text { carronadas }\end{array}$ \\
\hline 2 & Montezuma * & $\begin{array}{l}\text { Goleta, el } \\
\text { buque } \\
\text { corsario }\end{array}$ & $\begin{array}{l}?- \\
1832\end{array}$ & Un cañón de pivote y otros dos cañones \\
\hline 3 & $\begin{array}{l}\text { Moctezuma, Montezuma, } \\
\text { Bravo, General Bravo, } \\
\text { (¿Segundo Bravo?) }\end{array}$ & $\begin{array}{l}\text { La goleta de } \\
\text { guerra }\end{array}$ & $\begin{array}{l}1834- \\
1836 ?\end{array}$ & 1 cañón pivote y 4 cañones \\
\hline 4 & $\begin{array}{l}\text { Bravo, (¿Segundo Bravo?) } \\
\text { ** }\end{array}$ & $\begin{array}{l}\text { La goleta de } \\
\text { guerra }\end{array}$ & $\begin{array}{l}1836 ?- \\
1838\end{array}$ & $\begin{array}{l}\text { Cañón de pivote de } 16 \text { libras y } 4 \\
\text { carronadas de } 9 \text { libras. }\end{array}$ \\
\hline 5 & Montezuma & $\begin{array}{l}\text { El barco de } \\
\text { guerra a } \\
\text { vapor }\end{array}$ & $\begin{array}{l}1842- \\
1846\end{array}$ & $\begin{array}{l}\text { Cañón de proyectiles de } 68 \text { libras, } 2 \text { largos } \\
\text { de } 32 \text { libras, } 4 \text { carronadas de } 32 \text { libras, un } \\
\text { cañón pequeño de } 9 \text { libras. }\end{array}$ \\
\hline
\end{tabular}

* formalmente no formaba parte de la Marina mexicana, pero se utilizó durante un golpe de estado.

** un barco diferente si el registro no. 3 verdaderamente se hundió en abril de 1836.

\section{OTROS PECIOS DEL VALLE BAJO DEL RÍO BRAVO (RÍO GRANDE)}

Se ha dedicado un tiempo considerable en un intento de desentrañar el misterio detrás de la Bravo y su pérdida con la finalidad de investigar su posible candidatura como naufragio para el pecio 41CF184. Otros buques se hundieron en las proximidades del yacimiento arqueológico y estos naufragios pueden ser la clave para saber el papel del pecio Boca Chica No. 2. en la historia de Texas. No se sabe mucho acerca de la mayoría de estos naufragios por lo que la siguiente exposición sirve simplemente como una mera introducción a este prometedor rompecabezas - si no es la Bravo, ¿qué naufragio podría ser?

En enero de 2017 hay 297 naufragios históricos en la base de datos de la THC declarados en el Condado de Cameron: 49 están registrados como perdidos en o cerca de la desembocadura del río Bravo (río Grande), aproximadamente 120 naufragios ocurrieron en el puerto / paso de Brazos Santiago, y casi una docena están declarados entre la desembocadura y el paso. Todos los buques cerca de la desembocadura del río Bravo (río Grande) fueron seleccionados inicialmente, así como los de la zona sur de la playa de Boca Chica, a la hora de considerar unos potenciales candidatos alternativos para el pecio 41CF184, $(\mathrm{n}=49)$. Nueve de los buques en esta zona eran vapores y uno era una barcaza - 6 de ellos son desconocidos y los 34 restantes eran barcos de vela que incluían 11 balandras, 2 bricbarcas y barcos ligeros. De los 21 barcos de vela de dos mástiles confirmados dentro de este grupo (Tabla 4), todos ellos eran goletas. La base de datos de la THC solo tiene las dimensiones de dos de estas goletas, la Lodi (naufragada en 1832) y la Liberty (naufragada en 1892). 
Tabla 4. Pérdidas de buques de dos mástiles cerca de la desembocadura del río Bravo (río Grande).

\begin{tabular}{|c|c|c|c|c|c|c|c|c|}
\hline $\begin{array}{l}\text { Nombre del } \\
\text { buque }\end{array}$ & $\begin{array}{l}\text { Fecha de } \\
\text { construc- } \\
\text { ción }\end{array}$ & $\begin{array}{l}\text { Fecha } \\
\text { del } \\
\text { naufragio }\end{array}$ & $\begin{array}{l}\text { Tipo de } \\
\text { barco }\end{array}$ & Eslora & Manga & Puntal & $\begin{array}{l}\text { Causa } \\
\text { del } \\
\text { naufragio }\end{array}$ & $\begin{array}{l}\text { Número de la } \\
\text { base de datos* }\end{array}$ \\
\hline Alice And Mary & - & 1863 & goleta & - & - & - & - & $\begin{array}{l}\text { THC } 671 \\
\text { THC 680, GOM }\end{array}$ \\
\hline Bonita & 1831 & 1837 & goleta & 60 & 19.3 & 5.9 & tormenta & 120 \\
\hline Caroline & - & & goleta & - & - & - & - & $\begin{array}{l}\text { THC } 687 \\
\text { THC 697, GOM }\end{array}$ \\
\hline Coffin & - & 1847 & goleta & - & - & - & tormenta & 1552 \\
\hline $\begin{array}{l}\text { Emma } \\
\text { Farmer's }\end{array}$ & - & 1878 & goleta & - & - & - & - & $\begin{array}{l}\text { THC } 712 \\
\text { THC } 719, \text { GOM }\end{array}$ \\
\hline $\begin{array}{l}\text { Return } \\
\text { Florence }\end{array}$ & 1837 & 1842 & goleta & 60.6 & 19.6 & 5.6 & - & 411 \\
\hline $\begin{array}{l}\text { Bernice } \\
\text { General C. C. }\end{array}$ & - & $1800 \mathrm{~s}$ & goleta & - & - & - & incendio & THC 721 \\
\hline Pinckney & - & 1863 & goleta & - & - & - & - & $\begin{array}{l}\text { THC } 724 \\
\text { THC } 731, \text { GOM }\end{array}$ \\
\hline Halcyon & 1829 & 1836 & goleta & 72.5 & 22 & 8 & - & $\begin{array}{l}513 \\
\text { THC 733, GOM }\end{array}$ \\
\hline Hunter & - & 1847 & goleta & - & - & - & & 1571 \\
\hline Ike Davis & - & 1864 & goleta & - & - & - & - & THC 736 \\
\hline James Duckett & - & 1865 & goleta & - & - & - & - & THC 739 \\
\hline Liberty & 1866 & 1892 & goleta & 66 & 21 & 4 & - & $\begin{array}{l}\text { THC } 756 \\
\text { THC760, GOM }\end{array}$ \\
\hline Lodi & 1835 & 1836 & goleta & 71 & 21 & 6 & - & $\begin{array}{l}691 \\
\text { THC 761, GOM }\end{array}$ \\
\hline Louisiana & - & 1837 & goleta & - & - & - & - & $\begin{array}{l}70 \\
\text { THC 765, GOM }\end{array}$ \\
\hline Mary Emma & - & 1847 & goleta & - & - & - & - & $\begin{array}{l}1579 \\
\text { THC 766, GOM }\end{array}$ \\
\hline Mary Marshall & - & 1846 & goleta & - & - & - & - & $\begin{array}{l}1578 \\
\text { THC 790, GOM }\end{array}$ \\
\hline Phoenix & - & 1834 & goleta & - & - & - & - & $\begin{array}{l}913 \\
\text { THC 813, GOM }\end{array}$ \\
\hline Spartacus & 1834 & 1835 & goleta & 71.2 & 18.6 & 7.9 & - & $\begin{array}{l}1084 \\
\text { THC 828, GOM }\end{array}$ \\
\hline Virginia & - & 1847 & goleta & - & - & - & & $\begin{array}{l}1597 \\
\text { THC 832, GOM }\end{array}$ \\
\hline W. C. Preston & - & 1848 & goleta & - & - & - & - & 1595 \\
\hline
\end{tabular}

Las referencias cruzadas de los 19 buques restantes con la base de datos personal de la autora para embarcaciones regionales de principios del siglo XIX solo proporcionaron las dimensiones adicionales para las goletas Farmer's Return, Halcyon, Spartacus y Bonita, aunque es difícil confirmar si estos son, de hecho, los mismos barcos que aparecen en la base de datos de la THC. Sin información acerca del tamaño, el capitán, la ciudad en que fueron construidos o el origen, es difícil relacionar estos buques con la información del registro y matrícula (Survey of Federal 
Archives 1942), ya que muchos buques compartían los mismos nombres. Las dimensiones para los 15 buques restantes en la Tabla 4 son todavía desconocidas. Probablemente hay otros naufragios que son desconocidos para la THC y no se encuentran documentados en la base de datos de la agencia.

La Bonita, Farmer's Return y Liberty son más pequeñas que el 41CF184, aunque la Lodi, Halcyon y Spartacus tienen un tamaño similar. Con una manga de $5.5 \mathrm{~m}$ (18 pies), la Spartacus es demasiado estrecha para ser considerada como un posible candidato y la Lodi es más de un pie más corta, aunque esto puede ser nominal debido a la inexactitud en de las verdaderas dimensiones de registro del 41CF184. La goleta Halcyon es la más parecida en tamaño al pecio 41CF184, con unas dimensiones de registro de 22.1 (longitud) x 6.7 (manga) x $2.4 \mathrm{~m}$ (puntal) $(72.5$ x 22 x 8 pies). Tenía un desplazamiento de 110 22/95 toneladas. Fue construida en el condado de Sussex, Delaware en 1829 y se registró por primera vez en Baltimore en 1831 (Survey of Federal Archives 1942: 92). El primer anuncio en el New Orleans Bee (1836b: 2), descubierto por la autora, que enumera su disponibilidad para Matamoros sugiere que no tenía forro de cobre ya que no se incluye en la descripción, lo cual es típicamente la moda para los barcos de alquiler en este momento.

La Halcyon era una goleta muy conocida de Nueva Orleans que navegaba con frecuencia entre Nueva Orleans y Matamoros. Se anunciaba regularmente para Matamoros en el New Orleans Bee entre el 7 de mayo y el 4 de noviembre de 1836, momento en el que era propiedad de Thomas Cucullu, Manuel Simón Cucullu y Jean Martial Lapreyre (NOB 1836b: 2, 1836c: 1; Survey of Federal Archives 1942: 92). Ellos operaban este buque en nombre de M.S. Cucullu Lepeyre \& Co. y también actuaron como agentes en el comercio de esclavos de La Habana. La Halcyon se registró para esta empresa el 12 de mayo (NOB 1836d: 1; Macauley y Lewis 1839; Survey of Federal Archives 1942: 92). No solo llevaba carga y pasajeros, sino que también se usaba para transmitir despachos y noticias a los periódicos de los sucesos en México (BMP 1835: 2; NOB 1836e: 1, 1836f: 2; Huron Reflector 1836: 2; The Morning Chronicle 1836b: 1). En junio y agosto de 1836, transportó casi \$200,000 en especias de Matamoros a Nueva Orleans (NOB 1836g: 2; 1836h: 2; Huron Reflector 1836).

Durante uno de sus viajes en el Golfo, la tripulación de la Halcyon se involucró inadvertidamente en un incidente internacional en Tampico, México. El general José Antonio Mexia conspiró con sus partidarios en Nueva Orleans y Texas para planificar y suministrar una expedición para atacar Tampico, México. Después de llegar frente a Tampico el 14 de noviembre de 1835, el barco de Mexia encalló mientras intentaba acercarse a la ciudad al amparo de la noche, 
sus tropas tuvieron que desembarcar durante las primeras horas del 13 de noviembre. La demora en el desembarco permitió a las tropas mexicanas preparar una respuesta y Mexia y sus tropas no tuvieron éxito en su intento de atacar el pueblo. Sus soldados se retiraron y se dispersaron, y muchos fueron tomados prisioneros. Mexia permaneció 10 días más en el fuerte, pero ante la ausencia de los refuerzos esperados, alquiló la goleta Halcyon por \$2,000 para regresar a Nueva Orleans. Abandonó algunas de sus tropas, muchas de las cuales afirmaron más tarde no ser conscientes de la verdadera naturaleza de la empresa. Fueron juzgados y ejecutados el 14 de diciembre (Gómez 1835; Barker 1903: 171-177).

Según una lista de naufragios compilada por el historiador Albert Alfonso Champion y enviada a la THC (Champion 1974), la Halcyon se hundió en la desembocadura del río Bravo (río Grande) en 1836. La THC no ha podido verificar de forma independiente este naufragio, aunque aparecen listados de alquiler para la Halcyon en el New Orleans Bee para después de principios de noviembre de 1836, sugiriendo que quizás se hundió a finales de aquel año. El barco Mexicana, una embarcación totalmente diferente con clavazón y forro de cobre, anteriormente anunciado para alquiler general a México, fue incluido específicamente para Matamoros (como lo había sido la Halcyon) el 22 de noviembre (NOB 1836i: 1, 1836j: 2). La Halcyon no aparece registrada en Nueva Orleans después del 12 de mayo de 1836 (Survey of Federal Archives 1942: 92).

En general, el pecio 41CF184 es consistente con el tamaño y la ubicación de los restos de la Halcyon y es solo un poco más grande que la Spartacus - lo suficiente como para quizás mantener esta última goleta como posible candidata. La Halcyon fue construida en el condado de Sussex, Delaware, que es una fuente regional de ciprés calvo y la zona más septentrional donde se localiza esta especie en los Estados Unidos. A pesar de esta información circunstancial, las dimensiones del pecio 41CF184 son bastante comunes para los buques mercantes que se utilizaban en el Golfo y el análisis actual podría fácilmente pasar por alto a otros posibles candidatos históricos para los cuales las dimensiones del casco no son conocidas. Sin información histórica más completa sobre los naufragios históricos conocidos, y hasta el momento no documentados, en esta región y en ausencia de artefactos históricos en el pecio 41CF184, puede que nunca sea posible identificar de manera concluyente este importante State Antiquities Landmark.

\section{CONCLUSIÓN}

Como el pecio 41CF184 no parece contener ningún artefacto, probablemente recuperados en el momento de su pérdida y en los años posteriores, solo sus dimensiones y características del casco pueden realmente proponer o eliminar buques históricos como candidatos. Independientemente de la complejidad de las diferentes historias de los veleros Moctezuma, Montezuma, Bravo, 
General Bravo y si uno de ellos finalmente naufragó en Brazos Santiago o en la desembocadura del río Bravo (río Grande), ninguno de los estudios publicados disponibles sobre las Marinas de México y Texas, la documentación de archivos asociada o las historias regionales examinadas por la autora, incluyen las dimensiones para estos veleros de la Marina mexicana.

La evidencia histórica indica que el velero candidato Moctezuma, si de verdad fue hundido por la Invincible, encalló en el lado norte de la barra en el paso de Brazos Santiago y no cerca de la desembocadura del río Bravo (río Grande) - siendo esta última la ubicación del pecio 41CF184. La fiabilidad de estos relatos históricos y la gran posibilidad de que la Bravo no se hundiera, ofrece suficientes dudas para descartar a la Bravo como candidata para el naufragio.

Además, el pecio 41CF184 no tiene ninguno de los atributos que lo identificarían como un buque militar de esa época, especialmente uno descrito como una goleta-clíper. Las dimensiones del casco, la ratio eslora-manga, y la ausencia de forro de cobre concuerdan más con las de un barco mercante y, en particular, con ejemplo específico (Halcyon) que frecuentaba el área entre 1835 y 1836. Otros barcos desconocidos o menos documentados también pueden igualmente cumplir los requisitos como candidatos.

Así que la historia del Moctezuma no concluye, sino que simplemente insinúa una narrativa más grande y compleja. Eso también resalta la falibilidad de los relatos históricos y de testigos presenciales. El barco fantasma sigue siendo esquivo, tal vez no a sus perseguidores originales en 1835 y 1836, sino a aquellos arqueólogos que buscan esa evidencia de nuestra historia.

\section{AGRADECIMIENTOS}

Este artículo no hubiera sido posible sin la generosidad y el arduo trabajo del antiguo arqueólogo marino estatal Steve Hoyt y los marine stewards de la Texas Historical Commission (THC). El seguimiento vigilante del pecio desde 1999 ha hecho posible este resumen. Un agradecimiento especial se extiende al colega, autor e historiador Gregg Dimmick, quien ha compartido documentos de archivo a lo largo de los años, especialmente sus más recientes investigaciones que incluyeron trabajos sobre la Marina mexicana. Del mismo modo, las investigaciones personales de Andreas von Mach han proporcionado datos invaluables sobre algunos de estos barcos históricos. La THC extiende su gratitud y agradecimiento a Keith Reynolds por rescatar el palo de trinquete del 41CF184, un importante e informativo artefacto, y a Bill Turner por coordinar su regreso a la THC. Gracias adicionales a David Camarena y Gregg Dimmick por su ayuda en la traducción de aspectos de documentos de archivo mexicanos. Peter Rindlisbacher 
creó generosamente y expresamente para este artículo la imagen de la batalla entre la Invincible y la Bravo.

Mi más profundo agradecimiento también se extiende a los investigadores de pecio Boca Chica No. 2, Steve Hoyt, Andy Hall y Tom Oertling por su revisión de este artículo y los comentarios editoriales. Estos arqueólogos realizaron el trabajo principal sobre el naufragio, que yo misma (desafortunadamente) nunca he visitado.

Nota del editor: la autora ha preparado documentación adicional sobre el tema que aparece en una carpeta separada a través de un enlace de acceso. El apéndice incluirá una muestra de las fotografías de Boca Chica No. 2. de la colección de fotografías de la THC. Actualmente hay más de 700 imágenes de este pecio en formato de diapositivas en color, película de $35 \mathrm{~mm}$ y fotografía digital. Las imágenes en el apéndice se proporcionan solo para fines de investigación y son propiedad intelectual con derechos de autor de la THC, Austin, Texas. No se pueden utilizar en ningún formato de publicación sin permiso escrito expreso de la Agencia. Si existe algún interés en utilizar estas fotografías para publicación, marketing o cualquier uso comercial, pónganse en contacto con la THC para obtener información sobre la política de uso de las imágenes de la agencia. Por favor permita un tiempo de descarga prolongado debido al tamaño del archivo. Haga clic aquí para la descargar el Apéndice. 


\section{BIBLIOGRAFÍA}

Añorga, Juan

1835 Mexican Schooner Bravo Ship's Log. Dolph Briscoe Center for American History, The University of Texas at Austin.

Arnold, J Barto and Robert Weddle,

1978 The Nautical Archeology of Padre Island. Academia Press, New York, New York.

Bancroft, Hubert Howe

1889 The Works of Hubert Howe Bancroft, Vol. XVI, History of the Mexican States and Texas. The History Company Publisher, San Francisco, California.

Barker, Eugene C.

1903 The Tampico Expedition. The Quarterly of the Texas State Historical Association 6(3):169-186.

Barrett, Don Carlos

1836 Resolution presented to the General Council, Council Hall, San Felipe de Austin 8 January. In Journal of the Proceedings of the General Council of the Republic of Texas Nov 14th 1835, pp. 283-284. National Intelligencer, Houston, Texas, 1839.

Bidwell, Robert L.

1960 The First Mexican Navy 1821-1830. Ph.D. dissertation, Corcoran Department of History, University of Virginia, Charlottesville, Virginia.

Bonilla, Juan de Dios

1946 Apuntes para la Historia de la Marina Nacional. Mexico.

Borgens, Amy and Amber Cabading

2016 Foremast Documentation, 41CF184. Manuscript on file, Marine Archeology Program, Texas Historical Commission, Austin, Texas.

Borgens, Amy

2008 Historic Context in Ben Ford, Amy Borgens, William Bryant Dawn Marshall, Peter Hitchcock, Cesar Arias, and Donny Hamilton, Archeological Excavation of the Mardi Gras Shipwreck (16GOM01), Gulf of Mexico Continental Slope, pp. 39-74, U.S. Department of Interior, Minerals Management Service, Gulf of Mexico OCS Region, OCS Report MMS 2009-037, New Orleans, Louisiana.

2010 Field Investigation of Unknown Beach Site, North Padre Island, Willacy County. In Texas Historical Commission Annual Report for Permit No. 2035, September 2009-August

2016a Recovery of the Foremast from State Antiquities Landmark 41CF184. In Texas Historical Commission Annual Report for Permit No. 2035, September 2015-August 2016. pp. 2-4. Manuscript on file, Marine Archeology Program, Texas Historical Commission, Austin, Texas. 
2016b Preliminary Observations on the Recent Beached Shipwreck at Boca Chica in Texas Historical Commission Annual Report for Permit No. 2035, September 2015-August 2016. pp. 16-21. Manuscript on file, Marine Archeology Program, Texas Historical Commission, Austin, Texas.

Boston Morning Post (BMP) [Boston, Massachusetts]

1835 The New Orleans American of the 4th instant says-. 27 November:2. Boston, Massachusetts.

1836 Very Important from Mexico. 6 September:1. Boston, Massachusetts.

1837a From Mexico. 6 March:2. Boston, Massachusetts (Toro on board)

1837b From Mexico 24 July:2. Boston, Massachusetts (Thompson desertion)

Boudriot, Jean

1986 The Seventy-Four Gun Ship: A Practical Treatise on the Art of Naval Architecture. Vol. 2, Fitting Out the Hull. Translated by David H. Roberts. Naval Institute Press, Paris.

British Traveler and Commercial and Law Gazette [London, Middlesex],

1832 Foreign Intelligence. 17 October 17:2. London, Middlesex.

Brown, Jeremiah

1836 Letter to James Morgan. Galveston Harbor, 7 April. In Official Correspondences of the Texas Revolution 1835-1836, Vol. II, edited by William C. Brinkley, p. 605. 1936 Appleton-Century Company, Inc., New York, New York.

Bryan, M. A.

1835 Letter to James F. Perry, 2 miles from Bexar. In The Austin Papers October 1834-January 1837, edited by Eugene C. Barker, p 217. 1927 University of Texas Press, Austin, Texas, 1927.

Bush, Leslie L.

2016 Wood from Five Shipwrecks in the Gulf of Mexico. Manuscript on file, Marine Archeology Program, Texas Historical Commission, Austin, Texas.

Champion, Albert A.

1974 Letter to J. Barto Arnold of the Texas Antiquities Committee, 26 April. Manuscript on file, Marine Archeology Program, Texas Historical Commission, Austin, Texas.

Covington Western Constellation [Covington, Indiana]

1836 Naval Engagement. May 20:2. Covington, Indiana.

Dawson, Frederick and Samuel M. Williams

1839 Document A. Contract for one Ship, two Brigs, and three Schooners, pp 13-22. In Annual Report of the Secretary of the Navy, November 1839. Whitings Print.

Demerliac, Alain

2007 La Marine de la Restauration et de Louis-Philippe 1er: Nomenclature des navires Français de 1815 á 1848. A.N.C.R.E. Nice, France. 
Dienst, Alexander

1909a The Navy of the Republic of Texas, I, The First Navy of Texas. The Quarterly of the Texas State Historical Association 2(3):165-203.

1909b The Navy of the Republic of Texas, II, The First Navy of Texas. The Quarterly of the Texas State Historical Association 12(4):249-275.

Drake, Jerry

2005 The Search for Two Ancient Adversaries. Texas Navy Association. Electronic document, http://www.texasnavy.com/resources/Documents/Historical/Ships/Discovery_of what_is_possibly the Montezuma.pdf, accessed on February 18, 2015.

Escamilla, Juan Ortiz

2008 El teatro de la guerra: Veracruz 1750-1825 Publicaciones de la Universidad Jaume, Castelló de la Plana, Spain.

Espino, Jose Maria

1836 Letter to Fernando Fernandez, DATE. In Partes de Las 223. Comandancias Generales de Matamoros, Tamps., Veracruz Y Yucatan, Dando Cuenta del Movimiento Dd Barcos con Motivo de la Campana de Texas. Ano de 1836, pp. 67-70. Archivo Expediente Histórico Militar XI/481.3/1656. Electronic document, http://www.archivohistorico2010.sedena.gob.mx/busqueda/MostrarImg.php; (now http://www.archivohistorico2010.sedena.gob.mx/mostrarimagen?expid=20589\&expno=1656), accessed by Gregg Dimmick October 2013.

Fannin, James W.

1835 Letter to Daniel W. Smith, 11 December. In The Papers of the Texas Revolution, 1835-1836, Vol. 3, edited by John H. Jenkins, pp. 158-160. 1973 Presidial Press, Austin, Texas.

Filosola, D. Vincent

1849 Memorias para la historia de la guerra de Tejas, Volume 1. Imprente de Ignacio Cumplido, Mexico.

Fischer, Ernest G.

1976 Robert Potter: Founder of the Texas Navy. Pelican Publishing Company. Gretna, Louisiana.

Fisher, Samuel Rhodes

1835 Letter to Public, 11 Jan. In The Papers of the Texas Revolution, 1835-1836, Vol. 4, edited by John H. Jenkins, pp. 211-219. 1973 Presidial Press, Austin, Texas.

1836 Audited Claim. Republic Claims, Texas Comptroller's Office. Archives and Information Services Division, Texas State Library and Archives Commission. 
Fleury, Anthony B.

ca. 1874Pension Claim. Republic Claims, Texas Comptroller's Office. Archives and Information Services Division, Texas State Library and Archives Commission.

Ford, Ben, Amy Borgens, William Bryant, Dawn Marshall, Peter Hitchcock, Cesar Arias, and Donny Hamilton

2008 Archaeological Excavation of the Mardi Gras Shipwreck (16GM01), Gulf of Mexico Continental Slope. U.S. Department of Interior, Minerals Management Service, Gulf of Mexico OCS Region, OCS Report MMS 2009-037, New Orleans, Louisiana.

Ford, Ben, Amy Borgens, and Peter Hitchcock

2010 The Mardi Gras Shipwreck: Results of a Deep-Water Excavation, Gulf of Mexico, USA. The International Journal of Nautical Archaeology 39:76-98.

Forsyth, Mr.

1836 Letter to Mr. Ellis, Department of State, Washington, 20 July. Washington Globe 3

February:3. Washington DC.

General Council (Texas)

1835 Journal of the Proceedings of the General Council of the Republic of Texas Nov 14th 1835. 1839 National Intelligencer, Houston, Texas.

Gomez Palomino, Gregorio

1835 Letter and Report to Santa Anna, Matamoros 30. Broadside dated November 26, 1835. Reel: 14 Texas as a Province and Republic 1795-1845. Reel: 14 Texas as a Province and Republic 1795-1845. Electronic document, http://www.essaydocs.org/texas-as-a-province-and-republic1795-1845-author-index.html?page=81, assessed August 5, 2015.

Grajales, Gloria

1969 Guia de documentos para la historia de Mexico en archivos ingleses Siglo 29. Universidad Nacional Autonoma de Mexico, Mexico.

Gray, William Fairfax

1909 From Virginia to Texas, 1835: Diary of Col. Wm. F. Gray. Gray, Dillate \& Co., Printers, Houston, Texas.

Gritton, Eduardo

1835 Letter to Domingo de Ugartechea, Gonzales, 5 July. In The Papers of the Texas Revolution, 1835-1836, Vol 1, edited by John H. Jenkins, pp. 203-205. 1973 Presidial Press, Austin, Texas.

Guerra, J.M.

1835 Letter to Daniel W. Smith, 14 December. In The Papers of the Texas Revolution, 1835-1836, Vol. 3, edited by John H. Jenkins, p. 188. 1973 Presidial Press, Austin, Texas. 
Hall, Andrew, John Luce, and Doug Nowell

2002 Field Report: Boca Chica Wreck. Manuscript on file, Marine Archeology Program,Texas Historical Commission, Austin, Texas

Hall, William

1835 Letter to Stephen F. Austin. In The Austin Papers October 1834-January 1837, edited by Eugene C. Barker, pp. 264-265. 1927 University of Texas Press, Austin, Texas.

Hayes, Charles W.

1974 [1879] History of the Island and the City of Galveston. Cincinnati, Ohio. 1974 fascmile ed. Jenkins Garrett Press, Austin, Texas.

Hill, Dan

1987 The Texas Navy: in Forgotten Battles and Shirtsleeve Diplomacy. Reprinted. State House Press, Austin, Texas. Originally published 1937, University of Chicago Press, Chicago, Illinois.

Horrell Chris and Amy A. Borgens

2017 The Mardi Gras Shipwreck Project: A Final Overview with New Perspective. Historical Archaeology 51(3):433-450.

Hoyt, Steven D.

1999a Boca Chica Emergency Shipwreck Investigation. In Texas historical Commission Annual report for Antiquities Permit No. 2035. Manuscript on file, Marine Archeology Program, Texas Historical Commission, Austin, Texas.

1999b Boca Chica \#2 Field Investigations. 5 May. Manuscript on file, Marine Archeology Program, Texas Historical Commission, Austin, Texas.

2002a Boca Chica No. 2-41CF184. In Texas historical Commission Annual Report for Antiquities Permit No. 2035, pp. 3-4. Manuscript on file, Marine Archeology Program, Texas Historical Commission, Austin, Texas.

2002b Boca Chica \#2 Revisited, 9 May. Manuscript on file, Marine Archeology Program, Texas Historical Commission, Austin, Texas.

Hunt, Richard S and Jesse E. Randel

1841 Karte von Texas entworfen nach den Vermessungen, welche in den Acten der General-LandOffice der Republic liegen bis zum Jahr 1839 von Richard S. Hunt \& Jesse F. Randel. In George A. Scherpf, Entstehungsgeschichte und gegenwärtiger Zustand des neuen, unabhängigen, amerikanischen Staates Texas. Ein Beitrag zur Geschichte, Statistik und Geographie dieses Jahrhunderts, Im Lande selbst gesammelt von G. A. Scherpf. Mit zwei Karten, von Texas, Rio Grande und dem West-Land am Stillen Ocean Augsburg. Verlag der Matth. Rieger'schen Buchhandlung, 1841. Perry-Castañeda Library Historical Maps of Texas, Republic of Texas 1836-1845. Map Collection. Electronic document, http://www.lib.utexas.edu/maps/historical/scherpf-texas-1841.jpg, accessed Oct 2, 2016. 


\author{
Huron Reflector [Norwalk, Ohio] \\ 1836 From Matamoras (Reprinted from the New Orleans Commercial Bulletin) 10 August:2. \\ Norwalk. \\ Jones, Charles C. \\ 1878 The Life and Services of Commodore Josiah Tattnall. Morning. News Steam Printing House, \\ Savannah, Georgia. \\ Jordan, Jonathon W. \\ 2006 Lone Star Navy: Texas, the Fight for the Gulf of Mexico, and the Shaping of the American West. \\ Potomac Books, Inc., Washington D.C. \\ Kent and Essex Mercury [London, Middlesex] (UK) \\ 1824 Kent. 17 May:4. London, Middlesex. \\ Kauffman, Henry J. \\ 1968 American Copper and Brass. Thomas Nelson \& Sons, Camden, New Jersey. \\ Lerdo de Tejada, Miguel M. \\ 1857 Apuntes Historicos de la Herioica Cuidad de Vera-Cruz. Imprente de Vincent Garcia Garcia \\ Torres, Mexico. \\ Livingston, Edward \\ 1832 Letter to Jose Montoya. October 26. 678-679. In Executive Documents: 13th Congress, 2d \\ Session-49th Congress, 1st Session, Volume 12, pp. 676-677. Government Printing Office, \\ Washington D.C. \\ London Lloyd's List (LLL) [London, Middlesex] (UK) \\ 1825a Gravesend. 12 July:1. London, Middlesex. \\ 1825b Deal. 15 July:1. London, Middlesex. \\ 1825c Falmouth. 2 August:2 London, Middlesex. \\ 1827 29 May:1. London, Middlesex. \\ London Morning Post (LMP) [London, Middlesex] (UK) \\ 182829 September:3. London, Middlesex. \\ 183610 June:5. London, Middlesex. \\ London Public Ledger [London, Middlesex] (UK) \\ 183516 December:3. London, Middlesex. \\ London Shipping Gazette [London, Middlesex] (UK) \\ 1836 American Papers. 12 September:1. London, Middlesex. \\ London St. James Chronicle and General Evening Post [London, Middlesex] \\ 183524 November:4. London, Middlesex.
}


Long, David F.

2014 Nothing to Daring: A Biography of Commodore David Porter 1780-1843. Naval Institute Press, Annapolis Maryland.

Lyman, John

1945 Register Tonnage and Its Measurement. The American Neptune 5(3):223-234.

Macauley H.W and W.W. Lewis

1839 Letter to Viscount Palmerston. In Class A, Correspondence with the British Commissioners at Sierra Leone, The Havana, Rio de Janiero, and Surinam Relating to the Slave Trade, p. 62. 1841. W. Cloves and Sons, London.

McKinney, Thomas F.

1835a Letter to President of the Council, Quintana, 11 Nov. In Official Correspondences of the Texas Revolution 1835-1836, Vol. II, edited by William C. Brinkley, pp. 65-66. Appleton-Century Company, Inc., New York New York.

1835b Letter read to the General Council. San Felipe de Austin, 11 October. In. Journal of the Proceedings of the General Council of the Republic of Texas, p. 10. National Intelligencer, Houston, Texas, 1839.

McKinney, Thomas F. and Samuel M. Williams

1835a Letter to R.R. Royal, Quintana, 29 Oct. In Official Correspondences of the Texas Revolution 18351836, Vol. II, edited by William C. Brinkley, pp. 26-27. Appleton-Century Company, Inc., New York New York.

1835b Letter to R.R. Royal, Quintana, 9 Nov. In Official Correspondences of the Texas Revolution 18351836, Vol. II, edited by William C. Brinkley, pp. 63-64. Appleton-Century Company, Inc., New York New York.

McMullen, John

1836 To the People of Texas. In Journal of the Proceedings of the General Council of the Republic of Texas, Held at San Felipe de Austin, November 14th 1835, pp. 297-302. National Intelligencer, Houston, Texas 1839.

Meed, Douglas V.

2001 The Fighting Texas Navy 1832-1843. Taylor Trade Publishing, Boulder. Colorado.

Mexico Ministerio de Hacienda

1837 Memoria de la Hacienda General de la Repúblic a Mexicana; presentadad á las Cámaras por el Ministro el Ramo en 29 de Julio de 1837. Imprenta del Águila, Mexico.

Michelena, José Mariano de

1825 Letter to Gómez Pedraza, October 30, 1825. Juan E. Hernández y Dávalos Manuscript Collection, Benson Latin American Collection, General Libraries, The University of Texas at Austin. 
Montoya, Jose M.

1832 Letter to Edward Livingston. October 11. In Executive Documents: 13th Congress, 2d Session-49th Congress, 1st Session, Volume 12:676-677. Government Printing Office, Washington D.C.

Morning Chronicle (MC) [London, Middlesex]

1836a America. 10 June:4 London, Middlesex.

1836b American Papers. 7 November:1. London, Middlesex.

New Albany Gazette [New Albany, Mississippi]

1836 From the Louisiana Advertiser, May 2. 20 May:2. New Albany, Mississippi.

New Orleans Bee (NOB) [New Orleans]

1836a Mexican Traders. For Matamoras. 29 November:1. New Orleans.

1836b Mexican Traders. For Matamoras. 7 May:2. New Orleans.

1836c Mexican Traders. For Matamoras. 4 November:1. New Orleans.

1836d Mexican Traders. For Matamoras. 9 May:1. New Orleans.

1836e Mexican Traders. For Matamoras. 1 November:1. New Orleans.

$1836 \mathrm{f}$ From Mexico. 10 August:2. New Orleans.

$1836 \mathrm{~g}$ Arrived. 20 June:2. New Orleans.

1836h Imports. 10 August:2. New Orleans.

1836i Mexican Traders. For Freight or Charter. 17 November:2. New Orleans.

1836j Mexican Traders. For Matamoras. 22 November:1. New Orleans.

New Times [London, Middlesex]

1827 Mexican and Spanish Squadrons. 26 April 1826:2 London

Niles Weekly Register [Baltimore, Maryland]

1832 Miscellaneous, 6 October:82-83. Baltimore, Maryland.Oertling, Thomas

Oertling, Thomas

2002 Personal report on the Boca Chica Wreck, Cameron County, Texas. Survey by the Marine Steward's Program, August $16-17^{\text {th }}$ (Fri-Sat), 2002. Manuscript on file, Marine Archeology Program, Texas Historical Commission, Austin, Texas.

Penot, Jacques

1976 Les relations entre la France \& le Mexique de 1808 à 1840: un chapitre d'histoire écrit par les marins et diplomates français, Volume 1. Atelier Reproduction des thèses, Université Lille. Paris, France.

Pering, Richard

1812 Brief Enquiry into the Causes of Premature Decay in our Wooden Bulwarks with an Examination of the Means, Best Calculated to Prolong their Duration. L. Congdon, Plymouth-Dock (Devonport). 
Pierce, Frank

1917 A Brief History of the Lower Rio Grande Valley. George Banta Publishing Company, Menasha, Wisconsin.

Porter David, D.

1875 Memoir of Commodore David Porter of the United States Navy. J. Munsell Publisher, Albany, New York.

Procurador del Pueblo [Veracruz]

1834 Capitania del Puerto. 18 April. Veracruz

Powers, John

2006 The First Texas Navy. Woodmont Books. Austin, Texas.

Reibaud, D. Franciso

1836 Letter. July 20 pp 141-142. In Partes de Las 223. Comandancias Generales de Matamoros, Tamps., Veracruz Y Yucatan, Dando Cuenta del Movimiento Dd Barcos con Motivo de la Campana de Texas. Ano de 1836318 Fojas. Archivo Expediente Histórico Militar XI/481.3/1656. Electronic document, http://www.archivohistorico2010.sedena.gob.mx/busqueda/MostrarImg.php; (now http://www.archivohistorico2010.sedena.gob.mx/mostrarimagen?expid=20589\&expno=1656), accessed by Gregg Dimmick October 2013.

Ronnberg, Erik A. R.

1980 The Coppering of 19th Century American Merchant Sailing Ships. Nautical Research Journal, 26 (3):125-148.

Secretaria de Guerra y Marine

1836 Memorandum. In Partes de Las 223. Comandancias Generales de Matamoros, Tamps., Veracruz Y Yucatan, Dando Cuenta del Movimiento Dd Barcos con Motivo de la Campana de Texas, pp. 137-140. Ano de 1836318 Fojas. Archivo Expediente Histórico Militar $\mathrm{XI} / 481.3 / 1656$. Electronic document, http://www.archivohistorico2010.sedena.gob.mx/busqueda/MostrarImg.php; (now http://www.archivohistorico2010.sedena.gob.mx/mostrarimagen?expid=20589\&expno=1656), accessed by Gregg Dimmick October 2013.

Scheina, Robert L.

1969 Vessels of the Mexican Navy 1846-1848. In Surfboats and Horse Marines: U.S. Naval Operations in the Mexican War, by K. Jack Bauer. United States Naval Institute, Annapolis, Maryland.

1970 The Forgotten Fleet: The Mexican Navy on the Eve of War, 1845. American Neptune 30(1):46-55. 
Smith, D.C.

1835 Letter to Principal Commandant of the State of Tamaulipas, 12 December. In The Papers of the Texas Revolution, 1835-1836, Vol. 3, edited by John H. Jenkins, p. 173. Presidial Press, Austin, Texas, 1973.

Staniforth, Mark

1985 The Introduction and Use of Copper Sheathing-A History. Australian Institute of Maritime Archaeology, 9(1, 2):21-48.

Steffy, Richard

1994 Wood Ship Building and the Interpretation of Shipwrecks. Texas A\&M Press, College Station, Texas.

Survey of Federal Archives in Louisiana

1941 Ship Registers and Enrollments of New Orleans, Louisiana, Vol. 1, 1804-1820. Survey of Federal Archives in Louisiana, Service Division, Works Progress Administration, Hill Memorial Library, Louisiana State University, Baton Rouge.

1942 Ship Registers and Enrollments of New Orleans, Louisiana, Vol. 3, 1831-1840. Survey of Federal Archives in Louisiana, Service Division, Works Progress Administration, Hill Memorial Library, Louisiana State University, Baton Rouge.

Telegraph and Texas Register [San Felipe de Austin, Texas].

1836 San Felipe de Austin, 9 January:2. [San Felipe de Austin, Texas].

Tenori, Antonio

1835a Letter. Anahuac, 7 May. Microfilm, Roll 165, General Manuscript Series, 1717-1836, Béxar Archives, Briscoe Center for American History at the University of Texas at Austin, Austin.

1835b Letter to Domingo de Ugartechea, 18 May. Microfilm, Roll 165, General Manuscript Series, 1717-1836, Béxar Archives, Briscoe Center for American History at the University of Texas at Austin, Austin.

Tornel, Don Jose Maria

1836 Letter to Mr. Jose Maria Ortiz Monasterio, Mexico, 15 June. In Congressional Series of United States Public Documents, Volume II, p. 115. Gales and Seaton, Printers, Washington D.C. 1837.

Viele, John

1999 The Florida Keys, Vol. 2: True Stories of the Perilous Straights. Pineapple Press, Inc. Sarasota Florida.

Ward, Henry G.

1828 Mexico in 1827. Harry Colburn, London.

Washington Globe [Washington D.C.]

1835 From a New Orleans Paper. 24 June:2. Washington D.C. 
Washington National Intelligencer [Washington D.C.]

1832 New Orleans Aug. 30. 15 September:3. Washington D.C.

Wells, William R.

1998 "Every Protection that was Asked for..." The United States Revenue Cutter Ingham, Texas Independence, and New Orleans 1835. Journal of the Louisiana Historical Association 30 (4):457479.

Webster, Joseph Dana; Mullowny, T. E.; Schedler, J.

1847 Map of the Country Adjacent to the Left Bank of the Rio Grande below Matamoros. In en. Ex. Doc. 1 sess. 31st Congress, No. 65. Ackerman, New York, New York. Electronic document, http://library.uta.edu/usmexicowar/collections/image/usmw-500028.jpg, accessed March 16, 2017.

Williams, C. Herndon,

2010 Texas Gulf Coast Stories. Acadia Publishing.

Wilson, James T. D.

1874 Pension Claim. Republic Claims, Texas Comptroller's Office. Archives and Information Services Division, Texas State Library and Archives Commission.

York Herald and General Advertiser [York, North Yorkshire] (UK)

1825 Domestic. 15 October:2. York, North Yorkshire.

Zimmerman, Walter

1836 Letter to Eliza Zimmerman. Texas Navy Record Subject File, Vol. 1836-1860. Box 689 National Records and Archives Administration (NARA). 


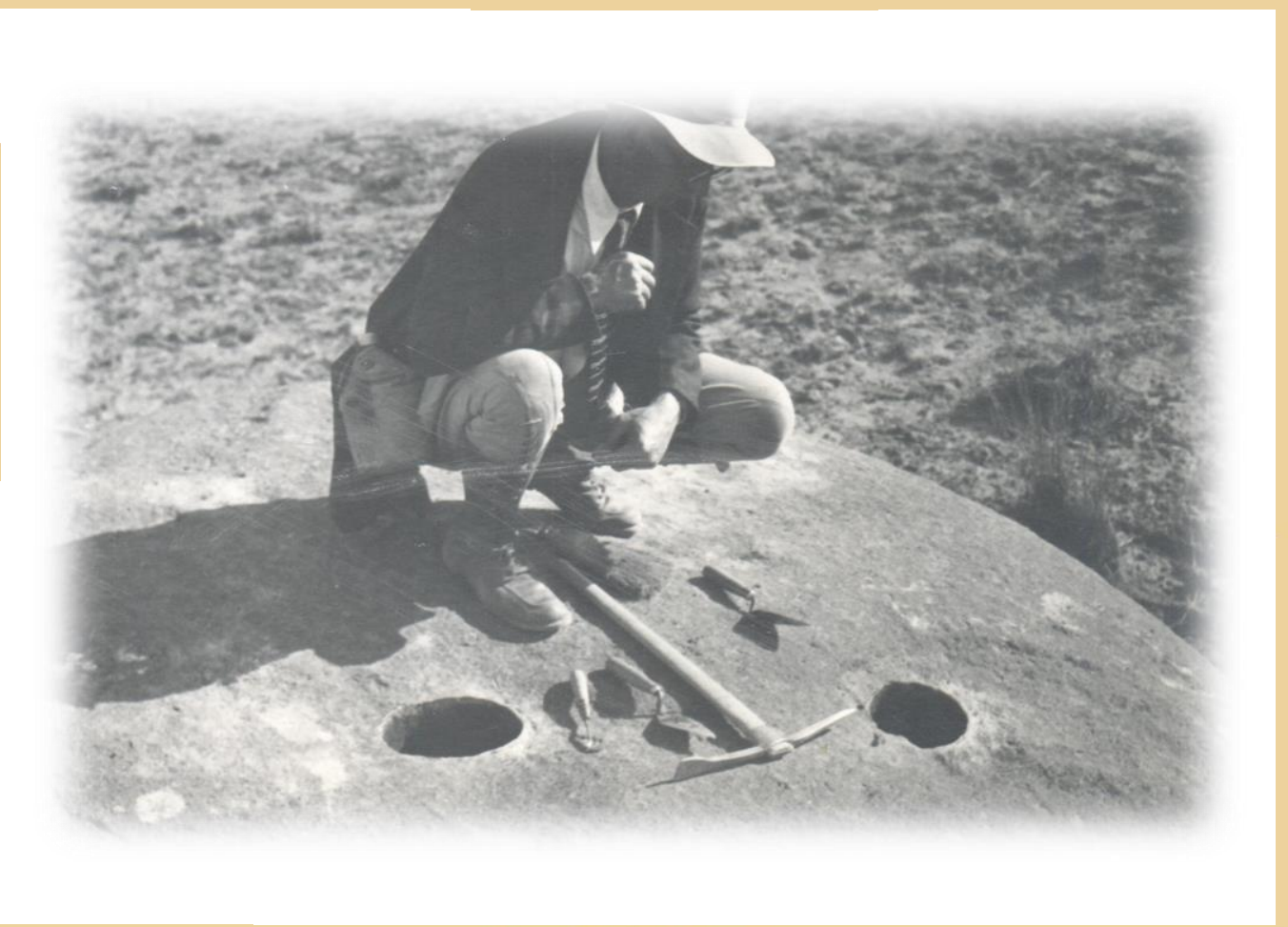

\section{Iournal of Texas Archeology and History.org}

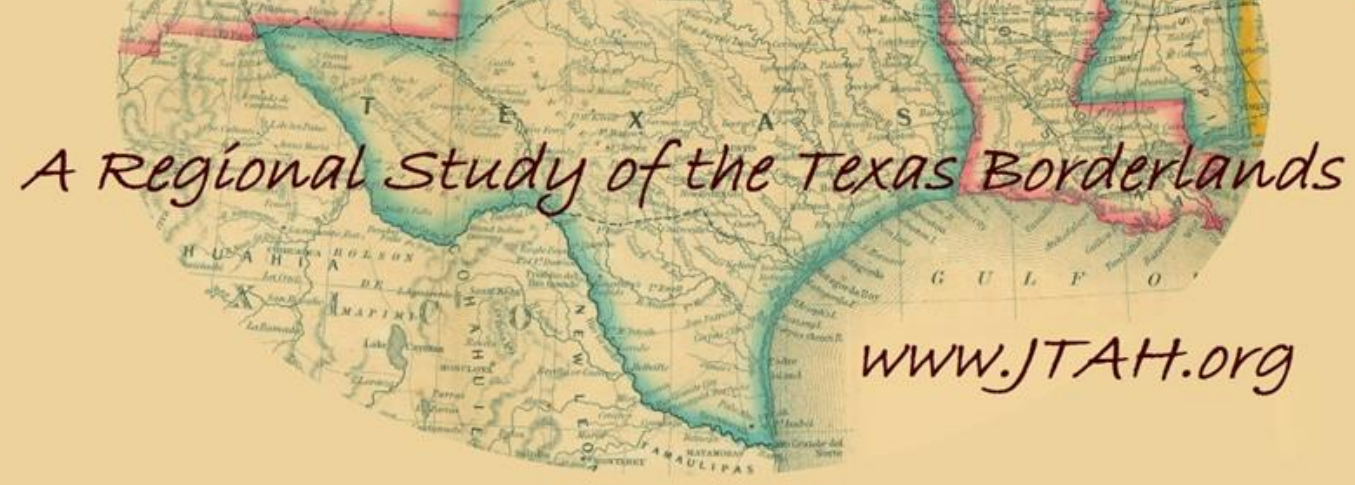

Journal of Texas Archeology and History.org, Inc.

Suite 307, Box 361

5114 Balcones Woods Drive

Austin, Texas 78759 